\title{
THERMAL BEHAVIOR OF PHASE CHANGE MATERIAL (PCM) BASED CAVITY: EXPERIMENTAL AND NUMERICAL VALIDATION
}

\author{
by \\ Md Ali Ahamed Shak \\ B.Sc. in Mechanical Engineering, IUBAT, Bangladesh, 2012
}

A thesis presented to

Ryerson University

in partial fulfillment of the

requirement for the degree of

Master of Applied Science

in the program of

MECHANICAL \& INDUSTRIAL ENGINEERING

Toronto, Ontario, Canada, 2019

(C) M. A. A. Shak 2019 


\begin{abstract}
AUTHOR'S DECLARATION
I hereby declare that I am the sole author of this thesis. This is a true copy of the dissertation, including any required final revisions, as accepted by my examiners.

I authorize Ryerson University to lend this dissertation to other institutions or individuals for scholarly research.

I further authorize Ryerson University to reproduce this dissertation by photocopying or by other means, in total or in part, at the request of other institutions or individuals for scholarly research.
\end{abstract}

I understand that my dissertation may be made electronically available to the public. 


\title{
ABSTRACT \\ Thermal Behavior of Phase Change Material (PCM) Based Cavity: Experimental and Numerical Validation
}

\author{
Md Ali Ahamed Shak \\ Master of Applied Science \\ Mechanical and Industrial Engineering, 2019 \\ School of Graduate Studies \\ Ryerson University, Toronto, On, M5B 2K3, Canada
}

Recently, thermal energy storage (TES) includes technologies for collecting and storing energy for later use in domestic and industry by using Phase Change Materials (PCMs) which is a main topic for many researchers. In this experimental and numerical study, melting process and thermal behavior due to a U-shaped heat source embedded in the PCM is investigated which has been simulated in COMSOL-3D Multiphysics. The three-dimensional governing equation is solved for the fluid flow and heat transfer behavior. Two different cases are analyzed in this study. In the first case, the experimental results of a rectangular cavity filled with PCM, and a Ushaped heating source embedded in it is validated with a numerical model. PCM is used that has melting point temperature $32{ }^{\circ} \mathrm{C}$, and flow of water at temperature $39{ }^{\circ} \mathrm{C}$ for six hours period through the U-shaped tube to intensify the PCM`s temperature. PCM melts and absorbs latent heat as energy which is analyzed horizontally and vertically. PCMs temperature increased uniformly with increasing of time inside the cavity. The melting rate was high around the heating source than the far distances of heating source. After six hours, 100\% PCM was melted around the U-shaped tube, however, far from the U-shaped tube was not significantly melted in both experimental study and numerical model. The numerical results are in good agreement with the experimental data with a small number of relative error in all cases. In the second case, PCM and Bentonite are used in four different models in the same rectangular cavity, then hot-water and, cold-water flowing through the U-shaped tube, and the numerical results were validated for all models. It was observed that, when Bentonite is used, the heat transfer rate was higher compare to the case when PCM is used for anywhere in the cavity. The reason is that, Bentonite has higher thermal conductivity and temperature gradient than the PCM. So, Bentonite was more 
sensitive for heat transfer whenever used in heating or cooling. It is clear from this study that PCM and Bentonite can be a good media for storing thermal energy for later use such as room heating, space heating, industrial and commercial uses. PCM has a great possibility to it, because of its low initial and maintenance cost, and its availability. 


\section{ACKNOWLEDGEMENTS}

I would like to thank Dr. M. Ziad Saghir, my supervisor, for his help in providing me with opportunities, trust, confidence, full guidance and tireless support during my MASc study. I am very grateful to him for all his valuable help and guide.

I also acknowledge the support for my thesis experimental work and useful suggestions of my colleague Dr. Ayman Mahmoud Bayomy, post-doctoral fellow at Ryerson University. Special thanks to Dr. Seth Dworkin at Ryerson University and his team members for the support of my experimental work. I thank all my colleagues of the Microgravity Research Lab at Ryerson University for making the lab a place of paradise for me and for making every morning enjoyable. It was my pleasure to work, discuss and share knowledge with them.

I would like to thank to my MASc supervisory committee members Dr. Krishnan Venkatakrishnan and Dr. Habiba Bougherara.

I would also like to express my appreciation to my parents Md. Abu Bakar Sheikh and Sarifunnesa Begum, brother Dr. Md Abdur Rahman, sister Ayesha Begum, sister-in-law Lusaka Khan for their support. Through their continuous support, constant love, caring advise, teaching of ethics, hard work and honesty, I can continue the journey of my life. I would like to express my deepest gratitude to all my others family members, especially my beloved nieces and nephew. I thank them all for their love, patience, and support during my studies.

I acknowledge the financial support of Natural Sciences \& Engineering Research Council of Canada (NSERC), Ryerson University, and McClymont \& RaK Engineers Inc for funding this project. 


\section{TABLE OF CONTENTS}

AUTHOR'S DECLARATION ...................................................... ii

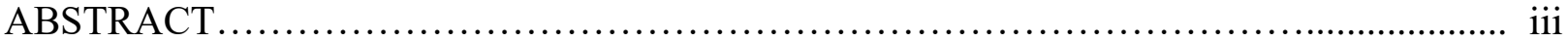

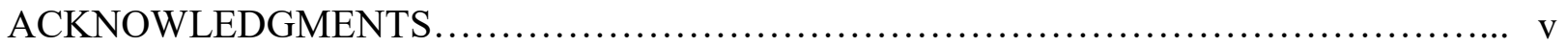

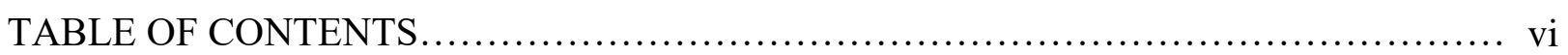

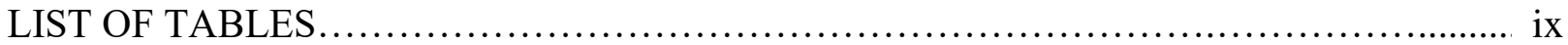

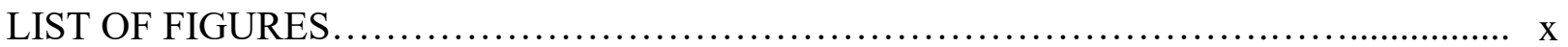

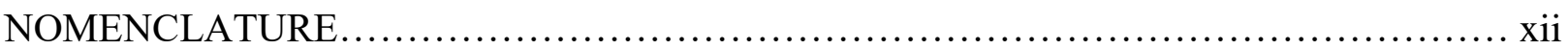

CHAPTER 1 - INTRODUCTION AND APPLICATION............................... 1

1.1 Introduction of PCM and Bentonite.......................................... 1

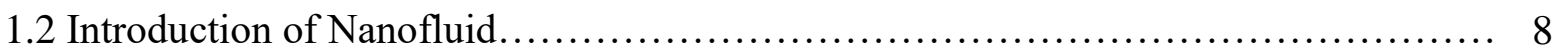

1.3 Summaries........................................................... 15

1.4 Objectives........................................................... 15

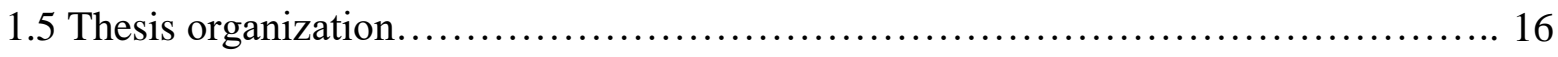

CHAPTER 2 - MODEL DESCRIPTION......................................... 17

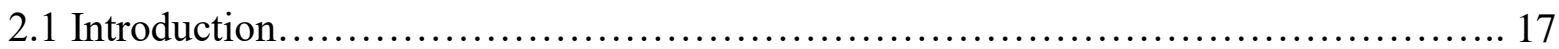

2.2 Experimental model description......................................... 17

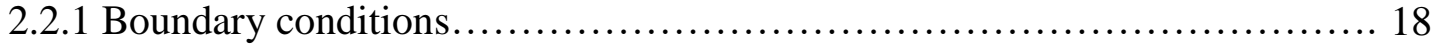

2.2.2 Experimental apparatus and procedures.................................. 19

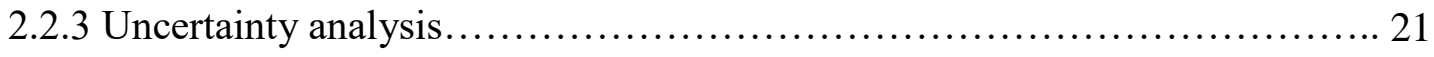

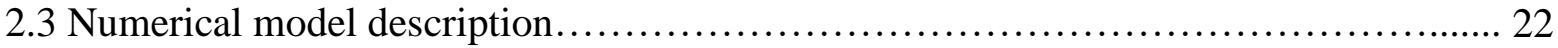

2.3.1 Governing equations and boundary conditions........................ 22

2.4 Mesh sensitivity analysis and convergence criteria.............................. 24

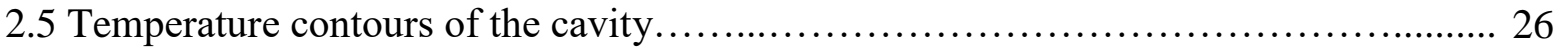

2.6 Thermal energy storage media (Paraffin Wax) ................................... 26

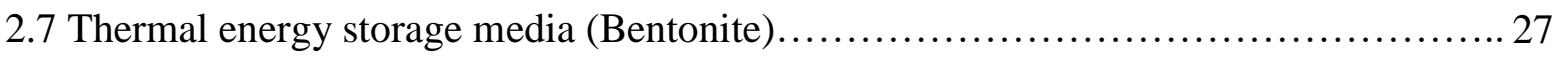

2.8 Numerical model validation between PCM and Bentonite.......................... 27

2.8.1 Model A: Entire cavity filled with PCM............................... 28

2.8.2 Model B: entire cavity filled with bentonite............................ 28 
2.8.3 Model C: Inner part of the cavity is filled with PCM and outer part is filled with bentonite.

2.8.4 Model D: Inner part of the cavity is filled with bentonite and outer part is filled with PCM.

CHAPTER 3 - RESULTS AND DISCUSSION.

3.1 Introduction.

3.2 Experimental study and numerical model validation.

3.2.1 Surface temperature distributions of the cavity along $\mathrm{x}$-axis

3.2.1.1 Surface temperature distributions at $\mathrm{y}=0 \mathrm{~m}$ of the cavity along $\mathrm{x}-$ axis

3.2.1.2 Surface temperature distributions at $\mathrm{y}=0.04741 \mathrm{~m}$ of the cavity along $\mathrm{X}$-axis.

3.2.1.3 Surface temperature distributions at $\mathrm{y}=-0.04741 \mathrm{~m}$ of the cavity along $\mathrm{X}$-axis.

3.2.2. Surface temperature distributions of the cavity along $y$-axis......

3.2.2.1 Surface temperature distributions at $\mathrm{x}=0 \mathrm{~m}$ of the cavity along $\mathrm{y}-$ axis.

3.2.2.2 Surface temperature distributions at $\mathrm{x}=0.02 \mathrm{~m}$ of the cavity along $\mathrm{y}$-axis.

3.2.2.3 Surface temperature distributions at $\mathrm{x}=0.06 \mathrm{~m}$ of the cavity along $\mathrm{y}$-axis.

3.2.2.4 Surface temperature distributions at $\mathrm{x}=-0.02 \mathrm{~m}$ of the cavity along $\mathrm{y}$-axis.

3.2.2.5 Surface temperature distributions at $\mathrm{x}=-0.06 \mathrm{~m}$ of the cavity along $\mathrm{y}$-axis.

3.3 Numerical model validation between PCM and bentonite. ... 46

3.3.1 Surface temperature distributions of the cavity along $\mathrm{x}$-axis

3.3.1.1 Surface temperature distributions at $\mathrm{y}=0 \mathrm{~m}$ of the cavity along $\mathrm{x}-$ axis. 
3.3.1.2 Surface temperature distributions at $\mathrm{y}=0.04741 \mathrm{~m}$ of the cavity along $\mathrm{x}$-axis....

3.3.1.3 Surface temperature distributions at $\mathrm{y}=-0.04741 \mathrm{~m}$ of the cavity

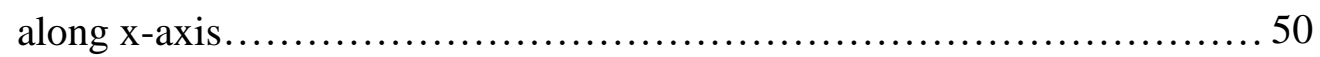

3.3.2. Surface temperature distributions of the cavity along vertical or $y$-axis....... 50

3.3.2.1 Surface temperature distributions at $\mathrm{x}=0 \mathrm{~m}$ of the cavity along $\mathrm{y}-$ axis.

3.3.2.2 Surface temperature distributions at $\mathrm{x}=0.02 \mathrm{~m}$ of the cavity along $\mathrm{y}$-axis.

3.3.2.3 Surface temperature distributions at $\mathrm{x}=0.06 \mathrm{~m}$ of the cavity along $\mathrm{y}$-axis.

3.3.2.4 Surface temperature distributions at $\mathrm{x}=-0.02 \mathrm{~m}$ of the cavity along $\mathrm{y}$-axis.

3.3.2.5 Surface temperature distributions at $\mathrm{x}=-0.06 \mathrm{~m}$ of the cavity along $\mathrm{y}$-axis.

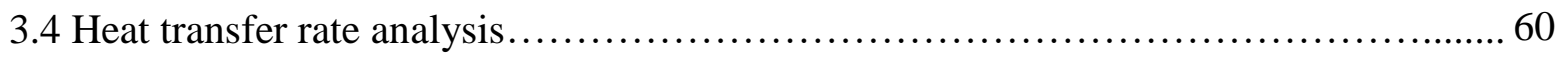

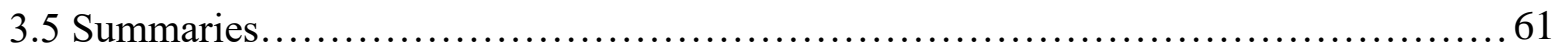

CHAPTER 4 - CONCLUSIONS AND FUTURE WORK...................................... 62

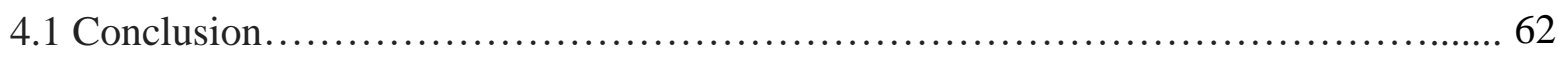

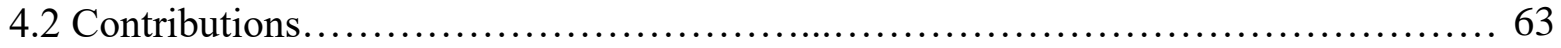

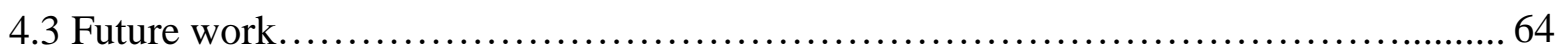

REFERENCES...........................................................................65 


\section{List of Tables}

Table 2.1: Average temperature using various mesh types ............................. 25

Table 2.2: Thermo-physical properties of PCM at room temperature $\ldots \ldots \ldots \ldots \ldots \ldots \ldots \ldots \ldots 27$

Table 2.3: Thermo-physical properties of Bentonite at room temperature.....................27

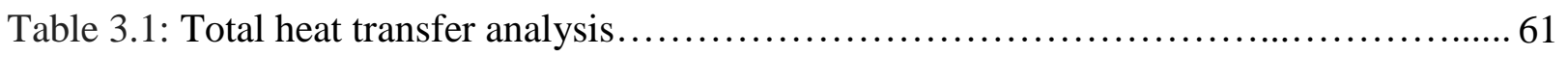




\section{List of Figures}

Figure 1.1: U-Shaped borehole Cavity filled with PCM or Bentonite....................... 1

Figure 2.1: U-shaped tube in a rectangular cavity filled with PCM $\ldots \ldots \ldots \ldots \ldots \ldots \ldots \ldots \ldots \ldots \ldots \ldots \ldots$

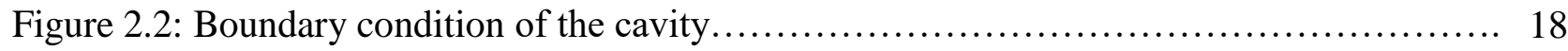

Figure 2.3: Schematic diagram of experiment ........................................ 19

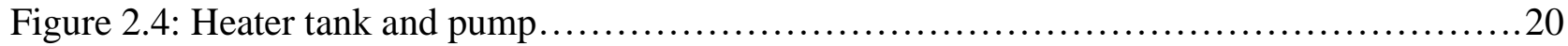

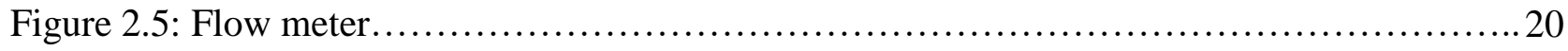

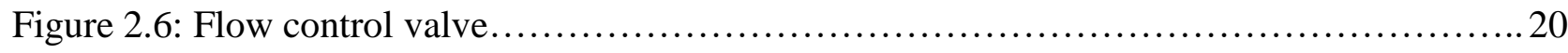

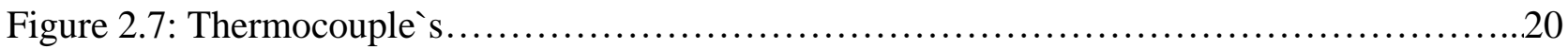

Figure 2.8: Rectangular cavity with U-shaped tube filled with PCM $\ldots \ldots \ldots \ldots \ldots \ldots \ldots \ldots \ldots \ldots . \ldots \ldots$

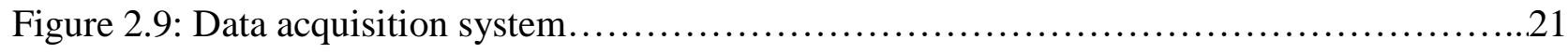

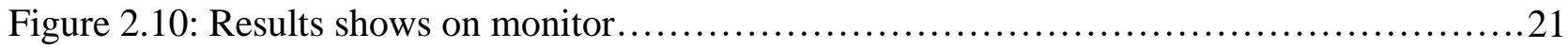

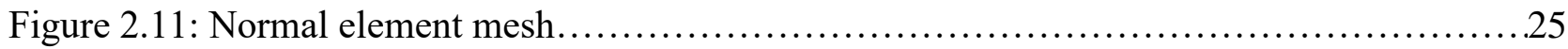

Figure 2.12: Temperature contours at different time of numerical model....................26

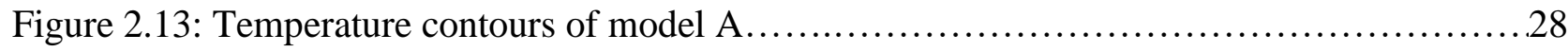

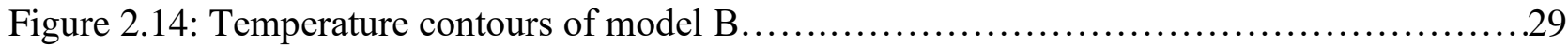

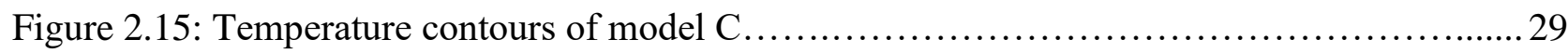

Figure 2.16: Temperature contours of model D..................................... 30

Figure 3.1: Temperature distributions at $\mathrm{y}=0 \mathrm{~m}$ of the cavity along $\mathrm{x}$-axis...................33

Figure 3.2: Temperature distributions at $\mathrm{y}=0.04741 \mathrm{~m}$ of the cavity along $\mathrm{x}$-axis..............35

Figure 3.3: Temperature distributions at $\mathrm{y}=-0.04741 \mathrm{~m}$ of the cavity along $\mathrm{x}$-axis................37

Figure 3.4: Temperature distributions at $\mathrm{x}=0 \mathrm{~m}$ of the cavity along $\mathrm{y}$-axis................................39

Figure 3.5: Temperature distributions at $\mathrm{x}=0.02 \mathrm{~m}$ of the cavity along $\mathrm{y}$-axis...............40

Figure 3.6: Temperature distributions at $\mathrm{x}=0.06 \mathrm{~m}$ of the cavity along $\mathrm{y}$-axis...............42

Figure 3.7: Temperature distributions at $\mathrm{x}=-0.02 \mathrm{~m}$ of the cavity along $\mathrm{y}$-axis...............44

Figure 3.8: Temperature distributions at $\mathrm{x}=-0.06 \mathrm{~m}$ of the cavity along $\mathrm{y}$-axis............. 45

Figure 3.9: Temperature distributions at $\mathrm{y}=0 \mathrm{~m}$ of the cavity along $\mathrm{x}$-axis...........................47

Figure 3.10: Temperature distributions at $\mathrm{y}=0.04741 \mathrm{~m}$ of the cavity along $\mathrm{x}$-axis.............49

Figure 3.11: Temperature distributions at $\mathrm{y}=-0.04741 \mathrm{~m}$ of the cavity along $\mathrm{x}$-axis............51

Figure 3.12: Temperature distributions at $\mathrm{x}=0 \mathrm{~m}$ of the cavity along $\mathrm{y}$-axis $\ldots \ldots \ldots \ldots \ldots \ldots \ldots$

Figure 3.13: Temperature distributions at $\mathrm{x}=0.02 \mathrm{~m}$ of the cavity along $\mathrm{y}$-axis...............54 
Figure 3.14: Temperature distributions at $\mathrm{x}=0.06 \mathrm{~m}$ of the cavity along $\mathrm{y}$-axis...............56

Figure 3.15: Temperature distributions at $\mathrm{x}=-0.02 \mathrm{~m}$ of the cavity along $\mathrm{y}$-axis................58

Figure 3.16: Temperature distributions at $\mathrm{x}=-0.06 \mathrm{~m}$ of the cavity along $\mathrm{y}$-axis...............59 


\section{Nomenclature}

\begin{tabular}{|c|c|c|c|}
\hline TES & Thermal energy storage & V & Velocity $(\mathrm{m} / \mathrm{s})$ \\
\hline PCM & Phase change material & $\mathrm{F}$ & Body force $\left(\mathrm{N} / \mathrm{m}^{3}\right)$ \\
\hline MEPCM & Microencapsulated phase change material & $d$ & Diameter $(\mathrm{m})$ \\
\hline $\mathrm{L}$ & Length of U-shaped tube (m) & Ste $_{\mathrm{m}}$ & Stefan number \\
\hline $\mathrm{Sb}_{\mathrm{c}}$ & Sub-cooling factor & $\mathrm{Q}_{\mathrm{h}}$ & Hot wall \\
\hline $\mathrm{N}_{\mathrm{c}}$ & Thermal conductivity parameter & $\mathrm{F}_{0}$ & Fourier number \\
\hline $\mathrm{N}_{\mathrm{v}}$ & Dynamic viscosity parameter & $\mathrm{t}$ & time (s) \\
\hline CFD & Computational fluid dynamics & $3 \mathrm{D}$ & Three dimensional \\
\hline HTF & Heat transfer fluid & $\mathrm{T}$ & Temperature $\left({ }^{\circ} \mathrm{C}\right)$ \\
\hline LHTES & Latent heat thermal energy storage & A & Area $\left(\mathrm{m}^{2}\right)$ \\
\hline $\mathrm{u}$ & Fluid velocity (m/s) & $\mathrm{P}$ & Pressure $(\mathrm{Pa})$ \\
\hline Q & Heat transfer rate $\left(\mathrm{w} / \mathrm{m}^{2} . \mathrm{K}\right)$ & $\mathrm{Nu}$ & Nusselt number \\
\hline $\mathrm{m}^{\mathrm{o}}$ & Mass flow rate (Liter/s) & I & Identical vector \\
\hline$C_{p}$ & Heat capacity $(\mathrm{J} / \mathrm{kg} . \mathrm{K})$ & $2 \mathrm{D}$ & Two dimensional \\
\hline$Q_{A}$ & Energy absorbs $\left(\mathrm{w} / \mathrm{m}^{2}\right)$ & $\mathrm{Q}_{\mathrm{s}}$ & Energy $\operatorname{supply}\left(\mathrm{w} / \mathrm{m}^{2}\right)$ \\
\hline $\mathrm{k}$ & Thermal conductivity (w/m.K) & FEM & Finite element method \\
\hline $\mathrm{R}_{\mathrm{s}}$ & Thermal resistance $(\mathrm{k} / \mathrm{w})$ & $\mathrm{Ra}$ & Rayleigh number \\
\hline $\mathrm{n}$ & Normal direction of vector & $\mathrm{Da}$ & Darcy number \\
\hline LBM & Lattice Boltzman method & EG & Ethylene glycol \\
\hline $\mathrm{PV} / \mathrm{T}$ & photovoltaic/thermal & $\mathrm{Ha}$ & Hartmann number \\
\hline HAM & Homotopy analysis method & $\operatorname{Re}$ & Reynolds number \\
\hline q & Heat flow rate $(1 / \mathrm{min})$ & & \\
\hline $\mathrm{T}_{0}$ & Temperature outside of the tube $\left({ }^{\circ} \mathrm{C}\right)$ & & \\
\hline $\mathrm{P}_{0}$ & Initial pressure of the fluid $(\mathrm{Pa})$ & & \\
\hline $\mathrm{U}_{0}$ & Initial velocity of the fluid $(\mathrm{m} / \mathrm{s})$ & & \\
\hline
\end{tabular}




\section{Subscript}

$q_{d}$

$\mathrm{n}_{\mathrm{d}}$

$\mathrm{q}_{\mathrm{u}}$

$\mathrm{d}_{\mathrm{s}}$

$\mathrm{k}_{\mathrm{s}}$

$\mathrm{C}_{\mathrm{p} \text { phase } 1}$

$\mathrm{C}_{\mathrm{p}}$ phase 2

$\mathrm{k}_{\text {phase } 1}$

$\mathrm{k}_{\text {phase } 2}$

$\rho$

$\theta$

$\alpha_{\mathrm{m}}$

$\mu$

$\eta$

$\rho_{\text {phase } 1}$

$\rho_{\text {phase } 2}$
Heat flow rate of thin layer ( $1 / \mathrm{min})$

Normal direction of thin layer

Initial heat flow rate of thin layer $(1 / \mathrm{min})$

Layer thickness (m)

Layer thermal conductivity (w/m.K)

Specific heat of solid PCM (J/kg.K)

Specific heat of liquid PCM (J/kg.K)

Thermal conductivity of solid PCM (w/m.K)

Thermal conductivity of liquid PCM (w/m.K)

\section{Greek symbols}

Density $\left(\mathrm{kg} / \mathrm{m}^{3}\right)$

Phase change indicator

Flow field

Dynamic viscosity (Pa.s)

Efficiency

\section{Subscript}

Density of solid PCM $\left(\mathrm{kg} / \mathrm{m}^{3}\right)$

Density of liquid PCM $\left(\mathrm{kg} / \mathrm{m}^{3}\right)$ 


\section{CHAPTER 1 - INTRODUCTION AND APPLICATION}

\subsection{Introduction of PCM and Bentonite}

Thermal energy storage (TES) in general, and phase change materials have been a main topic in research and industry for the last 20 years. North America faces a great challenge during the winter season, and one way to overcome this problem is thermal energy. There were many researchers tried to find solutions using experiment and numerical simulations. There are lot of studies for TES, some are conducted using PCMs, and others are using nanofluids. However, TES using PCM is the effective process nowadays for researchers.

In industry sectors company wants to store thermal energy by making a borehole cavity. In current study, some concepts for storing thermal energy by using PCM or Bentonite or mixer of PCM and bentonite in a cavity has been analyzed.

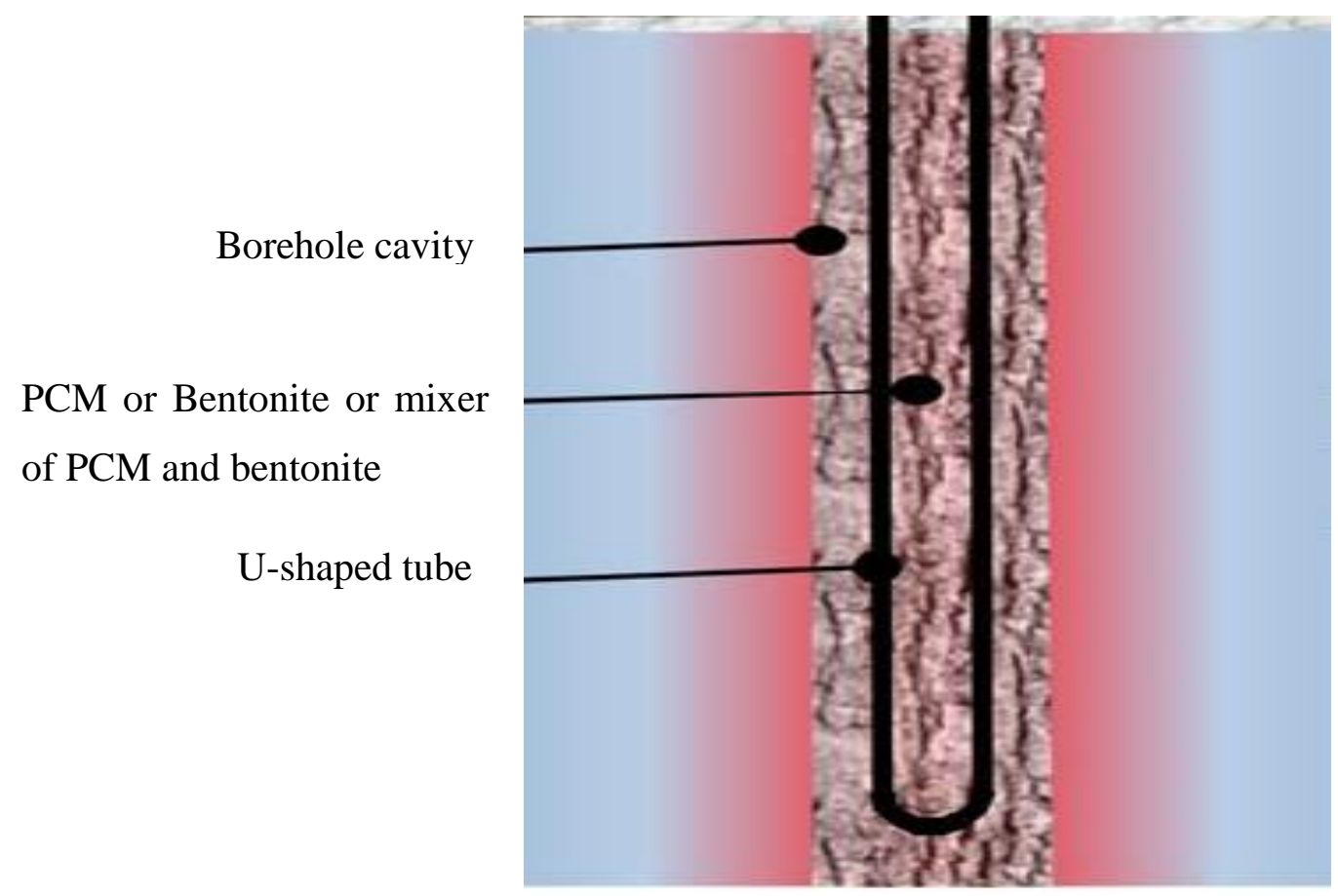

Figure 1.1: U-Shaped borehole Cavity filled with PCM or Bentonite

PCM can absorb, store and release large amounts of latent heat over a defined narrow temperature range while the material changes phase or state, and has been used for the storage of heat energy due to their high latent heat of transition, high energy densities and low cost. Sensible heat thermal energy storage, latent heat thermal energy storage, and chemical thermal 
energy storage are some important energy store processes. There are some significant applications of TES with PCM like thermal storage of solar energy, heating and cooling of water, maintenance room temperature, thermal protection of food and electrical devices, medical therapies, thermal comfort in vehicles, spacecraft thermal systems, and solar power plant etc.

Recently, research on phase change material to store thermal energy is the main topic. Many researchers have conducted experimental and numerical simulation for identifying the thermal behavior of PCM. Some of have a good results and others have a lack of consisting and coherent approach to the physical properties of PCM.

For transient thermal energy storage of microencapsulated phase change material (MEPCM) particles in an enclosure, Ho et al [1] conducted a study at two vertical hot and cold wall surfaces where the horizontal surfaces were thermally insulated. The experiment was taken for nine sets of hot and cold wall temperature dimensionless parameters which ranges: Stefan number, Ste $_{\mathrm{m}}=0.063-0.251$ and sub-cooling factor, $\mathrm{Sb}_{\mathrm{c}}=0.0-0.75$. Numerical simulation performed on a mathematically modeling configuration to consider the heat transfer characteristics and the thermal energy storage efficiency of the enclosure. Results showed that the faster melting transient has a higher temperature difference, a higher Stefan number and the sub-cooling number were the main parameters to represent the thermal latent heat storage of the MEPCM system. Also, dimensionless energy of hot wall, $\mathrm{Q}_{\mathrm{h}}$ was correlated with the Stefan number $\mathrm{St}_{\mathrm{m}}$, the sub-cooling number $\mathrm{Sb}_{\mathrm{c}}$, and the Fourier number $\mathrm{F}_{\mathrm{o}}$.

Ho et al [2] conducted an experiment of $\mathrm{Al}_{2} \mathrm{O}_{3}$ nanoparticles and microencapsulated phase change material (MEPCM) particles on convection effectiveness in a circular tube by using a scale analysis which explained that the combined effect changes in the thermal conductivity and the heat capacity of the water-based suspension related to the base fluid which have a predominant approach on their convective heat transfer performance. The effective thermal diffusivity of $\mathrm{Al}_{2} \mathrm{O}_{3}$ nanofluid was increased dramatically and its boundary layer promoted while the heat capacity of the melting phase change material has a significant decrease in the thermal conductivity. Results showed that the forced convective cooling efficacy of $\mathrm{Al}_{2} \mathrm{O}_{3} /$ water nanofluid strongly depends on the flow rate and particle fraction of the heat transfer fluid in the tube.

Ho et al [3] conducted another experimental investigation in water-based suspension of $\mathrm{Al}_{2} \mathrm{O}_{3}$ nanoparticles and microencapsulated phase change material (MEPCM) particles which has 
ternary suspension including the density, specific heat thermal conductivity, latent heat of fusion and dynamic viscosity. MEPCM particles was served as a dual functional thermal fluid for energy transport of forced convective heat transfer augment and thermal storage but Paraffin has the significant properties of MEPCM particles and dispersion fraction of $\mathrm{Al}_{2} \mathrm{O}_{3}$ nanoparticles caused the phase change material (PCM) suspension usually characterizes with lower thermal conductivity related to the base fluid. Results showed that the effective thermal properties of the hybrid water-based suspension and MEPCM particles suspension significantly enhanced the thermal conductivity of nanofluids.

Goel et al [4] conducted an experiment for heat transfer convection in micro-capsulated phase change material suspension using a hydrodynamically developed circular duct with a constant wall heat flux. The main parameters of that study were the bulk Stefan number and the volumetric concentration, but limited number of experiments have been done by particle diameter ratio and the homogeneity of the suspension. The volumetric concentration and the degree of homogeneity does not have a significant role of heat transfer. So, it was negligible. However, the phase change materials ratio of latent sensible heat capacity was high. So, the experiment showed that $50 \%$ wall temperature was reduced by the phase change material which had a single-phase fluid for the same non-dimensional parameters.

Ho et al [5] conducted a study of wall condition of solid-liquid phase change material suspension flow by using circular pipes with finite heated length. The latent heat transfer raised in the phase change suspension flow which was the cause of convective heat transport and raised the wall temperature of heated section. For preheating of the suspension flow in the non-directly heated region, melting of the particles may occurred and therefore the condition of the latent heat transfer to heat transfer to convection heat dissipation over the heated section was markedly attenuated. Result, indicated that sensible and latent heat caused to the total heat transfer rate of the relevant dimensionless parameters, the particle volumetric concentration, the modified Stefan number, the Peclet number, the wall thickness ratio, and the wall-to-fluid thermal conductivity ratio.

Chen et al [6] conducted an investigation that were including the relation between the increase in fluid temperature and the heat flux, the variation of the internal wall surface temperature, the Nusselt number in the developing thermal region and the pressure drop property in the heat transfer experiment of convective laminar flow heat transfer with microencapsulated 
phase change (MEPCM) material suspension in a circular tube under constant heat flux by using dual-functional medium for thermal energy transport or storage. The tested characteristic temperature and Stefan number are put forward in the experiments were the dimensionless internal wall temperature of the MEPCM suspension was lower than the pure water and the decrease was up to $30 \%$ of that water, the heat transfer augment ratio was 1.42 times of that of water at $\mathrm{x}^{+}=4.2 * 10^{-2}$ for $15.8 \mathrm{wt} \%$ MEPCM suspension, which was not as much as in some referenced and the pump consumption of the MEPCM suspension system decreased dramatically for the larger heat transfer rate compared with water, due to phase change.

Sabour et al [7] conducted a study that was a theoretically analysis of the laminar free convection heat transfer of fluids in a square cavity. The side walls of the cavity were subject to temperature difference, whereas the bottom and top were insulated. Based on the available experimental results in the literature, two new non-dimensional parameters, namely, the thermal conductivity parameter $(\mathrm{Nc})$ and dynamic viscosity parameter $(\mathrm{Nv})$ were introduced. Those parameters indicated the augmentation of the thermal conductivity and dynamic viscosity of the fluid by dispersing particles.

Rahman et al [8] conducted a study of Thermal Energy Storage (TES) in a sensible water tank which was significant due to its low cost and high heat capacity. It could increase the overall efficiency and operational flexibility of distributed energy simulation. The water tank had two heat exchangers which were supplied hot and cold water respectively by following 1-D transient heat balance equations and COMSOL 3-D simulations. The flow rate and heat loss inside the exchangers depend on the location, length and thermophysical properties. The study showed that an increase in flow-rate inside the hot heat exchanger increases the stored water temperature and the cold-water outlet temperature. However, increment of temperature causes diminishing the flow rate of hot fluid where the cold fluid outlet temperature was constant at certain values. So, the result showed that distributed generation system and heat generated system depends only on the size and configurations of a thermal storage tank.

Yaici et al [9] conducted an experiment for validation of the unsteady flow behavior, thermal stratification and performance of a hot water storage tank by using three-dimensional (3D) unsteady Computational Fluid Dynamics (CFD) simulations. There were some geometrical factors and operating conditions was considered for the design of thermal storage tank. The experiment showed the importance of combined effects of CFD on the performance of thermal 
storage tank. So, the 3D transient CFD simulations can be used as an effective tool to optimize thermal storage tank parameters. Thus, it may add to the value of thermal energy system performance and efficiency.

Kim and Han [10] conducted a study for a glazed solar flat plate collector system with heat storage tanks in different weather conditions which plays an important role for the improvement of performance of solar energy system. The solar collectors were categorized as nonconcentrating and concentrating. The important system variables including the solar collector plate temperature, heat loss of the tank, temperature of the tanks and the collector efficiency were investigated and, the result showed that the system parameters such as the monthly average daily total radiation on a terrestrial horizontal surface or the maximum temperature of a day affect greatly on the performance of solar energy system.

Ho et al [11] conducted a study of wall condition of solid-liquid phase change material suspension flow by using circular pipes with finite heated length. The latent heat transfer raised in the phase change suspension flow which was the cause of convective heat transport and raised the wall temperature of heated section. For preheating of the suspension flow in the non- directly heated region, melting of the particles may occurred and therefore the condition of the latent heat transfer to heat transfer to convection heat dissipation over the heated section is markedly attenuated. Results indicated that sensible and latent heat are caused to the total heat transfer rate of the relevant dimensionless parameters, the particle volumetric concentration, the modified Stefan number, the Peclet number, the wall thickness ratio and the wall-to-fluid thermal conductivity ratio.

Kant et al [12] conducted a study carrying out the numerical investigation for the melting of graphene nanoparticles dispersed PCM filled in an aluminum square cavity heated from one side. The graphene nanoparticles were mixed in three different volumetric ratios $(1 \%, 3 \%$, and $5 \%)$, with three different commonly used categories of organic, inorganic and paraffin PCM (namely, Capric Acid, $\mathrm{CaCl}_{2} \_6 \mathrm{H}_{2} \mathrm{O}$, and n-octadecane) to see the effect on melting of composite PCM developed. The resulting transient isotherms, velocity fields, melting front and melt fractions thus have been deliberated in detail. Those results clearly indicate that the addition of graphene nanoparticles increases melting rate but can also hamper the convection heat transfer within large cavities. The study also showed that such enhanced PCM can be effectively used for different TES applications in different fields. 
Gil et al [13] conducted an experiment with two identical storage tanks based on the shelland-tubes heat exchanger, one of them including 196 squared fins in the bundle of the tubes and the other without, were experimentally tested. Hydroquinone was selected as the storage material, having a latent heat of $205 \mathrm{~kJ} / \mathrm{kg}$ and a phase change temperature between 168 and $173^{\circ} \mathrm{C}$. The aim of this analysis was to test experimentally and, compare the average effectiveness of the TES systems analyzed using PCM for solar cooling and refrigeration applications. It was found out that for the same tank configurations (shell-and-tubes) even changing drastically the dimensions of the tank or the number and the diameter of the tubes, the average effectiveness curve proposed in the literature fits well with the results showed here.

Touatia et al [14] conducted a study that charging, and the discharging of solar thermal energy stored (TES) using latent heat from a storage unit contains PCMs. They also studied the improvement of the heat transfer between fluid which was the water and the PCMs by adding the fins to storage unit with various configurations, including in-line fins and staggered fins. Then, they studied the assembly of two PCMs in our storage unit. In addition, an experimental work has been validated. The ANSYSFLUENT 15 code was used to solve the formulation of the fusion/solidification processes, where three users define have been developed to describe the thermo-physical properties of the PCM.

Janagi et al [15] conducted a study to analyze the natural convection flow and heat transfer of cold water in a square porous cavity. The horizontal walls of cavity were adiabatic, and the vertical walls were maintained at different temperatures. The finite volume method was used to solve the governing equations. The heat transfer rate was increased on increasing the Darcy number and porosity. Also, the convective heat transfer rate was decreased first and then increased on increasing the density inversion parameter. The results can be used in the cooling of electronic components, thermal storage system and in heat exchangers. The choice of consideration of sinusoidal heating and density maximum effect produces good result in flow field and temperature distribution. The obtained results can be used in various fields.

Delgado et al [16] conducted a study that the results of heat transfer in an agitated tank containing a low-cost phase change material emulsion, heated by water flowing in a coil. By measuring the temperature dependency on time and solving the transient enthalpy balance, the heat transfer coefficient between the helical coil and the agitated phase change material emulsion was determined, based on the impeller Reynolds number. The thermal energy storage efficiency 
was also being analyzed. The results have showed that the overall heat transfer is higher when a stirring rate was high.

Zalba et al [17] conducted a study which carried out the process of thermal energy storage with solid-liquid phase change. There were three key aspects on that review: materials, heat transfer and applications. Materials used by researchers as potential PCMs were described, together with their thermophysical properties. Commercial PCMs have also been listed. Different methods of thermal properties determination could be found. Problems in long term stability of the materials and their encapsulation were discussed.

Bashar and Siddiqui [18] conducted an experiment to investigate the melting process and thermal behavior of Phase Change Material (PCM) due to heat transfer convection by a Ushaped tube which emerged in PCM. The experiment was conducted by four different input heat fluxes which was recorded by thermocouples and imaging system. Results showed that the local heat transfer coefficient, the volume of melting PCM was more inside the U-shaped tube rather than outside. Also, the Rayleigh number was higher inside the U-shaped over the whole domain. Finally, for the U-shaped heat source, a new Nusselt-Rayleigh number correlation was proposed during the melting process of PCM.

Koukou et al [19] investigated a Latent Heat Thermal Energy Storage System (LHTES) by using heat exchanger and organic Phase Change Materials (PCM). A LHTES test rig set was performed for energy storage and release by using Computational Fluid Dynamics (CFD) simulation. There was a pump which circulate the water as a Heat Transfer Fluid (HTF) affected the melting and solidification of PCM for bouncy effect. Results showed that the discharging performance was highly affected by the thermal transfer limitation and the cooling of the PCM.

Plotze et al [20] conducted a study to describing the thermal properties, heat conductivity, heat capacity, and the thermal diffusivity of Bentonite. The heat capacity was measured with a transient method. For measuring the thermal conductivity used an impulse of thermal flow into the analyzed material (Bentonite blocks) with a linear surface probe. Factors of influencing the results were composition, and orientation of the material density and porosity as well as the water content, and the temperature during the measurement. 


\subsection{Introduction of Nanofluid}

The thermal conductivity of nanofluid is higher than the PCM and water. So, nanofluid can be consider as the HTF in thermal storage system. Many researchers have conducted the experimental and numerical simulation for identifying the thermal behavior of nanofluid. Some of the literature have good results and others have a lack of consistency and coherent approach to the physical properties of nanofluid.

Saghir et al [21] conducted a numerical study by considering the fluid as a single phase or as a two-phase system, and the study was performed by using three different numerical approaches namely, the finite element method (FEM), the finite difference method (FDM), and Lattice Boltzmann method (LBM) techniques for 2D-FDM, 2D-LBM and 3D-FEM investigation. The numerical results were compared with experimental results for validation purposes. The simulation was performed for water-aluminum oxide nanofluid at a particle concentration range of $1 \%$ to $3 \%$ volume fraction. Different numerical strength and weak approaches were presented in the form of temperature, stream function, and velocity variation. Average Nussult number at the walls have been presented for a range of Rayleigh numbers.

Saghir et al [22] expressed a study where various ranges of nanoparticles were used in a nanofluid for improving its thermal conductivity and heat transfer properties. They used different numerical modeling approaches where single phase consisting of a fluid phase only, and other as a two-phase consisting of a liquid phase and a solid phase in a simple cavity as a model geometry. For simplicity of the cavity geometry, interaction of the fluid with surfaces was well known and proposed a cavity-based approach for the numerical modeling of thermos-fluidic flow in a nanofluid. The numerical and experimental result showed 1\% discrepancy for single phase model and $10 \%$ discrepancy for two phase models. Numerical simulation was performed using the finite element technique for a range of nanoparticles of aluminum oxide concentration from 1 vol\% to 3 vol\% in water. The study showed that single phase approach predicts the heat transfer with better accuracy than two-phase models.

For the estimation of thermophoresis, Eslamian and Saghir [23] investigated similarities between thermophoresis of nanoparticles and macromolecule dispersed in a base fluid with thermodiffusion of binary mixture. A nonequilibrium thermodynamics-based expression was developed for the estimation of thermos-diffusion factor in binary mixture and applied to thermophoresis in nanofluids. Also, a hydrodynamics-based expression and the nonequilibrium 
thermodynamics-based expression have been used to estimate the thermophoretic velocity in nanofluids. But, the hydrodynamics-based equation was performed for thermophoresis in nanosized and even sub-nanometer particles in liquid. So, the correct numerical parameter is still unresolved.

Eslamian et al [24] studied using a two-phase Lattice Boltzmann method (LBM) for laminar flow with Rayleigh Number ( $\mathrm{Ra}$ ) up to 106 with various particle loads. Results indicated that average Nusselt number $(\mathrm{Nu})$ increases with increase of $\mathrm{Ra}$ and particle loading. Also, an increase in the Ra causes in an increase in the nanofluid velocity, where nanofluid velocity was decreased with an increase of particle loading. But, laminar natural convective heat transfer rate and thermophoresis force was a significant contributor to heat transfer augmentation in nanofluid. So, finally it was concluded that nanofluids behave homogenously at low Ra and heterogeneously as Ra increases.

Ho and Chen [25] conducted an experiment using $\mathrm{Al}_{2} \mathrm{O}_{3} /$ water in some parallel rectangular copper minichannel heat sink as a replacement of pure water for investigating the thermal performance of nanofluid. Hydraulic and thermal performances of the nanofluid have been assessed with the results obtained for the pumping power which was based on the inlet and bulk temperature differences, also fixed with the ranges of Reynolds number. The average heat transfer coefficient based on the bulk and inlet temperature differences of $\mathrm{Al}_{2} \mathrm{O}_{3} /$ water nanofluid increase by more than $72 \%$ and $35 \%$ respectively, compared with that with pure water. So, the experiment concluded that thermal performance of nanofluids in a minichannel heat sink has more heat transfer coefficient than the pure cooled water.

Ho et al [26] conducted an experiment of forced convective cooling hydraulic and thermal performances of a microchannel heat sink where $\mathrm{Al}_{2} \mathrm{O}_{3}$ /water nanofluid was the coolant. Performance of microchannel heat sink with $\mathrm{Al}_{2} \mathrm{O}_{3}$ /water nanofluid have been assessed from the friction factor, the pumping power, the average heat transfer coefficient, the thermal resistance and the maximum wall temperature with the fixed Reynolds number ranges. They tested for the largest flow of 1 vol\% nanofluid, average heat transfer coefficient increased $70 \%$ compared with the pure water while inlet temperature and wall temperature can be decreased. Result indicated that nanofluid heat sink was more cooled than the water, also had higher heat transfer coefficient but low thermal resistance and wall temperature at high pumping power. 
Heris et al [27] conducted an experiment of laminar flow convective heat transfer of $\mathrm{Al}_{2} \mathrm{O}_{3}$ /water nanofluid in circular tube for investigating at the constant wall temperature. The experiment was based on the heat surface area, vibration of heated surface, injection or suction of fluid and electrical or magnetic fields of experiment particles. The Nusselt numbers, Peclet umber, Reynolds numbers and heat transfer coefficient due to the presence of single phase heat transfer correlation of nanoparticles increased the heat transfer of nanofluid. Also, dispersion and chaotic movement caused by Brownian motion and particle migration of nanoparticles might played the role of heat transfer enhancement.

Kasaeipoor et al [28] conducted an experiment in which the transfer and entropy generation analysis of natural convection was carry out using Lattice Boltzmann method in a cavity filled with MWCNT-MgO (15\%-85\%)/water. The thermo-physical properties of fluid were measured experimentally in five solid volume fractions of $0.25,0.5,1,1.5$ and 2 vol\% in a temperature range of 300 to $340\left({ }^{\circ} \mathrm{K}\right)$. To utilize those results, some correlations for dynamic viscosity and thermal conductivity in terms of temperature and solid volume fraction were develop and used in the numerical simulations. The considered cavity was heated with constant and uniform temperature from side walls and the top and bottom walls were insulated. It was concluding that the configuration of refrigerant had pronounced effect on the fluid flow, heat transfer and entropy generation.

Sheikholeslami and Rokni [29] conducted study of magnetic field on $\mathrm{CuO}-\mathrm{H}_{2} \mathrm{O}$ nanofluid free convection inside a curved porous cavity is reported. Simulations have been done via Lattice Boltzmann method (LBM). Kernkraftwerk Leibstadt model was applied to consider Brownian motion impact on nanofluid properties. Impacts of Rayleigh number (Ra), Darcy number (Da), nanofluid volume fraction (f), Hartmann number (Ha) on heat transfer treatment were illustrated. Outputs demonstrate that temperature gradient reduces with increase of Ha while it increases with augment of permeability of porous media and buoyancy forces.

Rahimpour and Moraveji [30] conducted a study of modeling of natural convection heat transfer in an inclined C-shape cavity. The enclosure was filled with $\mathrm{H}_{2} \mathrm{O}-\mathrm{Fe}_{3} \mathrm{O}_{4}$ nanofluid under the effect of magnetic field. The operating range of parameters used in this study were Hartmann number (Ha) from 0 to 80, Rayleigh number $(\mathrm{Ra})$ from $1 \mathrm{E} 2$ to $1 \mathrm{E} 6$, nanoparticles volume fraction from 0 to 0.1 , inclination angle (a) from 0 to 90 degrees, and aspect ratio from 0.2 to 0.8 . The employed model was solved using CFD tools based on the finite element method. The 
comparison with reference experimental data indicated the accuracy and generalization capability of the model.

Ueki et al [31] conducted a study that changes the thermal conductivity by mixing nanoparticles which was relevant to a characteristic length of the nanoparticles by carbon black fluid, and the carbon nano-powder fluid. The study employed soot fine particles, which can be produced by means of combustion method at relatively low cost and, investigated them for nanofluids. They measured effective thermal conductivity, and specific heat of each nanofluid by means of transient hot-wire method, and adiabatic method and found that the effective thermal conductivity increased with increase in the particle volume fraction. In addition, nanofluids enhanced their own thermal conductivities by approximately $7 \%$, and $19 \%$ respectively at the particle volume fraction of $1.5 \%$. Results showed that the nanoparticles geometry influenced its own thermal conductivity.

Mehryan et al [32] conducted a study which addressed the free convective heat transfer of the $\mathrm{Al}_{2} \mathrm{O}_{3}-\mathrm{Cu}$ water hybrid nanofluid in a cavity filled with a porous medium. The glass ball and aluminum metal foam were considered for the porous matrix which increased the strength of the formed recalculating cells. The thermal conductivity effect of each of the solid matrices increased with the porosity enhancement but, the solid matrix had no considerable variations in the thermal field inside the cavity. Thus, the actual available experimental data for the thermal conductivity and the dynamic viscosity of hybrid nanofluids were directly utilized in the study. The results showed reduction of the heat transfer rate was much higher for hybrid nanofluid compared to the single nanofluid.

Sajedi et al [33] conducted an experiment to judge thermal performance of nanofluids by excess heat transfer of nanofluids compared to the base fluid, neglecting the hydraulic effects. Constant Reynolds number and constant pumping power in convective heat transfer coefficient was the two criteria, between nanofluids and base fluid in developing laminar region. Results, showed that the concentration of nanoparticle had a significant impact on the amount of deflection of those two criteria, so that by increasing the nanoparticle's concentration the difference between those two measures became greater.

Dondapati et al [34] expressed a study that density, viscosity and thermal conductivity of nanofluid increase or decrease depends on the volume fraction of nanoparticles specific heat decreases or increases respectively. However, effective thermophysical properties were depend 
on both the volume fraction of nanoparticles and temperature. Moreover, the heat transfer increased, and pressure drop decreased with the suspension of nanoparticles in Liquid Nitrogen $\left(\mathrm{LN}_{2}\right)$. But, lower pressure drop was found with the suspension of $\mathrm{CuO}$ nanoparticles in $\mathrm{LN}_{2}$. Finally, it concluded that suspension of nanoparticles in $\mathrm{LN}_{2}$ exhibited desirable results thereby confirming the feasibility of using nano cryogenic fluids in micro heat exchangers.

Friedoonimehr and Rahimi [35] conducted an experiment that fluid flow and heat transfer and entropy generation analysis of the steady laminar nanofluid flow induced by a stretching/shrinking sheet with transpiration effect. The entropy generation equation was derived as a function of the velocity and the temperature gradients. The results showed that entropy generation number increases with increasing the values of nanoparticle volume fraction parameter, the magnetic parameter, the mass suction/injection parameter, the Reynolds number, the Brinkman number, and the Hartmann number.

Shamsi et al [36] expressed a study of computational fluid dynamics analysis of the laminar flow of the non-Newtonian fluid. The analysis was done on a rectangular two-dimensional microchannel, which was rectangular and two-dimensional in Cartesian coordinate. The power law was using to speculate the dynamic viscosity of the cooling nanofluid with Reynolds number range of $5<\operatorname{Re}<300$. The results showed that a sudden contact between the fluid and the ribs and a reduction in the coflowing length (length of the rib) cause a cut in heat transfer by the fluid in farther parts from the solid wall (tip of the rib).

Hamzah et al [37] conducted a study on the factors affected the performance of hybrid nanofluid in enhancing the thermal performance of heat transfer systems. The performances of the hybrid nanofluids was normally determined by its volume concentrations, mixing ratios and stability of the dispersions. However, mathematical models were one of the prime factor to determine the thermal properties of hybrid nanofluids, as well as to validate the analysis and reduced the error between predicted correlations and experimental data. Moreover, the study emphasized on the development of mathematical correlations to determined thermo-physical properties of hybrid nanofluids.

Yang and $\mathrm{Du}$ [38] conducted a study that was attempting to provide comprehensive summaries on preparation, properties, heat transfer and applications performance of various nanofluids. The thermal conductivity could be increased as the increase in particle loading and temperature as well as the decrease in particle size. However, most experimental and all 
numerical results showed that $\mathrm{TiO}_{2}$ nanofluid could enhance the convection and boiling heat transfer coefficient in various heat transfer processes.

Oliveira et al [39] conducted an experiment to investigate thermophysical properties by applying the technique of surface modification. The modified nanoparticles were used for the preparation of nanofluids with different volume percent loadings of nanoparticles in water ranging from $0.00125 \%$ to $0.1 \%$ and at temperature ranges from $20{ }^{\circ} \mathrm{C}$ to $50{ }^{\circ} \mathrm{C}$. However, with increasing in temperature there were also smaller increases in thermal conductivity, due to increased Brownian motion. Moreover, the volume fraction also influenced thermal conductivity so that with increased concentration of particles increased conductivity was observed. The results showed that use of the surface modification technique had a significant effect on the stability of $\mathrm{TiO}_{2}$ nanoparticles.

Satti et al [40] conducted an experiment that the thermal conductivity of five different nanofluids containing aluminum oxide, copper oxide, zinc oxide, silicon dioxide and titanium dioxide nanoparticles dispersed in a base fluid of propylene glycol and water mixture. The thermal conductivity of nanofluids indicated a strong dependence on particle volumetric concentration, particle size, properties of particles and the base fluid and temperature. Result showed that enhanced thermal conductivity with increasing temperature, nanofluids should be more beneficial at higher temperature applications.

Zyla et al [41] conducted an experiment that thermophysical properties of ethylene glycol (EG) based nanofluids containing titanium nitride (TiN) nanoparticles have been experimentally investigated at constant temperature. Nanoparticle size had different effect of nanofluids property. However, thermal conductivity and surface tension of nanofluids were higher with smaller nanoparticles for same nanoparticle content. Moreover, Lower the nanoparticle size, higher was the viscoelastic structure and the yield stress when they were present. Finally, physical properties determination of nanofluids was potential of TiN nanofluids as useful fluid in thermal and electrical applications.

Yazdanifard et al [42] conducted a study that the features, structures, and the outcomes of photovoltaic/thermal (PV/T) system which applied nanofluids and investigated the effectiveness of nanofluids and also, to comprehensively analyze the effective parameters on the performance of a nanofluid-based flat plate photovoltaic/thermal system in both laminar and turbulent regime. However, nanoparticles were more efficient in laminar regime compared to turbulent one. So, the 
results indicated that using nanoparticles of larger diameter leads to greater total energy and exergy efficiency in the turbulent regime, while contrary behavior was observed in laminar flow.

Geothermal energy is a clean and sustainable energy resource with virtually unlimited supply. Sui et al [43] conducted a study which investigate the potential of applying nanofluids as working fluids to extract more energy from reservoirs and to improve exploitation of the geothermal resources, by increasing the returning fluid temperature. Study showed the importance of fluid viscosity and heat capacity in geothermal energy production, and nanofluids had superior performance in heat transfer.

Khurana et al [44] conducted a study that forced convection heat transfer and pressure drop of $\mathrm{Al}_{2} \mathrm{O}_{3}, \mathrm{TiO}_{2}$ and $\mathrm{CuO}$ based nanofluids dispersed in water, ethylene glycol and water-ethylene glycol mixture by using less than $3 \%$ volume concentration of nanofluids. $\mathrm{CuO}$ nanoparticles had better heat transfer characteristics compared to $\mathrm{TiO}_{2}$ and $\mathrm{Al}_{2} \mathrm{O}_{3}$ due to high thermal conductivity of $\mathrm{CuO}$ nanoparticles. But, the size of nanoparticles had an important role. Lower the size, higher the chaotic movement of the nanoparticles within the fluid and higher the heat transfer coefficient.

Minakov et al [45] conducted an experiment that nanofluids were prepared based on distilled water and nanoparticles of silicon, aluminum, and iron oxides as well as diamond. The volumetric concentration of the nanoparticles varied from 0.05 to $1 \%$. The diameter ranged from 10 to $100 \mathrm{~nm}$ and the heater diameter was changed from 0.1 to $0.3 \mathrm{~mm}$. Result showed that the decreasing the heater diameter, the relative critical heat flux in nanofluids increases significantly and the deposition of nanoparticles on the heater surface played the leading role in the nanofluid boiling process.

Shahsavar et al [46] conducted a numerical study that focused on the heat transfer and entropy generation characteristics of the $\mathrm{CNT}-\mathrm{Fe}_{3} \mathrm{O}_{4} /$ water hybrid nanofluid in a double-pipe counter-flow heat exchanger. The global thermal, frictional, and total entropy generation rates augmented with the increase of Reynolds number, CNT concentration and magnetite concentration. However, to achieve the minimum total entropy generation along with the maximum heat transfer, applying the nanofluids with great nanoparticle concentrations alongside low Reynolds numbers was suggested.

Minea and Moldoveanu [47] performed a study to evaluate the effects on the performance of nanofluids due to the variations of density, specific heat, thermal conductivity and viscosity, 
which are the functions of nanoparticle volume concentration. Three nanofluids were compared in terms of Mouromtseff number ratios at different volume fraction and the efficiency of nanofluid was demonstrated. However, the efficiency of using nanofluids was increasing with nanofluid volume concentration. Finally, the results showed that the considered nanofluids could successfully replace water in specific applications for a single-phase forced convection flow in a tube.

Dinarvand et al [48] conducted a study that an incompressible electrically conducting nanofluid over a vertical permeable circular cylinder in the presence of transverse magnetic field was investigated by using the steady axisymmetric mixed convective stagnation-point flow. There were two systems of partial equations method homotopy analysis method (HAM) and fourth-order Runge-Kutta method with shooting technique was used for solving. The results illustrated that selecting alumina and copper as the nanoparticle leads to the minimum and maximum amounts of skin friction coefficient value, and copper and titania nanoparticles have the largest and lowest local Nusselt number.

\subsection{Summary}

Based on the brief literature review:

(a) the purpose of this study is to investigate an innovative way to store thermal energy for later uses.

(b) PCM has a huge capacity for thermal energy storage which can uses later in industrial and domestic sectors.

(c) the use of U-shaped heat source is a good alternative for heat transfer.

\subsection{Thesis objectives}

The objectives of this study are:

(a) This experimental and numerical study was conducted to investigate a time-depended heat transfer process during the process of solid-liquid interface of the PCM inside the rectangular cavity, a U-shaped heat source embedded in it.

(b) Study numerically the case when heat is added and extracted with PCM in the cavity.

(c) Predict the thermal behavior in the same cavity when PCM is replaced with Bentonite.

(d) Predict the thermal behaviors, and thermo-capabilities of combined PCM and Bentonite. 


\subsection{Thesis organization}

This study consists of four chapters:

(a) Introduction is shown in chapter 1; (b) experimental work and numerical model descriptions, numerical models by using PCM and Bentonite in different ways under heating and cooling conditions are shows in chapter 2; (c) results and discussion between experimental work and numerical model validation, comparison of the results of numerical models that uses PCM and Bentonite in different ways, heat transfer rate analysis are shown is chapter 3; and finally, conclusions, contributions, and future works are shown in chapter 4. 


\section{CHAPTER 2 - MODEL DESCRIPTION}

\subsection{Introduction}

In this study, PCM is placed in a rectangular cavity, and a U-shaped heat source is used to heat the PCM by using thermal technologies. This type of technologies is essential to prevent heat loss and saving energy [18]. This is the efficient process for reducing the initial cost of a research in TES sectors, and saves systems volume and space. Many researchers used this concept in research for their convenience.

\subsection{Experimental Model Description}

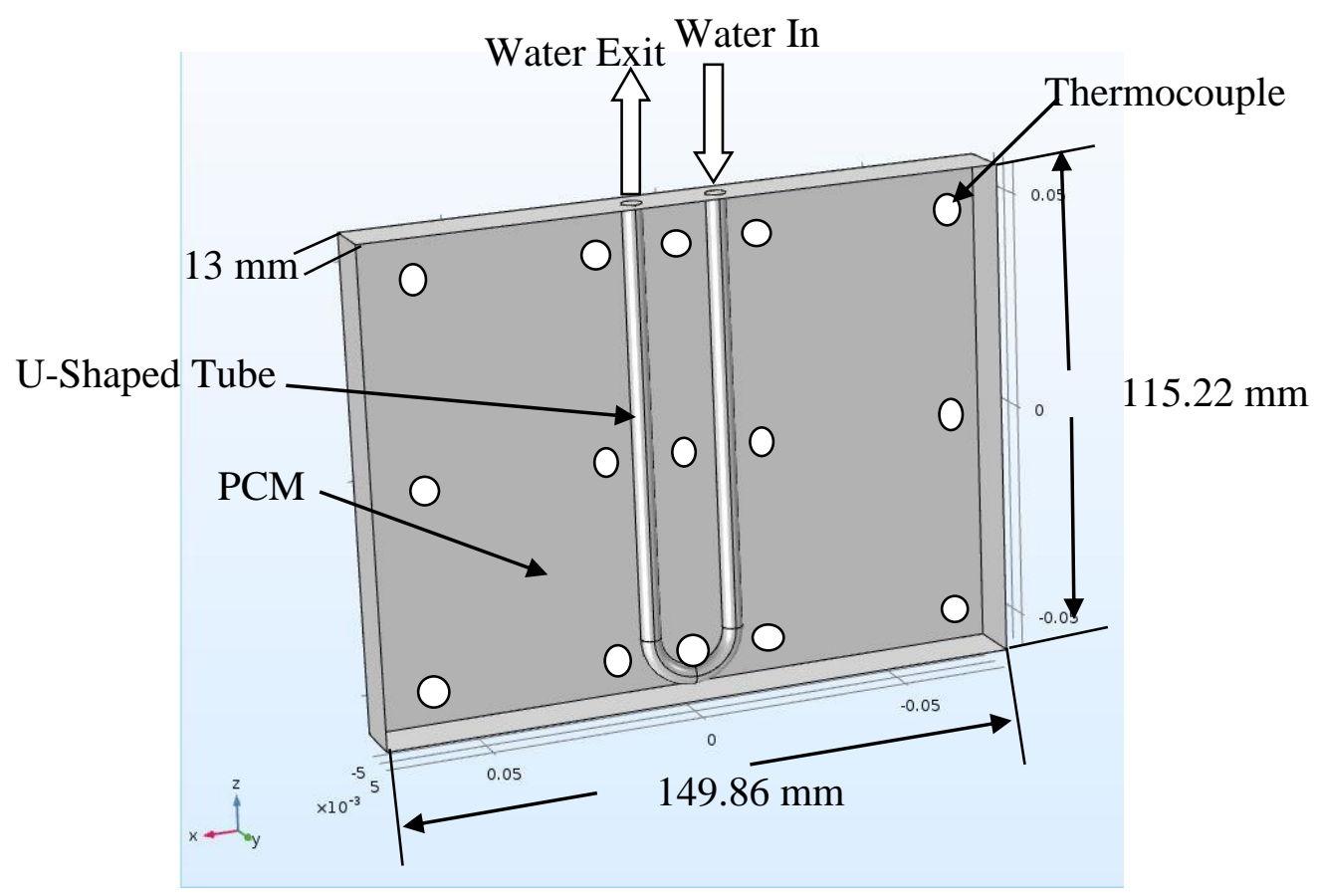

Figure 2.1: U-Shaped Tube in a Rectangular Cavity filled with PCM

Experiments were conducted in a U-shaped copper tube (Copper Alloy 122) of a threedimensional rectangular cavity which was filled with PCM (paraffin wax). Experimental setup is shown in the figure 2.1. The rectangular cavity is made by FC-2300-LD, Fibre Cast Inc. The length of the cavity is $149.86 \mathrm{~mm}$, height is $115.22 \mathrm{~mm}$, and depth is $13 \mathrm{~mm}$. U-shaped copper tube is used which has thickness $0.2 \mathrm{~mm}$, outer diameter $4.76 \mathrm{~mm}$, the vertical length of the tube is $113.22 \mathrm{~mm}$ that was used as the heat source for the storage chamber. Fifteen thermocouples 
were used for measuring the temperature at different positions of the cavity. A clearance of 14.95 $\mathrm{mm}$ was maintained between the two legs of the tube.

Hot water $\left(39^{\circ} \mathrm{C}\right)$ was flowing through the tube at a flow rate of $0.37 \mathrm{l} / \mathrm{min}$ for six hours to melting the PCM which had melting point $32{ }^{\circ} \mathrm{C}$. The inlet temperature of HTF selected as 39 ${ }^{\circ} \mathrm{C}$, because this temperature generally comes from the solar collector during the day time. Solar collector can be able to generate temperature up to $39^{\circ} \mathrm{C}$. The fluid flow inside the was a laminar flow. The walls of storage chamber were attached by bolts, and nuts.

\subsubsection{Boundary Conditions}

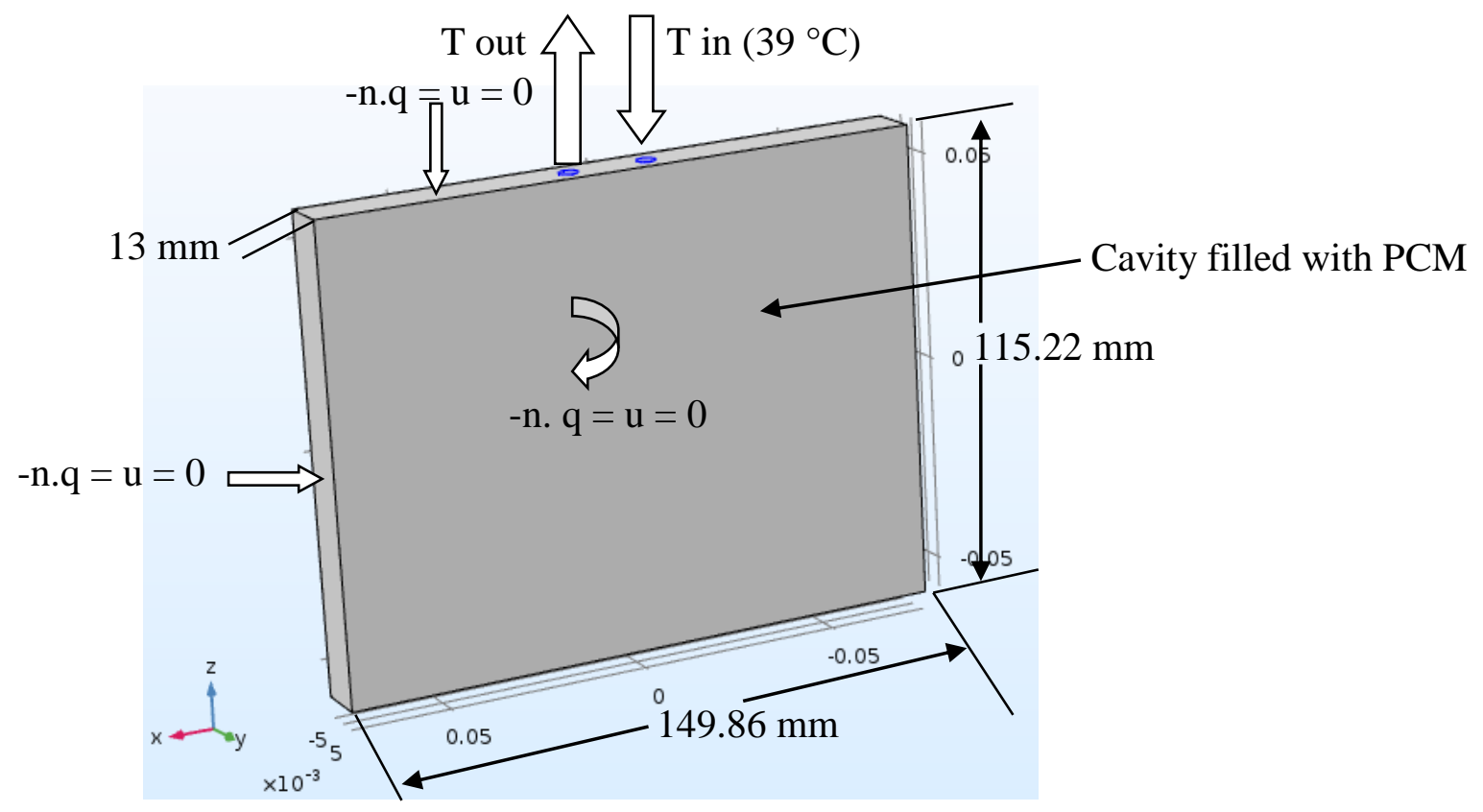

Figure 2.2: Boundary Conditions of the Cavity

Boundary conditions most commonly encountered in practice are the specified temperature, specific heat, conduction and, convection boundary conditions. In this study, it has been developed the normal element formulations for the three-dimensional rectangular cavity. No slip boundary condition was used in the rectangular cavity. Open boundary condition was used in inlet, and outlet of U-shaped copper tube. The heat flow rate was in normal direction, and the velocity was zero $(-n . q=u=0)$ as shows in figure 2.2 . That means that no heat flows from inside of the cavity to outside of the cavity. 


\subsubsection{Experimental Apparatus and Procedures}

Dr. Ayman Mahmoud Bayomy, post-doctoral fellow at Ryerson University, conducted the experiment in our lab. The heater tank heats the water using its operating switch. In this experiment as shown in Figure 2.3, the inlet water temperature was $39{ }^{\circ} \mathrm{C}$, and the hot water passed through the plastic tube by the water pump as shown in figure 2.4 to Figure 2.6. The inlet water flow rate was at $0.37 \mathrm{l} / \mathrm{min}$ which is controlled by a valve as shown in figure 2.6 . The water passed through the tube for 6 hours, and transfer heat to the PCM. The copper tube is used here for its higher thermal conductivity. Though the PCM melting point is $32{ }^{\circ} \mathrm{C}$, significant amount of PCM melts at $32{ }^{\circ} \mathrm{C}$ due the conduction and convection process. There were fifteen thermocouples as shown in figure 2.7 used for measuring temperatures in different points inside the cavity which is filled with PCM as shown in figure 2.8. The surface temperature, inlet and outlet temperature and water flow rate have been monitored by using the data acquisition system as shown in figure 2.9. Data acquisition system is also used to capture the images of the phase change process and tracked the solid-liquid interface and the flow behavior of the melted PCM. This acquisition system relates to Intel core i7 processor computer which shows the data during

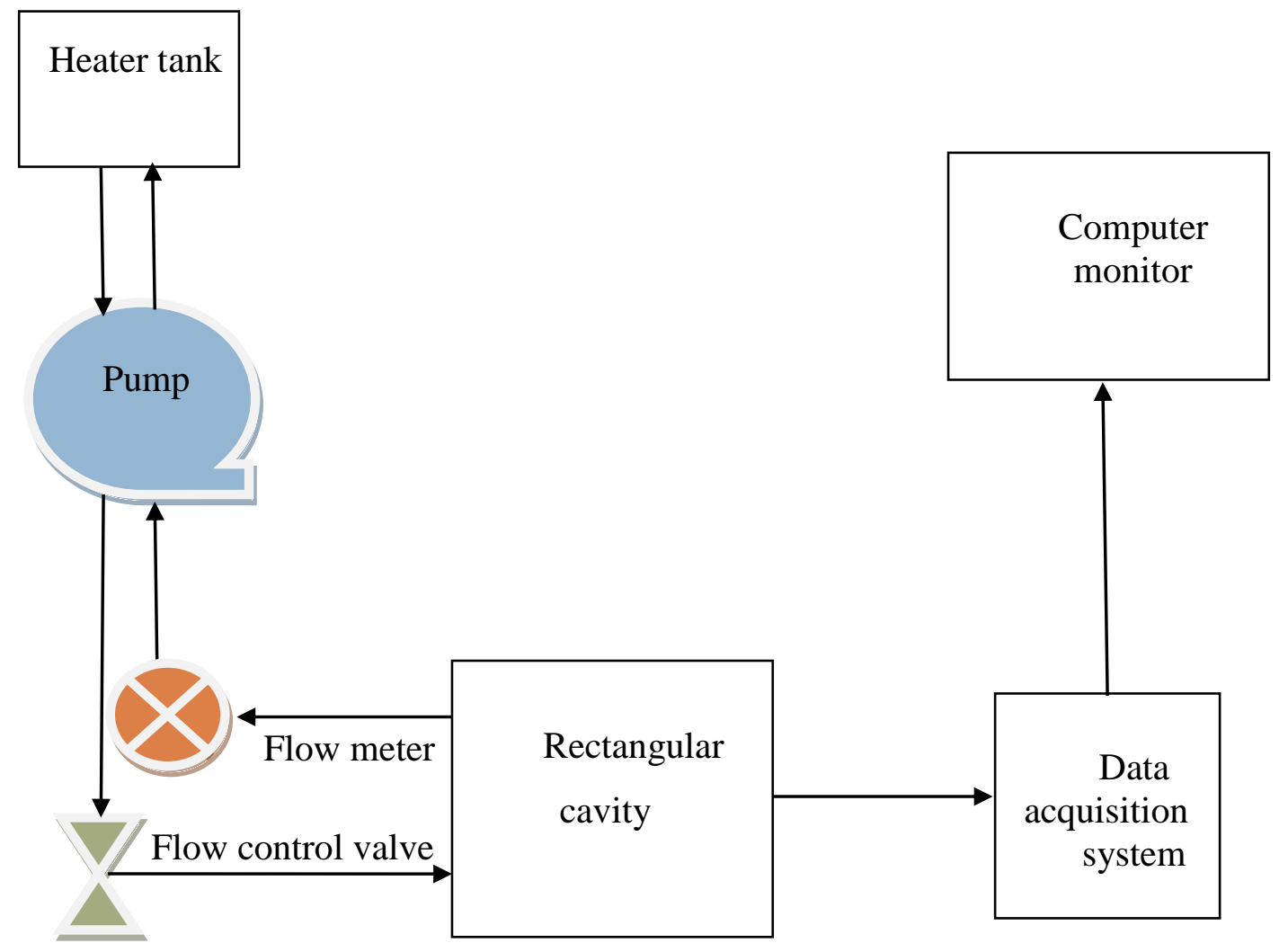

Figure 2.3: Schematic Diagram of Experiment 
the experiment on monitor, and at the same time stores inside its memory as shown in figure 2.10. The stored data and images have been transferred to a flexible format for further requirement.

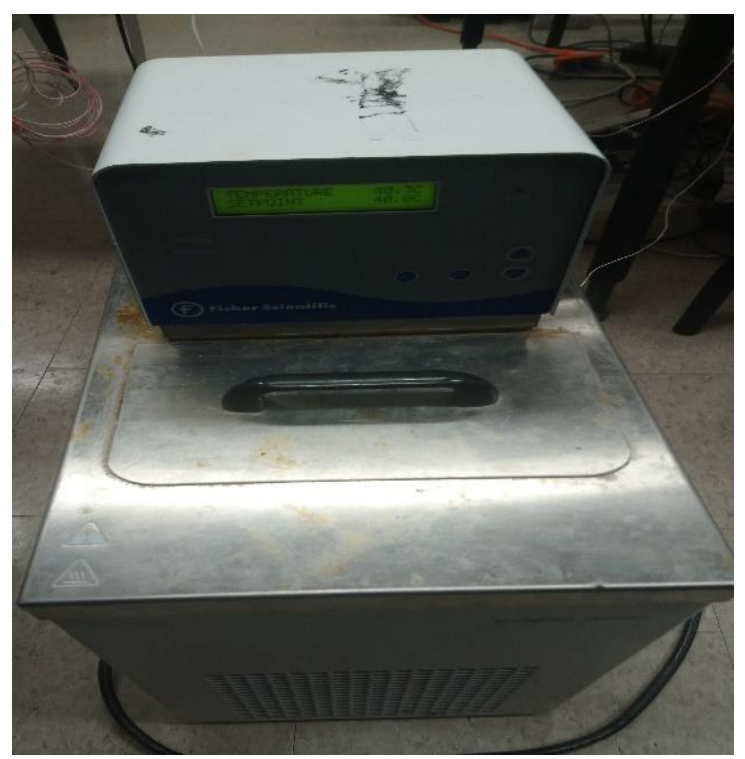

Figure 2.4: Heater tank and pump

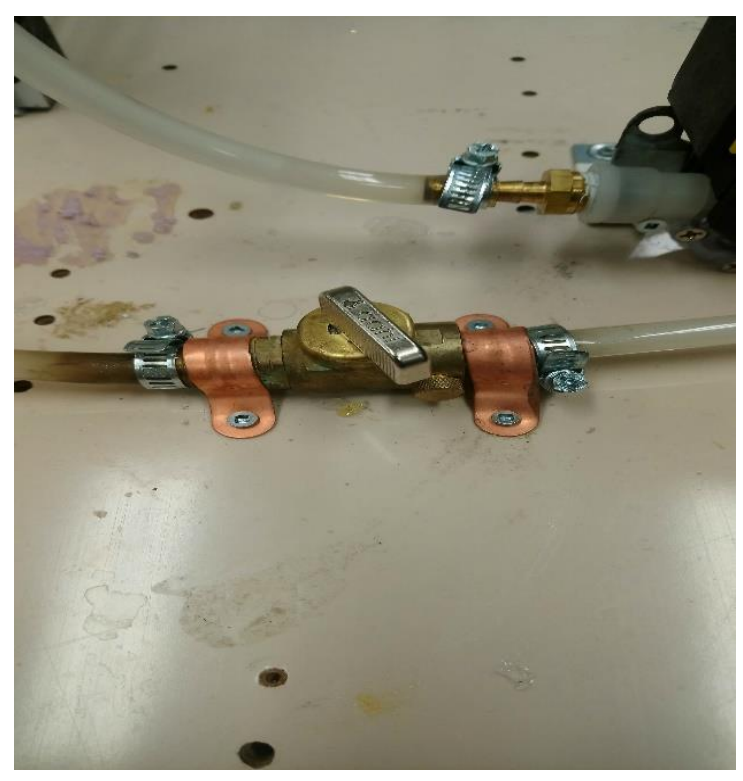

Figure 2.6: Flow control valve

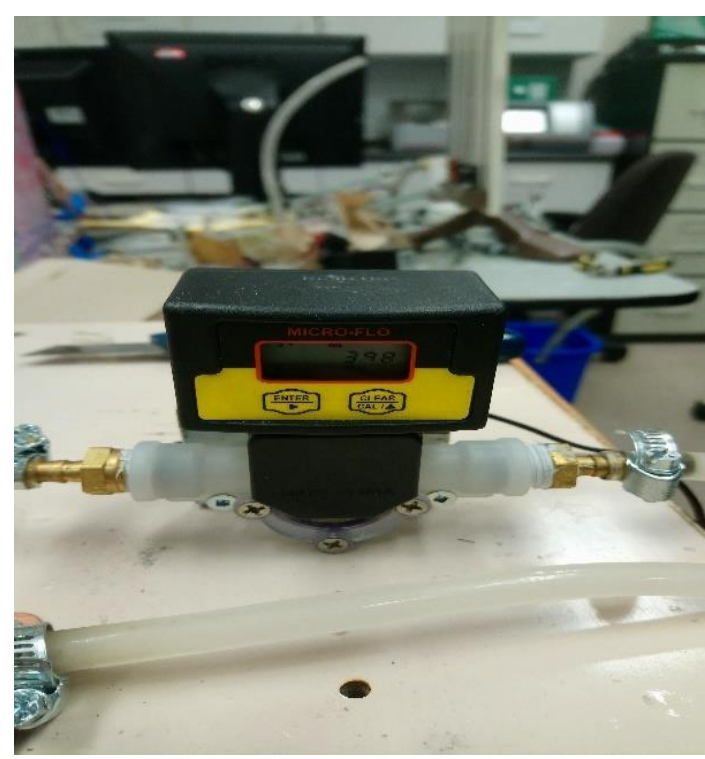

Figure 2.5: Flow meter

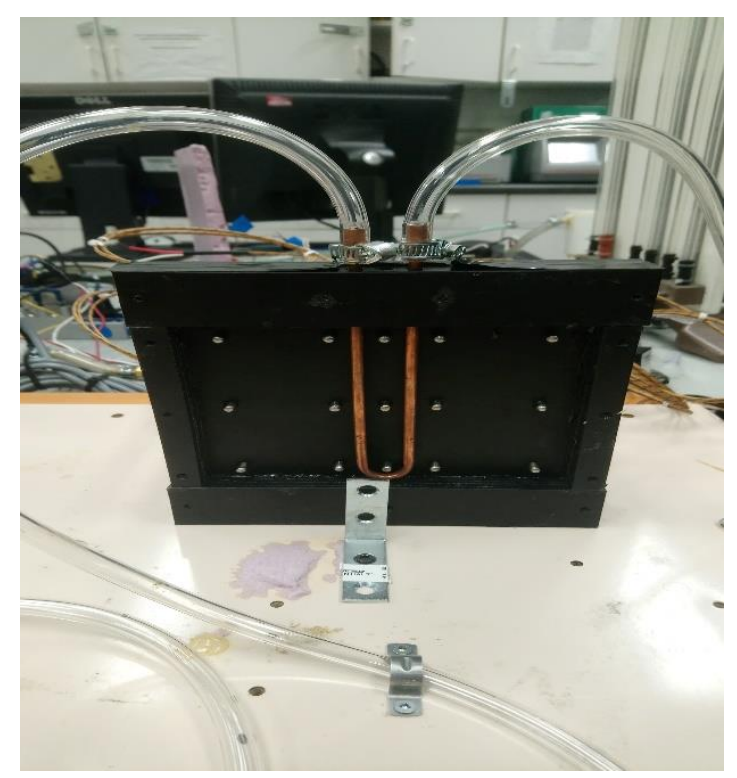

Figure 2.7 Thermocouple`s 

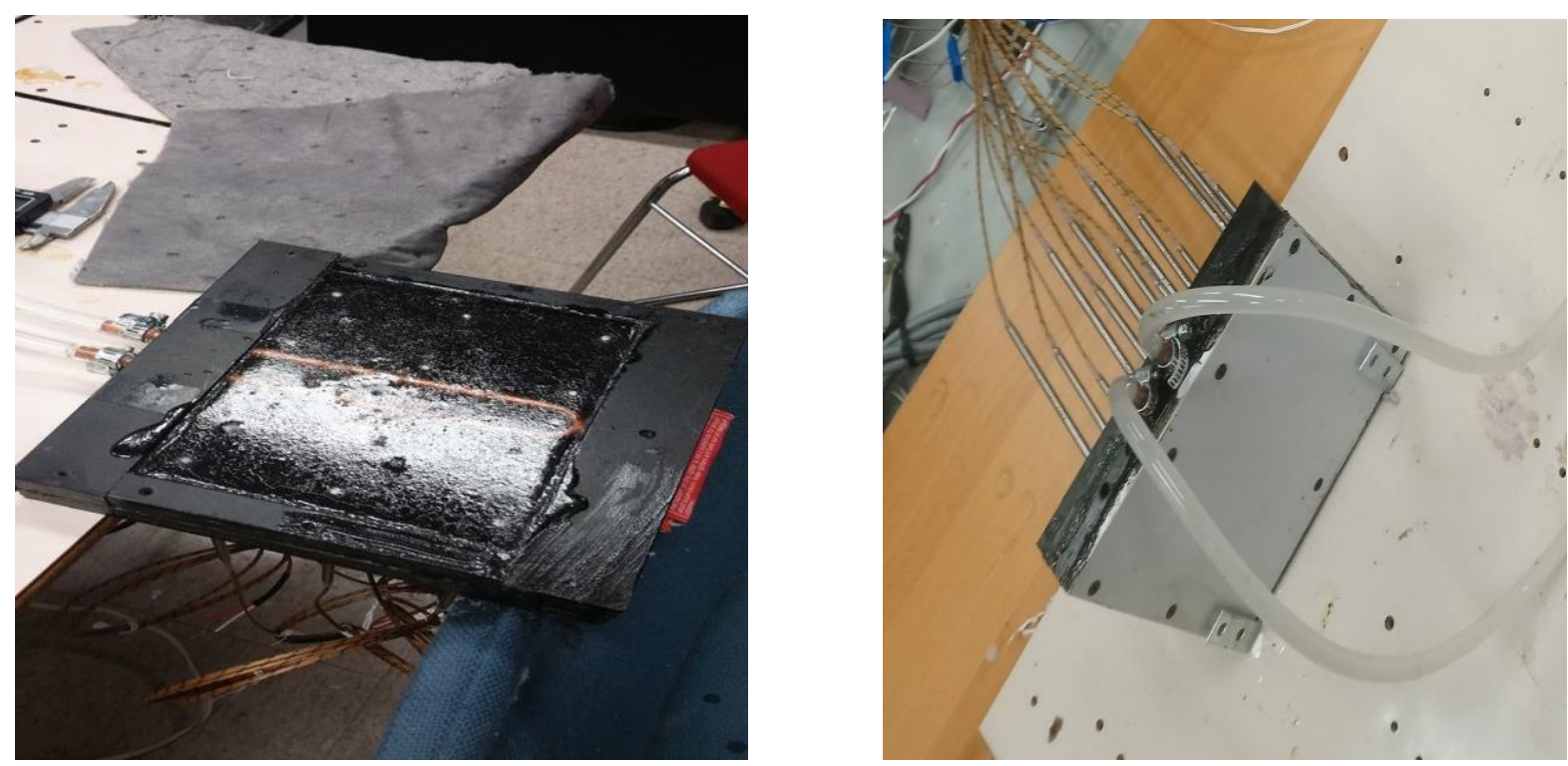

Figure 2.8: Rectangular Cavity with U-shaped tube filled with PCM

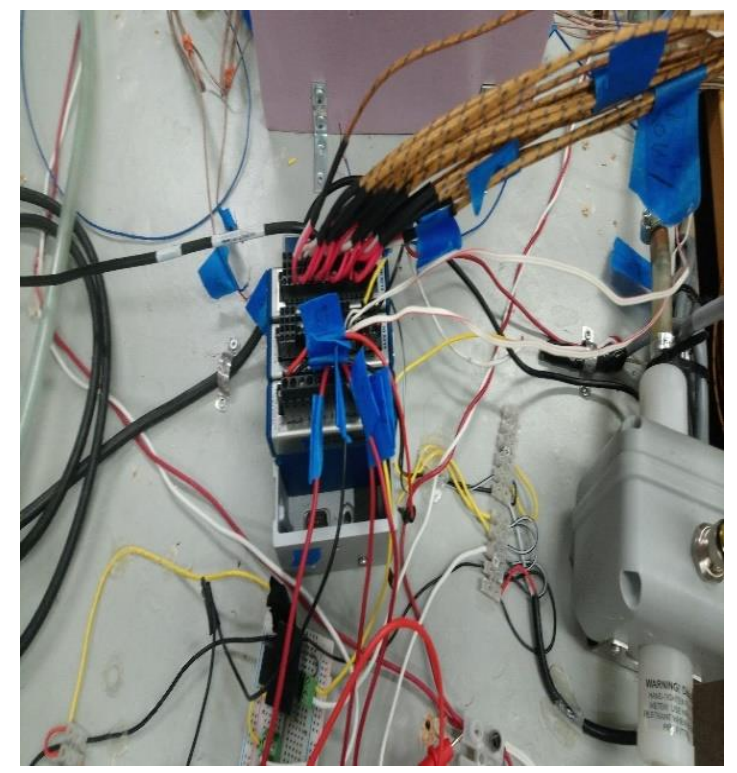

Figure 2.9: Data acquisition system

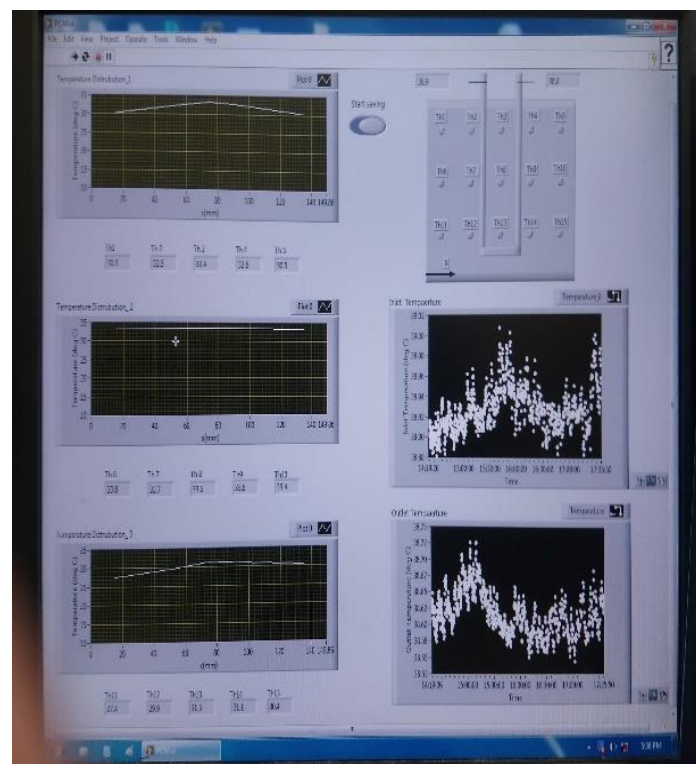

Figure 2.10: Results shows on monitor

\subsubsection{Uncertainty Analysis}

To calculate the uncertainty of parameter such as the uncertainty of temperature of measuring data must be known. The uncertainty of the temperature was $0.25{ }^{\circ} \mathrm{C}$ between each thermocouple inside the rectangular cavity. This uncertainty value was obtained from the calibration process 
for each instrument based on standard and random errors. The maximum uncertainty temperature of each thermocouple was $\pm 0.25^{\circ} \mathrm{C}$.

\subsection{Numerical Model Descriptions}

For experimental results validation, numerical model has been developed and computed having the same as shape, size and parameters of experimental works. A tetrahedral normal element is used to perform the numerical model with the number of domain elements is 102220 , boundary elements is 9460 and number of edge is 1024. The walls of the rectangular cavity were thermally insulated. After numerical simulation completed, all the data have been validated with experimental data.

\subsubsection{Governing Equations and Boundary Conditions}

The governing equations have been solved by using COMSOL that used finite element technique for simulating the model and describes the fluid flow, and heat transfer inside the rectangular cavity by using the following formulas:

The energy equation:

$$
\begin{aligned}
& \rho c_{p} \frac{\partial T}{\partial t}+\rho c_{p} u \cdot \nabla T+\nabla \cdot q=Q \\
& q=-k \nabla T
\end{aligned}
$$

Where $\rho$ represents the fluid density, $c_{p}$ represents the fluid heat capacity, $\frac{\partial T}{\partial t}$ represents the temperature gradient with time, $\mathrm{u}$ represents the fluid velocity, $\nabla T$ represents the temperature different, q represents the flow rate of fluid, Q represents the heat source of the fluid, and $\mathrm{k}$ represent the thermal conductivity of the copper tube filled with water. By using the energy equation Bashar and Siddiqui [18] conducted a study to investigate the melting process and behavior of Phase Change Material (PCM) due to heat transfer convection by a U-shaped tube which emerged in PCM.

For Thin Layer:

$$
\begin{aligned}
& -\mathrm{n}_{\mathrm{d}} \cdot \mathrm{q}_{\mathrm{d}}=\frac{\left(\mathrm{T}_{\mathrm{u}}-\mathrm{T}_{\mathrm{d}}\right)}{\mathrm{R}_{\mathrm{s}}}+\frac{1}{2} \mathrm{~d}_{\mathrm{s}} \mathrm{Q}_{\mathrm{s}} \\
& -\mathrm{n}_{\mathrm{d}} \cdot \mathrm{q}_{\mathrm{u}}=\frac{\left(\mathrm{T}_{\mathrm{d}}-\mathrm{T}_{\mathrm{u}}\right)}{\mathrm{R}_{\mathrm{s}}}+\frac{1}{2} \mathrm{~d}_{\mathrm{s}} \mathrm{Q}_{\mathrm{s}}
\end{aligned}
$$




$$
\mathrm{R}_{\mathrm{s}}=\frac{\mathrm{d}_{\mathrm{s}}}{\mathrm{k}_{\mathrm{s}}}
$$

Where $\mathrm{n}_{\mathrm{d}}$ represents the normal direction, $\mathrm{q}_{\mathrm{d}}$ represents the heat flow rate in the layer, $\left(\mathrm{T}_{\mathrm{u}}-\right.$ $\left.T_{d}\right)$ and $\left(T_{d}-T_{u}\right)$ represents the temperature difference inside, and outside of the thin layer, $R_{S}$ represents the thermal resistance of the layer, $d_{s}$ represents the thickness of the layer, $Q_{s}$ represents the heat transfer rate of layer, and $\mathrm{k}_{\mathrm{s}}$ represents the layer thermal conductivity.

For PCM:

$$
\begin{aligned}
& \rho c_{\mathrm{p}} \frac{\partial \mathrm{T}}{\partial \mathrm{t}}+\rho \mathrm{c}_{\mathrm{p}} \mathrm{u} . \nabla \mathrm{T}+\nabla \cdot \mathrm{q}=\mathrm{Q} \\
& \mathrm{q}=-\mathrm{k} \nabla \mathrm{T} \\
& \rho=\theta \rho_{\text {phase } 1}+(1-\theta) \rho_{\text {phase } 2} \\
& \mathrm{c}_{\mathrm{p}}=\frac{1}{\rho}\left(\theta \rho_{\text {phase } 1} \mathrm{c}_{\mathrm{p} \text { phase } 1}+(1-\theta) \rho_{\text {phase } 2} \mathrm{c}_{\mathrm{p} \text { phase } 2}\right)+\mathrm{L} \frac{\partial \mathrm{T}}{\partial \mathrm{t}} \\
& \mathrm{k}=\theta \mathrm{k}_{\text {phase } 1}+(1-\theta) \mathrm{k}_{\text {phase } 2} \\
& \alpha_{\mathrm{m}}=\frac{1}{2} \frac{(1-\theta) \rho_{\text {phase } 2}+\theta \rho_{\text {phase } 1}}{\theta \rho_{\text {phase } 1}+(1-\theta) \rho_{\text {phase } 2}}
\end{aligned}
$$

Where, $\theta$ represents the solid-liquid phase change indicator, $\rho_{\text {phase } 1}$ represents the density of solid PCM, $\rho_{\text {phase } 2}$ represents the density of liquid PCM, L represents the U-shaped tube length, $\mathrm{k}$ represents the thermal conductivity of the PCM, $\mathrm{k}_{\text {phase } 1}$ represents the thermal conductivity of the solid PCM, $\mathrm{k}_{\text {phase } 2}$ represents the thermal conductivity of the liquid PCM, and $\alpha_{\mathrm{m}}$ represents the flow field of PCM.

For Temperature:

$$
\mathrm{T}=\mathrm{T}_{\mathrm{o}}
$$

Where, $\mathrm{T}$ represents the temperature inside the tube, and $\mathrm{T}_{\mathrm{o}}$ represents the temperature outside of the tube. Both inside and outside temperature of the tube were same during the simulation period.

For Outflow:

$-\mathrm{n} \cdot \mathrm{q}=0$

There is no outflow during the simulation period.

For Fluid Properties:

Navier-Stokes formulated a general equation to describe fluid properties through the rectangular cavity which is used for numerical model simulation in COMSOL 3D. When normal 
element modeling assumptions are taken into consideration, Navier-Stokes equation which describes the fluid properties and heat transfer inside the cavity are solved using the following formula:

$$
\rho \frac{\partial u}{\partial t}+\rho(u . \nabla) u=\nabla \cdot\left[-P I+\mu(\nabla u+\nabla u)^{T}\right]+F
$$

The continuity equation:

$\rho \nabla .(\mathrm{u})=0$

Where, $\rho$ represents the density of the fluid, $\frac{\partial u}{\partial t}$ represents velocity gradient with time of fluid, $\mathrm{u}$ represents the velocity of the fluid, $\mathrm{P}$ represents the pressure acting of the fluid, I represent the identical vector of fluid, $\mu$ represents the dynamic viscosity of the fluid, $\mathrm{T}$ represents the temperature of the fluid, and F represents the body force of the fluid.

For Wall:

$\mathrm{u}=0$

The walls are thermally insulated, and the heat transfer process is adiabatic. So, there is no heat loss by the cavity walls during the simulations period.

For Inlet:

$\mathrm{u}=-\mathrm{U}_{\mathrm{o}} n$

Inlet velocity is acted in normal direction to inside the cavity with the initial fluid velocity.

For Outlet:

$\left[-\mathrm{PI}+\mu(\nabla \mathrm{u}+\nabla \mathrm{u})^{\mathrm{T}}\right] \mathrm{n}=-\mathrm{P}_{\mathrm{o}} \mathrm{n}$

Where, $\mathrm{P}$ represents the pressure acting of the fluid, I represents the identical vector of fluid, $\mu$ represents the dynamic viscosity of the fluid, $\nabla u$ represents the velocity difference of the fluid, $\mathrm{T}$ represents the temperature of the fluid, $\mathrm{n}$ represents the normal direction vector of the fluid flow, and $\mathrm{P}_{\mathrm{o}}$ represents the initial pressure of the fluid inside the cavity.

\subsection{Mesh Sensitivity Analysis and Convergence Criteria}

In the present study, a tetrahedral element is used to perform the numerical model. To observe the grid dependency, the calculation of maximum and minimum temperature on the surface for heat transfer fluid flow through the $\mathrm{U}$-shaped copper tube was performed for different numbers of domain, boundary and edge elements, as shown in Figure 2.11. 
This is a transient study, that took seven days to complete the simulation. The convergence criteria are depending on temperature, velocity, pressure, and number of iterations. The solution reached convergence which was below 1e-6 for each independent parameter, and the variation between the elements was less than 0.001 . The finer element mesh was used in the middle of the cavity to refinement because U-Shaped tube is placed there.

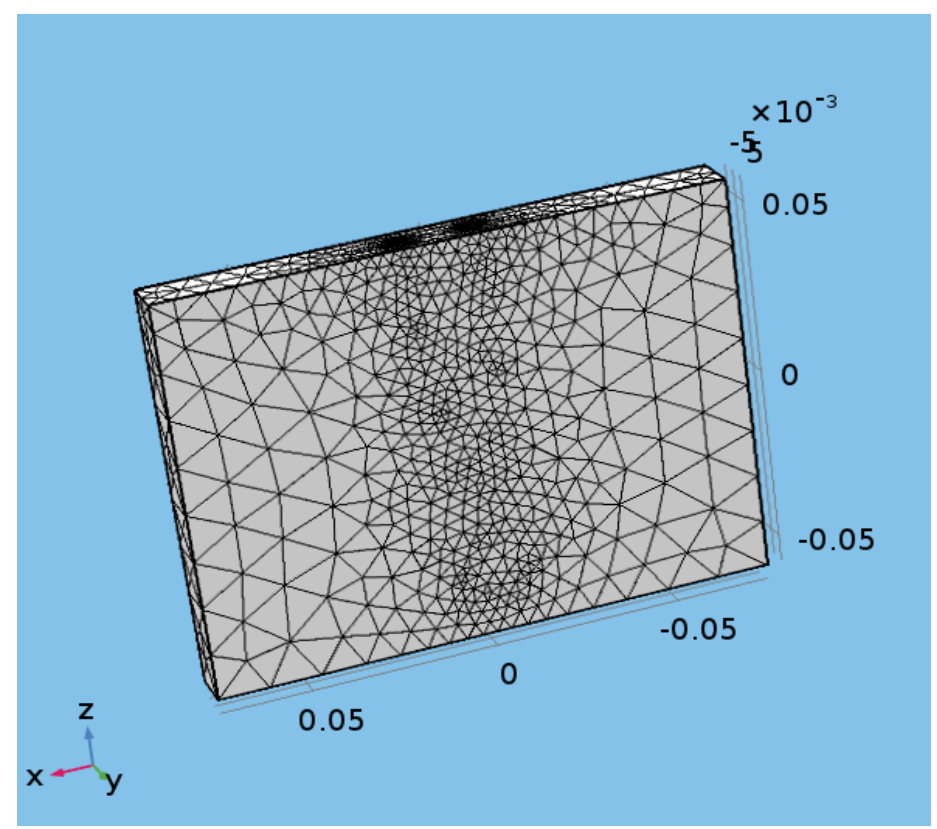

Figure 2.11: Normal element mesh

Table 2.1: Average temperature using various mesh types

\begin{tabular}{|c|c|c|c|c|c|}
\hline Mesh type & $\begin{array}{c}\text { Average } \\
\text { temperature } \\
\text { at t = } \mathbf{3} \text { hours } \\
\left({ }^{\circ} \mathrm{C}\right)\end{array}$ & $\begin{array}{c}\text { Percentage of } \\
\text { error (\%) }\end{array}$ & $\begin{array}{c}\text { Number of } \\
\text { domain } \\
\text { elements }\end{array}$ & $\begin{array}{c}\text { Number of } \\
\text { boundary } \\
\text { elements }\end{array}$ & $\begin{array}{c}\text { Number of } \\
\text { edge } \\
\text { elements }\end{array}$ \\
\hline Extremely Coarse & 28.061 & - & 14984 & 2376 & 538 \\
\hline Extra Coarse & 28.522 & 1.64 & 23383 & 3710 & 602 \\
\hline Coarser & 28.442 & 0.28 & 36164 & 4818 & 714 \\
\hline Coarse & 29.141 & 0.50 & 53231 & 5828 & 826 \\
\hline Normal & 28.655 & 0.24 & 102220 & 9460 & 1024 \\
\hline Fine & 28.989 & 1.16 & 174213 & 13840 & 1242 \\
\hline
\end{tabular}


Table 2.1 shows the average temperature, percentage of error between each mesh, number of elements, boundary elements and edge elements of different mesh at the time of three hours in the middle of the cavity along horizontal axis. From the table, a smaller number of error shows between coarse and normal element mesh which is 0.24 . It means that the most accurate results may come from the normal element mesh. So, in this study the normal element mesh is used for simulation of the model.

\subsection{Temperature Contours of the Cavity}

One way to test the numerical simulation first of all is to display the thermal behavior inside the cavity at different heating time. It was clear from the figures 2.12(a), 2.12(b) and 2.12(c) that by increasing the time, surface temperature inside the cavity was increased significantly. This is happened because, heating source U-shaped copper tube transfer heat to the PCM continuously during the simulation time and PCM absorbed the heat. Most of the PCM was soft after two hours of heating but was completed melted after six hours.

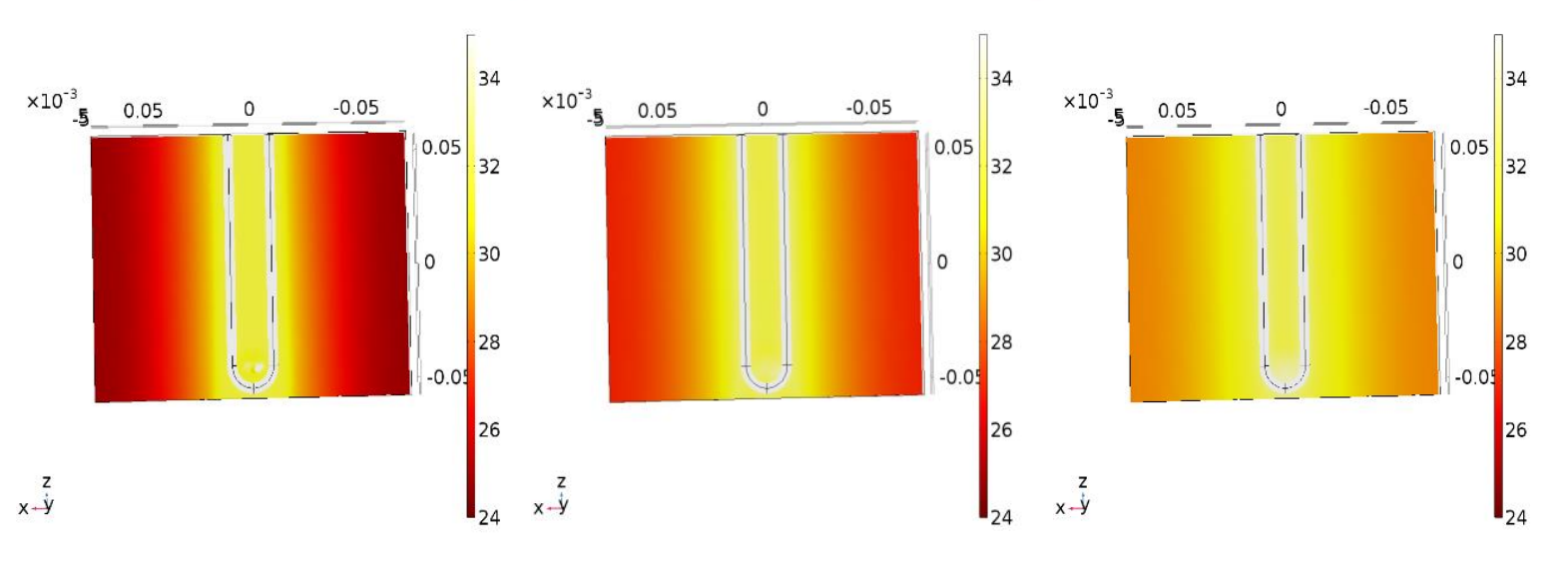

(a) $\mathbf{t}=\mathbf{2}$ hours

(b) $\mathbf{t}=\mathbf{4}$ hours

(c) $\mathbf{t}=6$ hours

Figure 2.12: Temperature contours at different times

\subsection{Thermal Energy Storage Media (Paraffin Wax)}

Paraffin wax is colorless or white, somewhat translucent is derived from petroleum, coal/oil shale, that consists of a mixture of hydrocarbon molecules. It melts at above approximately 32 ${ }^{\circ} \mathrm{C}$, and its boiling point is approximately $370{ }^{\circ} \mathrm{C}$. Different thermo-physical properties of 
Paraffin wax has shown in table 2.2. Paraffin wax absorbs thermal energy during the process of melting which can be generated during the solidifying process called solid-liquid interface.

Table 2.2: Thermo-physical properties of PCM at room temperature [18]

\begin{tabular}{|c|c|c|c|c|c|c|}
\hline $\begin{array}{c}\text { Melting } \\
\text { temperature } \\
\left({ }^{\circ} \mathrm{C}\right)\end{array}$ & $\begin{array}{c}\text { Density } \\
\left(\mathrm{kg} / \mathrm{m}^{3}\right)\end{array}$ & $\begin{array}{c}\text { Specific heat } \\
(\mathrm{KJ} / \mathrm{kg} / \mathrm{K})\end{array}$ & \multicolumn{2}{|c|}{$\begin{array}{c}\text { Thermal } \\
\text { conductivity }(\mathrm{W} / \mathrm{m} / \mathrm{K})\end{array}$} & $\begin{array}{c}\text { Latent } \\
\text { heat of fusion } \\
(\mathrm{KJ} / \mathrm{Kg})\end{array}$ & $\begin{array}{c}\text { Ratio } \\
\text { of specific } \\
\text { heats }\end{array}$ \\
\hline 32 & 830 & 2.890 & $\begin{array}{c}\text { Solid } \\
0.24\end{array}$ & $\begin{array}{c}\text { Liquid } \\
0.18\end{array}$ & 190 & 1.1 \\
\hline
\end{tabular}

\subsection{Thermal Energy Storage Media (Bentonite)}

Bentonite is the form of volcanic ash, in the presence of water which is bentonite clay. In this study, Bentonite has been used for its higher thermal conductivity, density and low-permeability barrier. Generally, Bentonite is used in industrial sector for many purposes. One of the important uses of Bentonite is to create clay liners around the pipe during the time of digging for extracting petroleum from the underground. Bentonite uses as a mud constituent for oil and water well drilling. Its roles are mainly to seal the borehole walls, to remove drill cuttings and to lubricate the cutting head. Various thermo-physical properties of bentonite are shown in table 2.3.

Table 2.3: Thermo-physical properties of Bentonite at room temperature [20]

\begin{tabular}{|c|c|c|}
\hline $\begin{array}{c}\text { Thermal conductivity } \\
(\mathrm{W} / \mathrm{m} . \mathrm{k})\end{array}$ & Density $\left(\mathrm{kg} / \mathrm{m}^{3}\right)$ & Heat Capacity $(\mathrm{J} / \mathrm{kg} . \mathrm{K})$ \\
\hline 1.15 & 1600 & 800 \\
\hline
\end{tabular}

\subsection{Numerical Model with PCM and Bentonite}

In this study, there were four different models (namely, model A, model B, model C and model D) having same size and shape of the experimental model but used PCM, and Bentonite in four different ways in the rectangular cavity. The water temperature is used $39{ }^{\circ} \mathrm{C}$ to flow with a flow rate at $0.37 \mathrm{l} / \mathrm{min}$ through the $\mathrm{U}$-shaped tube of first three hours, and $15{ }^{\circ} \mathrm{C}$ temperature used for next three hours with the same flow rate to energy generation during the melting and solidifying the PCM, and Bentonite for all four models. 


\subsubsection{Model A: Entire cavity filled with PCM during heating and cooling cycle}

Figure 2.13(a) shows the temperature contours at the time of three hours, and figure 2.13(b) shows the temperature contours at the time of six hours of numerical simulation of the rectangular cavity which has been filled by PCM. After three hours of heating, temperature of PCM around the U-shaped tube was reached more than $32^{\circ} \mathrm{C}$, and it was melted, but near the two walls temperature was not high, and PCM was solid. However, after six hours of cooling, temperature of the cavity was less than $28^{\circ} \mathrm{C}$ in everywhere. But, near the U-shaped tube temperature was around $22^{\circ} \mathrm{C}$.

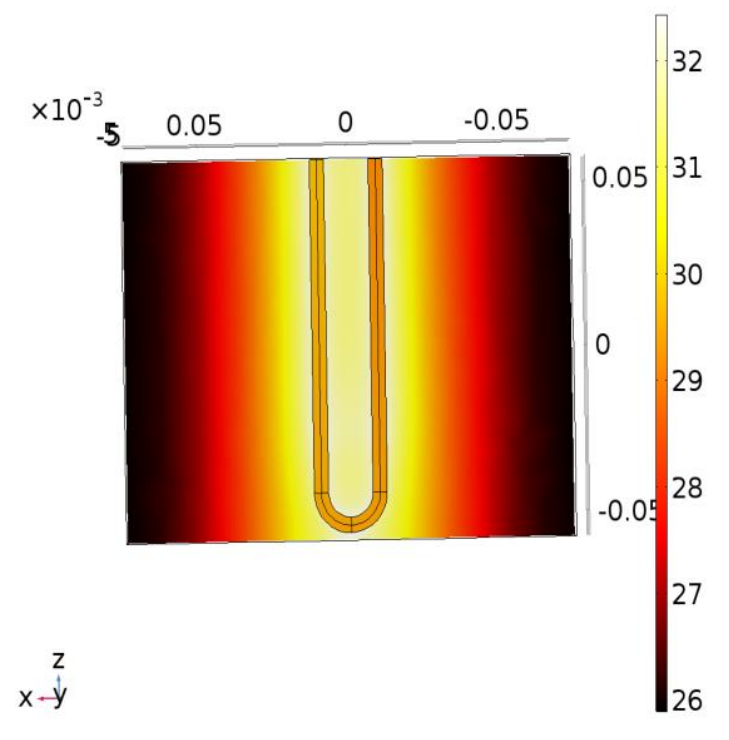

(a) $\mathrm{t}=\mathbf{3}$ hours

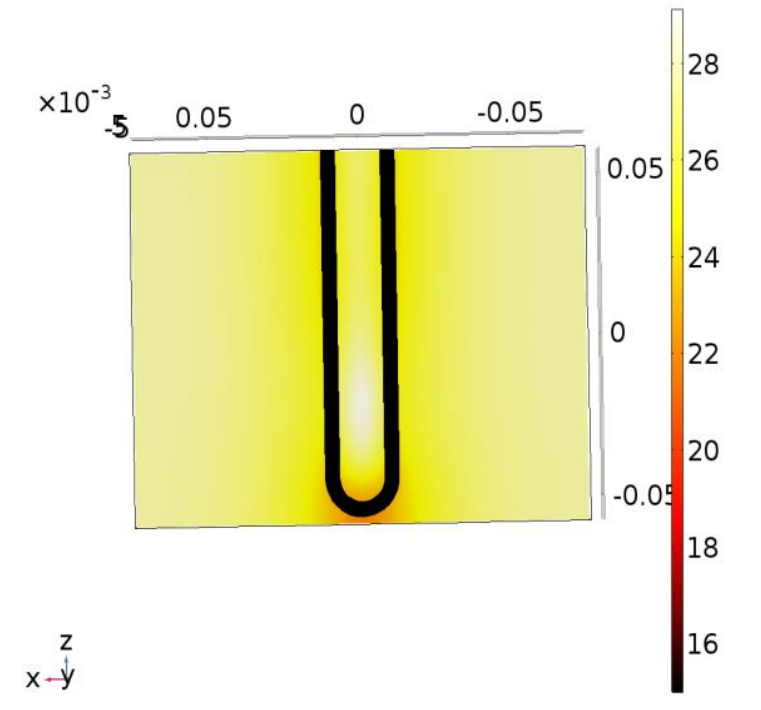

(b) $\mathbf{t}=6$ hours

Figure 2.13: Temperature contours of model A

\subsubsection{Model B: Entire cavity filled with bentonite with heating and cooling cycle}

Temperature contours at the time of three hours and six hours of numerical simulation of the rectangular cavity which has been filled out by bentonite is shown in figure 2.14(a) and figure 2.14(b) respectively. After three hours of heating, temperature of bentonite is reached above 32 ${ }^{\circ} \mathrm{C}$ in everywhere of the cavity. It was possible because, bentonite have the higher thermal conductivity and heat capacity. So, it can absorb and extract heat faster for its higher temperature gradient. For this property, after six hours, that means after cooling, temperature of the cavity was cooled rapidly to below $21^{\circ} \mathrm{C}$ in everywhere. 


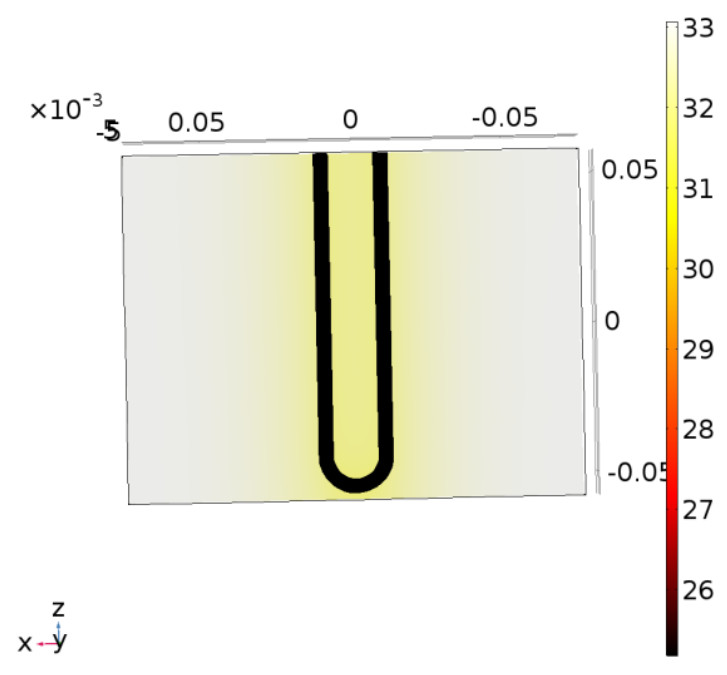

(a) $\mathbf{t}=\mathbf{3}$ hours

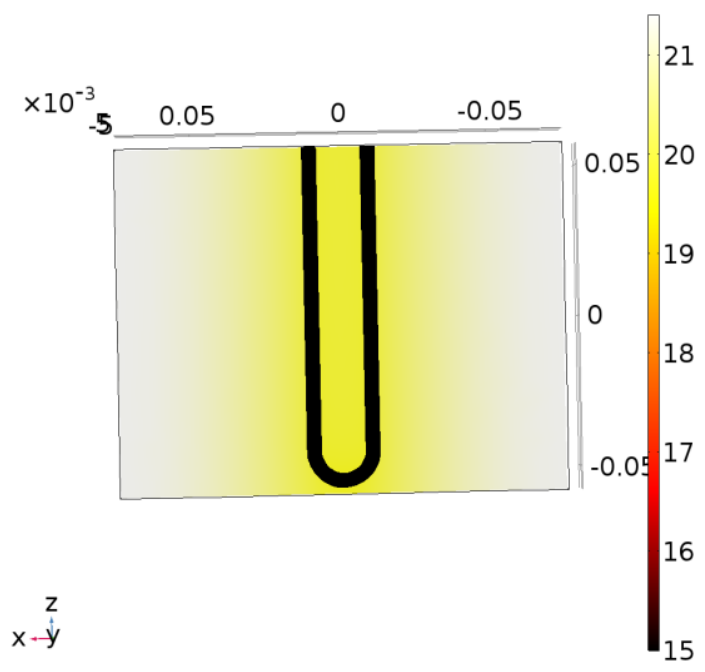

(b) $\mathrm{t}=6$ hours

Figure 2.14: Temperature contours of model $B$

2.8.3 Model C: Inner part of the cavity is filled with PCM and outer part is filled with bentonite with heating and cooling cycle

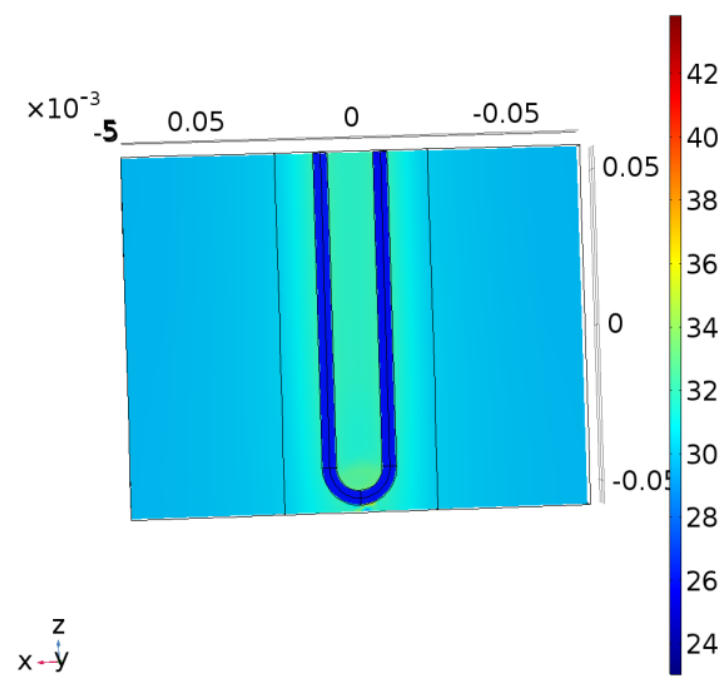

(a) $\mathrm{t}=\mathbf{3}$ hours

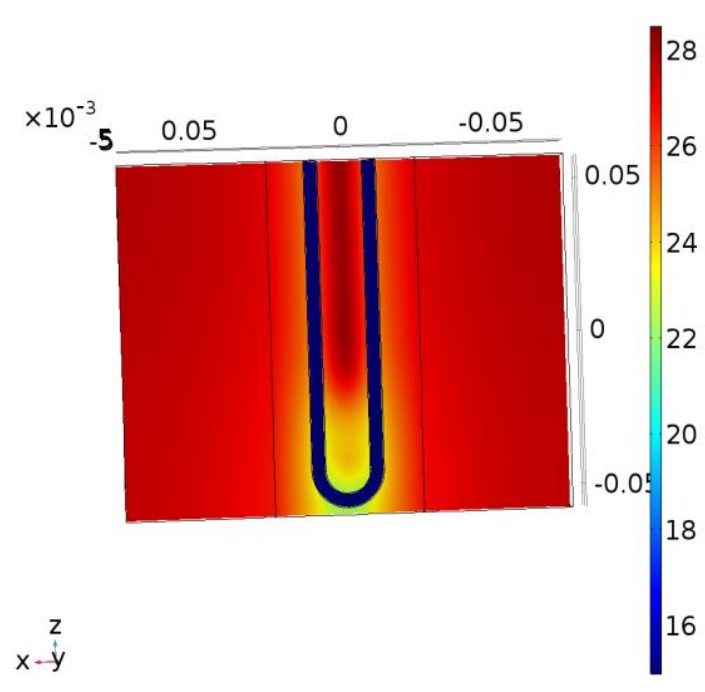

(b) $\mathbf{t}=6$ hours

Figure 2.15: Temperature contours of model $\mathrm{C}$

Temperature contours at the time of three hours and six hours is shown in figure 2.15(a) and figure 2.15(b) of numerical simulation of the rectangular cavity in which inner part of the cavity 
filled by PCM, and outer part filled by bentonite. After three hours of heating, temperature of the simulation reached approximately $32{ }^{\circ} \mathrm{C}$ around the heating tube, but near the walls it was less than $32{ }^{\circ} \mathrm{C}$. However, temperature was below $28{ }^{\circ} \mathrm{C}$ almost everywhere after six hours except near the U-shaped tube. Basically, at the bottom portion of the cavity it was approximately 22 ${ }^{\circ} \mathrm{C}$.

2.8.4 Model D: Inner part of the cavity is filled with bentonite and outer part is filled with PCM with heating and cooling cycle

Figure 2.16(a) shows the temperature contours at the time of three hours, and figure 2.16(b) shows the temperature contours at the time of six hours of numerical simulation of the rectangular cavity in which inner part of the cavity is filled with bentonite, and outer part is filled with PCM. After three hours of heating, temperature around the U-shaped tube where bentonite has been used reached more than $36{ }^{\circ} \mathrm{C}$, and it was fully melted, but near the two walls temperature was not higher, and it was solid. However, after six hours that means after cooling, temperature was around $30{ }^{\circ} \mathrm{C}$ near the two walls, but around the tube it was approximately 25 ${ }^{\circ} \mathrm{C}$.

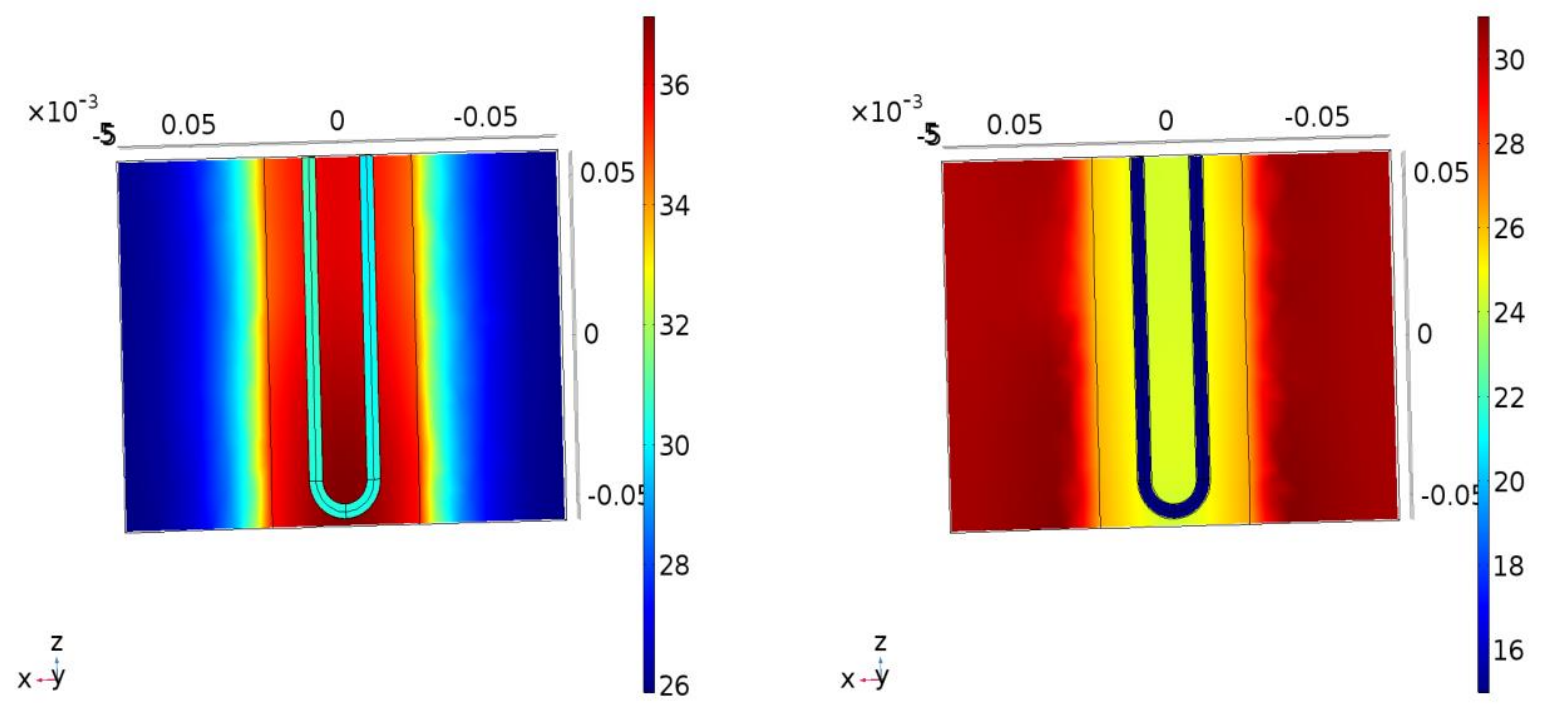

(a) $\mathbf{t}=\mathbf{3}$ hours

(b) $\mathbf{t}=6$ hours

Figure 2.16: Temperature contours of model $D$ 


\subsection{Summary}

From this chapter, the following summaries are drawn:

(a) The governing equations have been solved by using COMSOL Multiphysics that used finite element technique for simulating the model and describes the fluid flow, and heat transfer inside the rectangular cavity.

(b) A rectangular normal element is used same as the size and shape of experimental work to perform the numerical model.

(c) No slip boundary condition was used in the rectangular cavity.

(d) Open boundary condition was used in inlet, and outlet of U-shaped copper tube.

(e) Preliminary results of heating and cooling indicate that the code is working as expected. 


\section{CHAPTER 3 - RESULTS AND DISCUSSION}

\subsection{Introduction}

In recent years industrial and residential sectors consume much thermal energy, particularly in space or room heating, and water heating. This is a huge demand of thermal energy basically, the country like Canada for cold weather during the winter season. This demand can be reduced dramatically by using the PCM as thermal storage media. PCM can absorbed abundant number of heats during the period of changing its phase between solid to liquid. Bentonite is an important useful media for petroleum industry by making a clay liner. In this chapter, it shows the thermal behavior of PCM, and bentonite during the period of heating.

\subsection{Experimental Work and Numerical Model Validation}

In this experimental study, the U-shaped copper tube is placed in the rectangular cavity which was filled with PCM. The hot water was passed through the tube and transferred heat to the PCM. In addition, a numerical model was developed using the normal element technique, and the numerical results were compared with the experimental results. For discussing the results, some cut lines were considered in both horizontal axis and vertical axis in the cavity and took the data for comparing at three different time steps which were two hours, four hours, and six hours respectively. This time difference showed the significant fluctuations of the results in each position of the cavity.

\subsubsection{Surface temperature distribution of the cavity along $x$-axis}

For the fruitful discussion, three cut line at middle $(\mathrm{y}=0 \mathrm{~m})$, top $(\mathrm{y}=0.04741 \mathrm{~m})$ and bottom $(y=-0.04741 \mathrm{~m})$ of the cavity have been made along $\mathrm{x}$-axis. At different timewise data collected and analyzed with experimental model and numerical model.

\subsubsection{Surface temperature distributions at $y=0 \mathrm{~m}$ of the cavity along $\mathrm{x}$-axis}

Figure 3.1(a), 3.1(b) and 3.1(c) illustrates the surface temperature distributions along the direction of $\mathrm{x}$-axis in the middle of the rectangular cavity at different time.

The line graph revealed a good agreement between experimental and numerical temperature distributions after two hours. It is important to indicate that the error bar for the measured temperature is basically the error of the thermocouple. However, the thermocouples were calibra- 


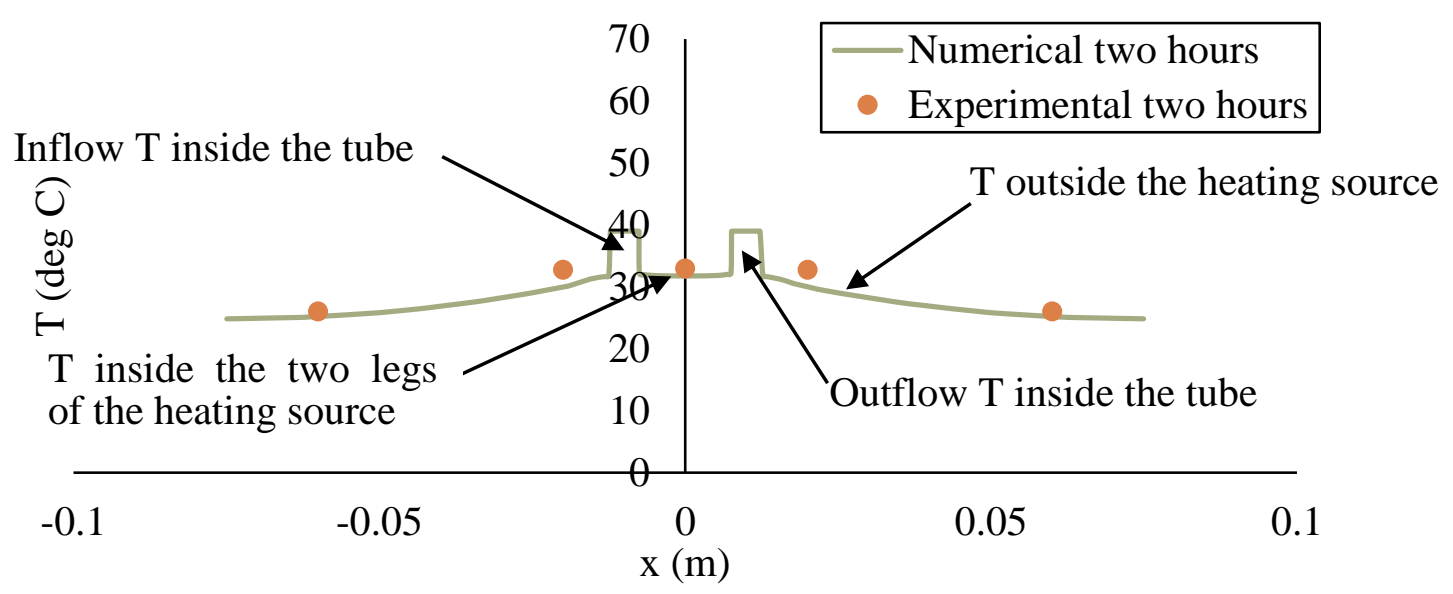

(a) $\mathrm{t}=\mathbf{2}$ hours

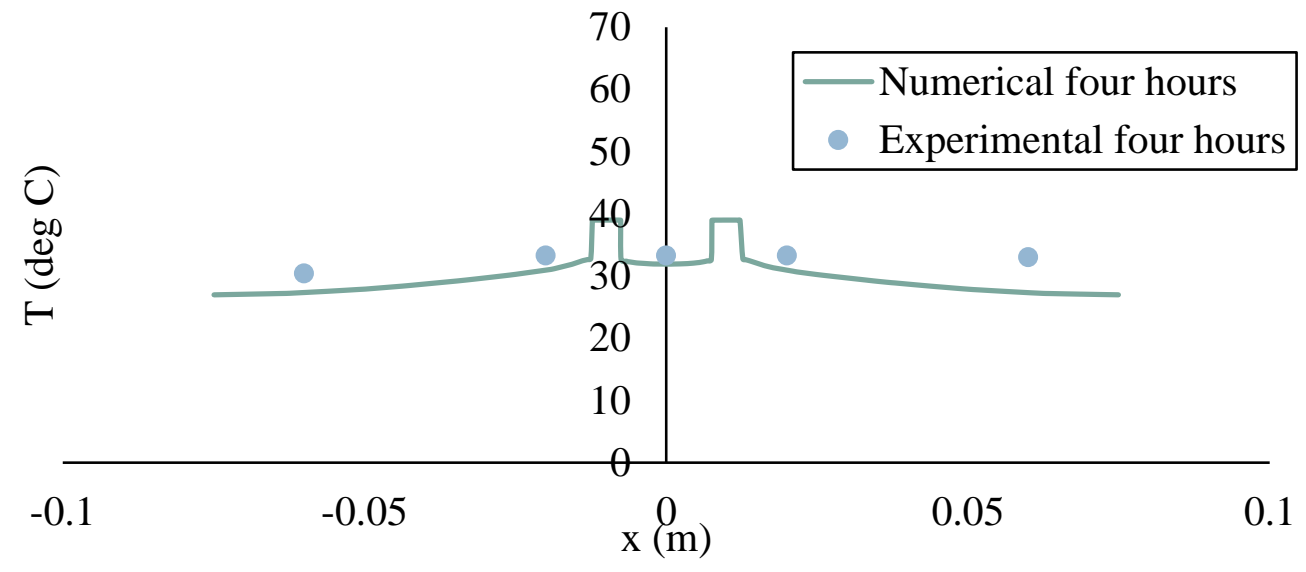

(b) $\mathbf{t}=\mathbf{4}$ hours

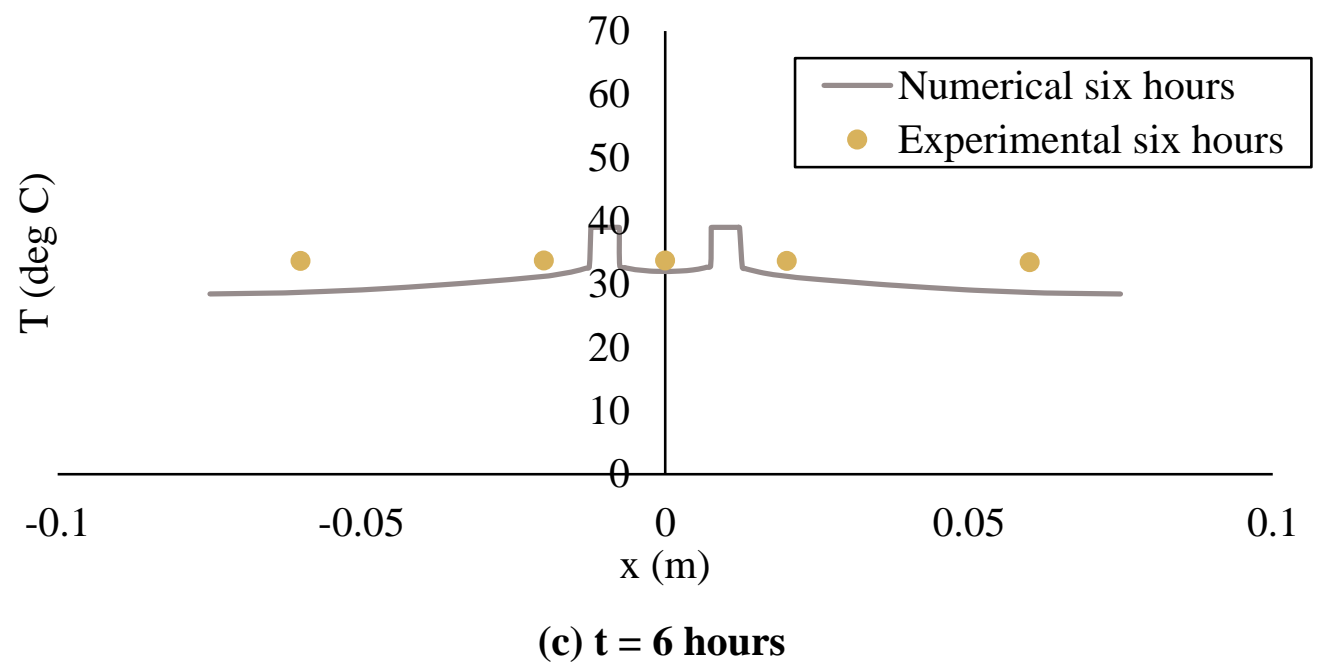

Figure 3.1: Temperature distributions at $y=0 \mathrm{~m}$ of the cavity along $x$-axis 
ted very accurately, so no error bars are shown in the plot. Figure 3.1(a) shows that the temperature near the U-tube was larger than around $33{ }^{\circ} \mathrm{C}$, and lower than $26{ }^{\circ} \mathrm{C}$ near the side walls for both simulations. So, after two hours, PCM was started to melt around the tube and absorbs heat from the water. There was a good agreement for both experimental and numerical results.

In figure 3.1(b), the temperature near the U-tube is still around $33{ }^{\circ} \mathrm{C}$, but the temperature near the side walls was increased significantly at approximately $30{ }^{\circ} \mathrm{C}$. With the increasing of time, heat transfer by conduction was the mode in the solid phase, and convection was the mode of liquid phase to changing the solid-liquid phase of PCM. Line graphs showed the little variation of temperature between experimental and numerical result which was negligible.

It was observed that after six hours the line graph was almost straight, it means the temperature of the PCM everywhere in the cavity was almost same as shows in figure 3.1(c). The rate of heat transfer was higher in liquid domain than the solid domain, because of convective motion which was created by bouncy effect. So, the heat inside the tube was transferred by convective motion to the solid phase of the PCM around the tube, and it absorbs more heat.

\subsubsection{Surface temperature distributions at $y=0.04741 \mathrm{~m}$ of the cavity along $x$-axis}

The surface temperature distributions along the direction of $\mathrm{x}$-axis at the top of the rectangular cavity in different timewise analysis is shown in figure 3.2(a), 3.2(b) and 3.2(c).

The line graph indicates a good agreement between experimental and numerical surface temperature distributions after two hours. Figure 3.2(a) shows that the temperature near the Utube was maximum around $32{ }^{\circ} \mathrm{C}$ and minimum was $27^{\circ} \mathrm{C}$ near one wall and was $29{ }^{\circ} \mathrm{C}$ on the other wall for both simulations. So, after two hours, PCM has been melted around the tube and absorbed heat from the water. Little variation was observed between experimental and numerical results beside the U-tube which was less than $5 \%$, so the error is negligible.

In figure 3.2(b), the temperature near the U-tube was around $32{ }^{\circ} \mathrm{C}$, but the temperature near the walls increased significantly at approximately $30{ }^{\circ} \mathrm{C}$. With the increasing of time, heat transfer by conduction was the mode of the solid phase, and convection was the mode of liquid phase to change the solid-liquid phase of PCM. Line graphs showed the variation between experimental and numerical results, which was negligible. The line graphs showing a very good 


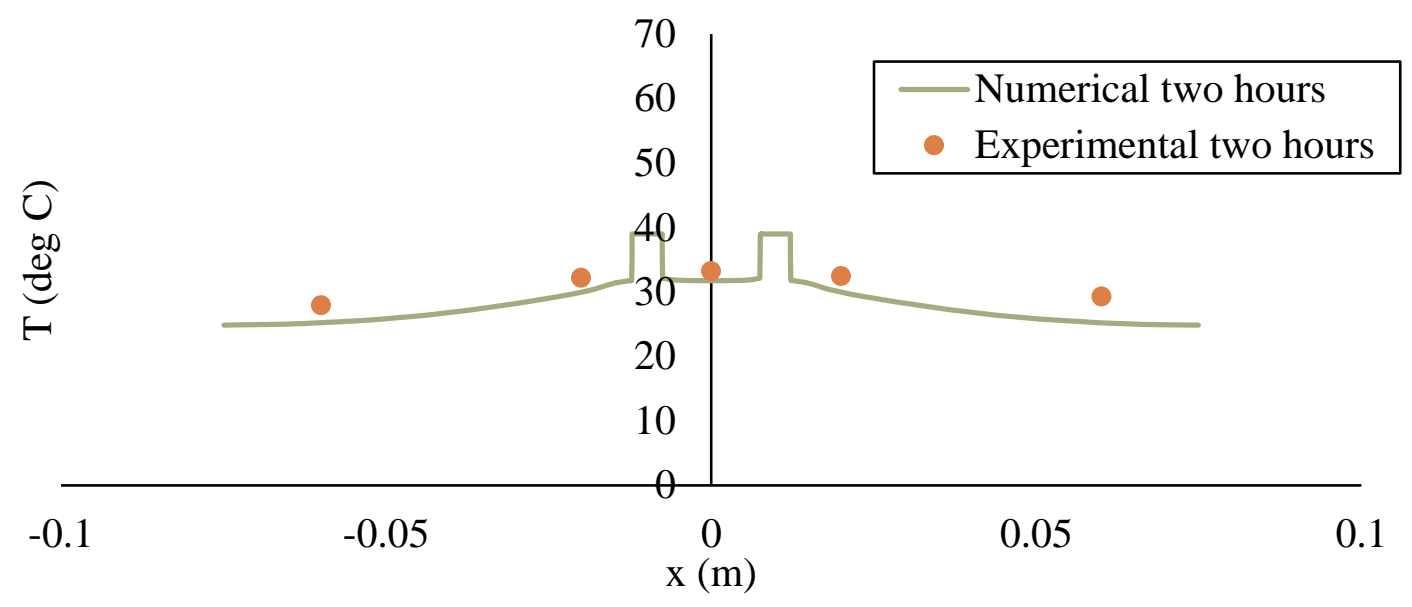

(a) $\mathbf{t}=\mathbf{2}$ hours

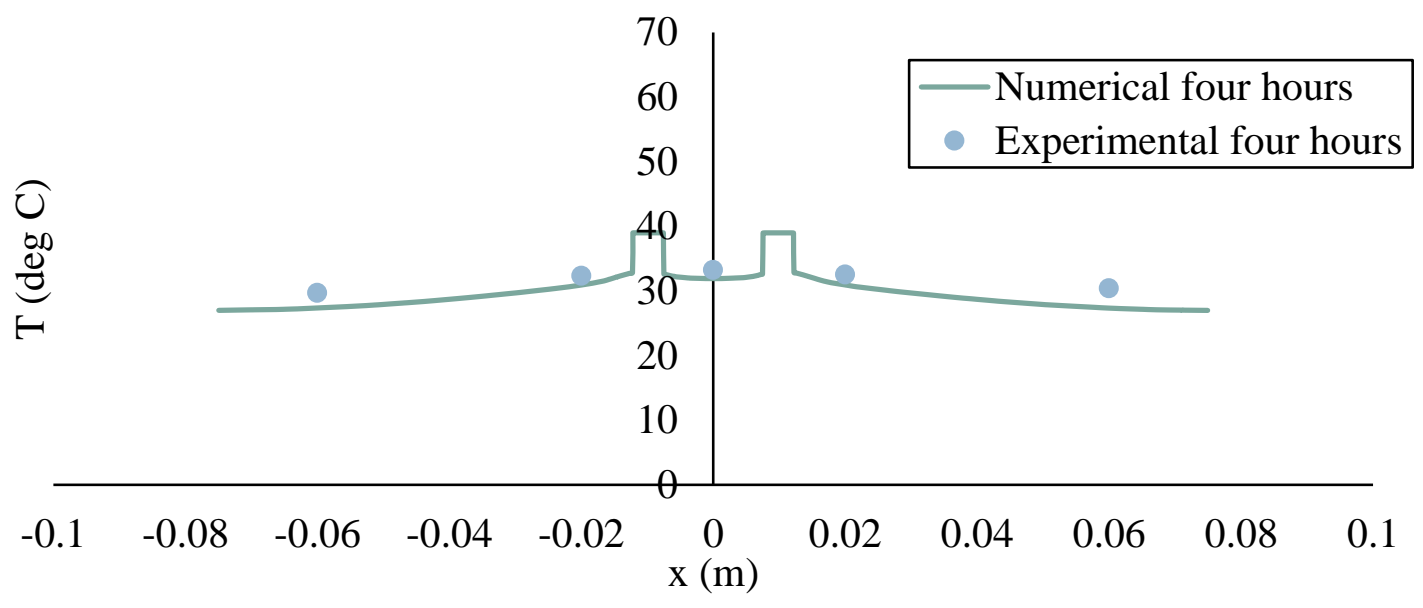

(b) $t=4$ hours

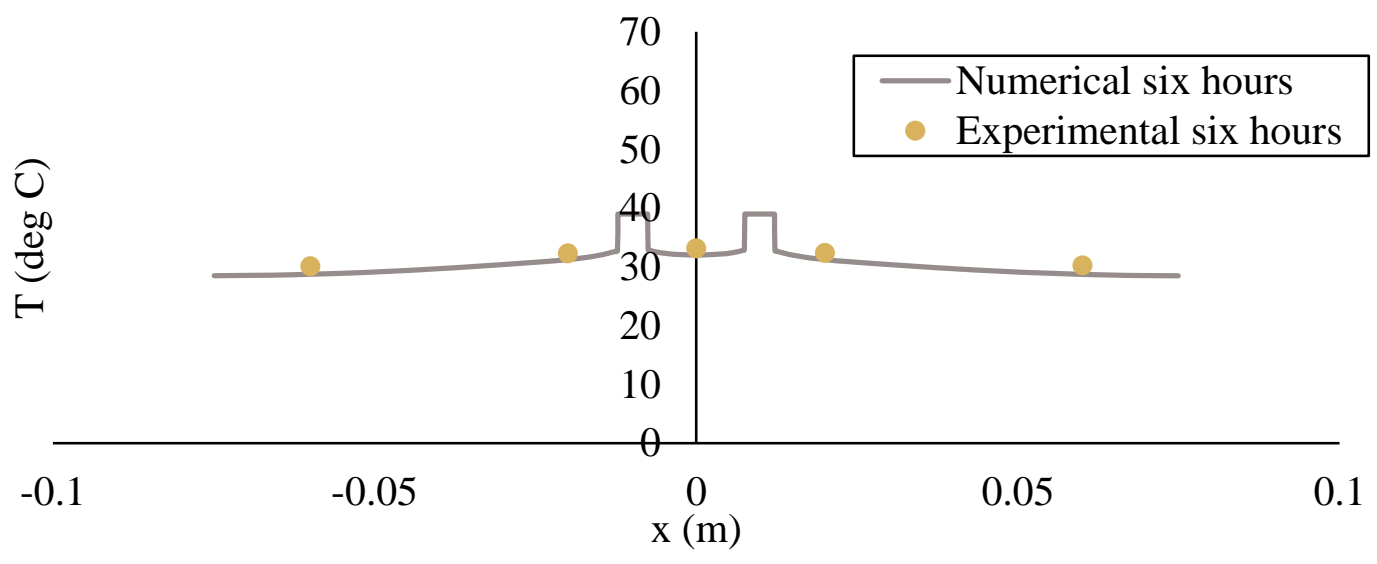

(c) $\mathbf{t}=\mathbf{6}$ hours

Figure 3.2: Temperature distributions at $y=0.04741 \mathrm{~m}$ of the cavity along $\mathrm{x}$-axis 
agreement for both experimental and numerical results after six hours as shown in figure 3.2(c). The surface temperature inside the tube was around 33 approximately fifty percent of the PCM in top of the cavity was melted completely after six hours.

\subsubsection{Surface temperature distributions at $y=\mathbf{- 0 . 0 4 7 4 1} \mathbf{m}$ of the cavity along $x$-axis}

Figure 3.3(a), 3.3(b) and 3.3(c) show the surface temperature distributions along the direction of $\mathrm{x}$-axis in the bottom of the rectangular cavity at three different time.

The results revealed that after two hours, experimental and numerical surface temperature distributions of bottom portion of the cavity is not as high as that is in the middle and top portion as shown in figure 3.3(a), because the temperature of inlet was too far from the bottom of the cavity. When the inlet water is reached to the bottom portion of the cavity, it already transfers some heat to the PCM of upper portion. The maximum temperature near the U-tube was around $30{ }^{\circ} \mathrm{C}$, and lower temperature was $25{ }^{\circ} \mathrm{C}$ near side walls for both simulations. So, after two hours, PCM of lower part of the cavity did not reached its melting point.

In figure 3.3(b), the temperature near the U-tube was above $31^{\circ} \mathrm{C}$, but the temperature near the walls was at approximately $27{ }^{\circ} \mathrm{C}$. That means that after four hours, the PCM in bottom of the cavity was going to melt. Line graphs shows almost exact results between experimental and numerical simulations.

Results shows a very good agreement for both experimental and numerical line graphs after six hours as shown in figure $3.3(\mathrm{c})$. The surface temperature inside the tube is around $32{ }^{\circ} \mathrm{C}$, and

near the one wall temperature is $28^{\circ} \mathrm{C}$, but near the other wall is approximately $31{ }^{\circ} \mathrm{C}$. The scenario is clear from the figure that temperature of outlet side was higher than the inlet side after six hours.

\subsubsection{Surface temperature distributions of the cavity along $y$-axis}

For the fruitful discussion, five cutline along middle $(x=0 \mathrm{~m})$, two in left side $(x=0.02 \mathrm{~m}$ and $\mathrm{x}=0.06 \mathrm{~m})$ and another two in right side $(\mathrm{x}=-0.02 \mathrm{~m}$ and $\mathrm{x}=-0.06 \mathrm{~m})$ of the cavity have been made along $y$-axis. At different timewise data collected and analyzed for both experimental study and numerical model. 


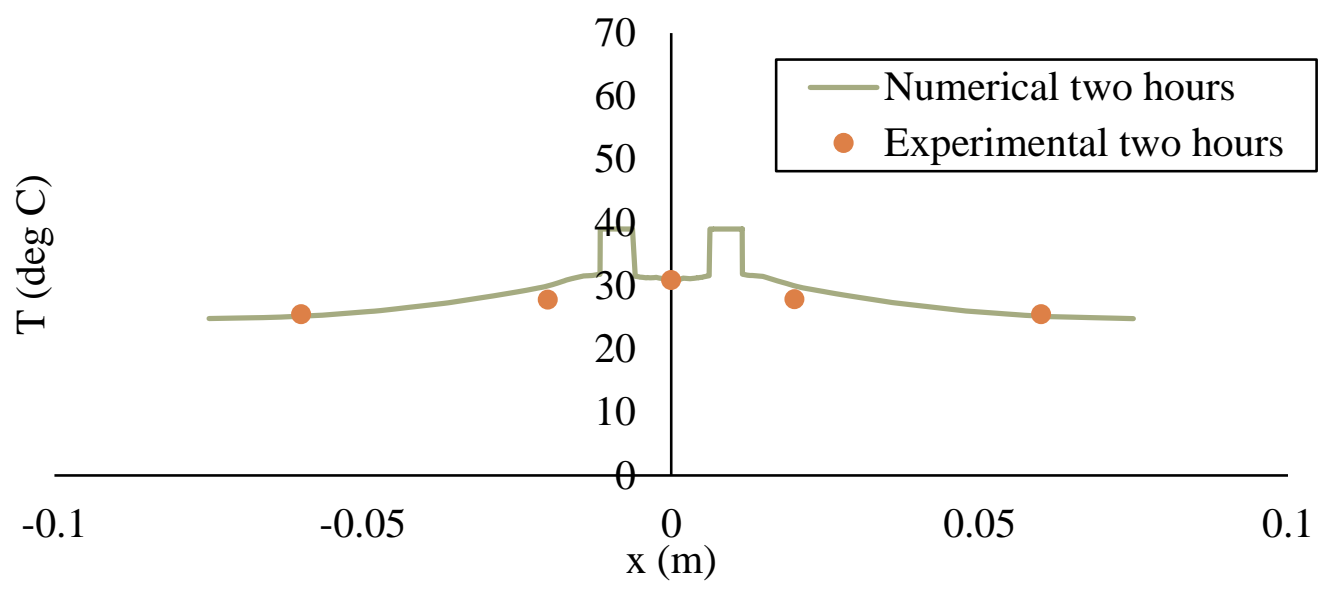

(a) $\mathrm{t}=2$ hours

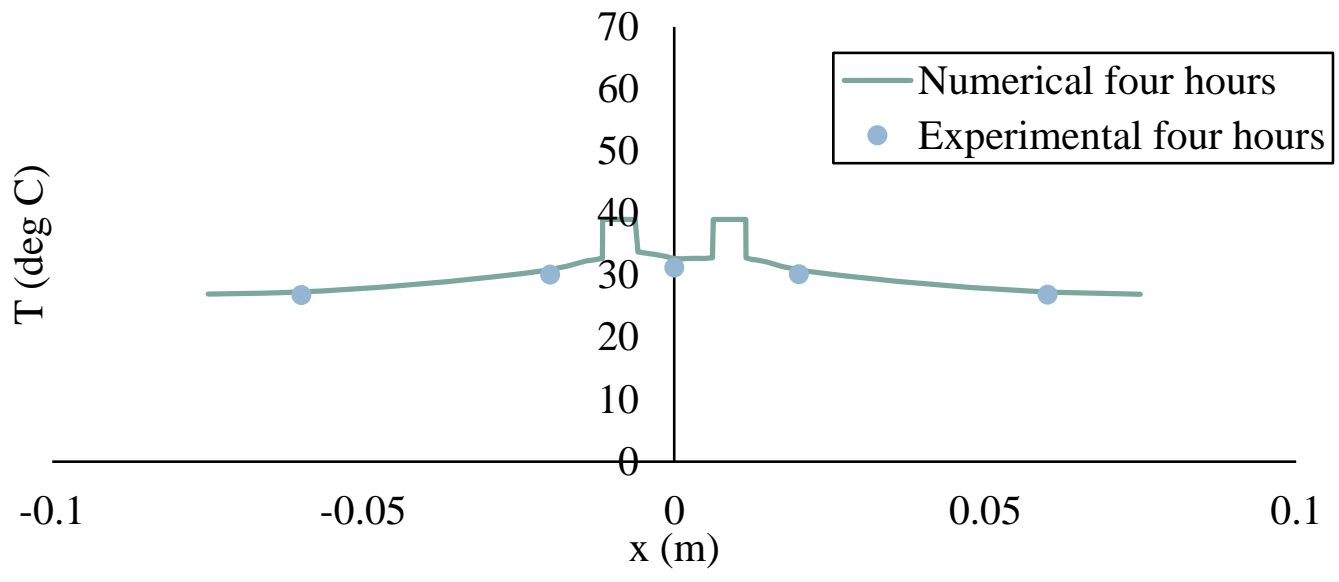

(b) $t=4$ hours

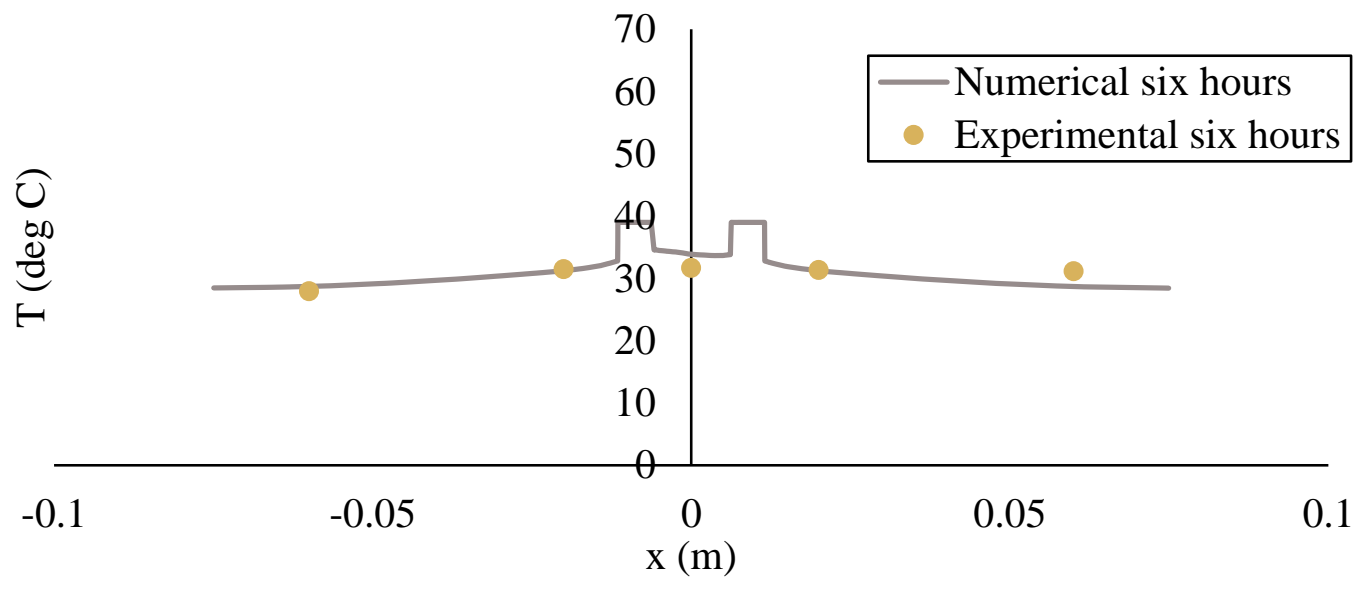

(c) $\mathbf{t}=6$ hours

Figure 3.3: temperature distributions at $y=\mathbf{- 0 . 0 4 7 4 1} \mathbf{m}$ of the cavity along $\mathrm{x}$-axis 


\subsubsection{Surface temperature distributions at $\mathrm{x}=0 \mathrm{~m}$ of the cavity along $\mathrm{y}$-axis}

Figure 3.4(a), 3.4(b) and 3.4(c) illustrates the surface temperature distributions along the direction of $y$-axis in the middle of the rectangular cavity at three different time.

The results revealed a good agreement in between experimental and numerical temperature distribution after two hours. Figure 3.4(a) shows that the temperature in the middle of the cavity was almost linear except near the tube. The temperature was around $32{ }^{\circ} \mathrm{C}$ outside the tube, but inside the tube it was around $39{ }^{\circ} \mathrm{C}$, which is almost the same as inlet temperature. So, after two hours, PCM was started to melt around the tube, and absorbed heat from the water. The agreement of experimental and numerical results was good.

Figure 3.4(b) shows the temperature distributions along the middle of y-axis after four hours in the cavity. The temperature was linear in almost everywhere which was logically make sense for both simulations. The temperature in everywhere along middle of y-axis was around $33{ }^{\circ} \mathrm{C}$ and, inside the tube was around $39^{\circ} \mathrm{C}$.

Temperature distribution of figure 3.4(b) and 3.4(c) was similar, because this position was inside the two legs of the heating source where temperature having its higher position after four hours. After six hours, temperature of middle and bottom portion was approximately $33^{\circ} \mathrm{C}$ of the cavity which was higher than the top portion around $32{ }^{\circ} \mathrm{C}$ as shown in figure $3.4(\mathrm{c})$. The reason for high temperature at the bottom portion is that the tube bended $\mathrm{U}$-shaped from there, so that area gets more in contact with tube rather than the other portion. For this reason, PCM`s temperature is more in bottom of the cavity.

\subsubsection{Surface temperature distributions at $x=0.02 \mathrm{~m}$ of the cavity along $\mathrm{y}$-axis}

The surface temperature distributions along the direction of the $\mathrm{y}$-axis at $\mathrm{x}=0.02 \mathrm{~m}$ of the rectangular cavity at different timewise analysis is shown in figure 3.5(a), 3.5(b) and 3.5(c).

The results revealed that a good agreement at two hours between experimental and numerical surface temperature distribution at $\mathrm{x}=0.02 \mathrm{~m}$ of $\mathrm{y}$-axis of the cavity is shown in figure 3.5(a). The surface temperature of top portion of the cavity is above $32{ }^{\circ} \mathrm{C}$, that means PCM of top portion of the cavity in this position is melted at two hours. However, the surface temperature of bottom portion of the cavity is around $28{ }^{\circ} \mathrm{C}$ at two hours, which means the PCM of that part is still solid after two hours. The error of the results of experimental and numerical model is less than $5 \%$, so it is negligible. 


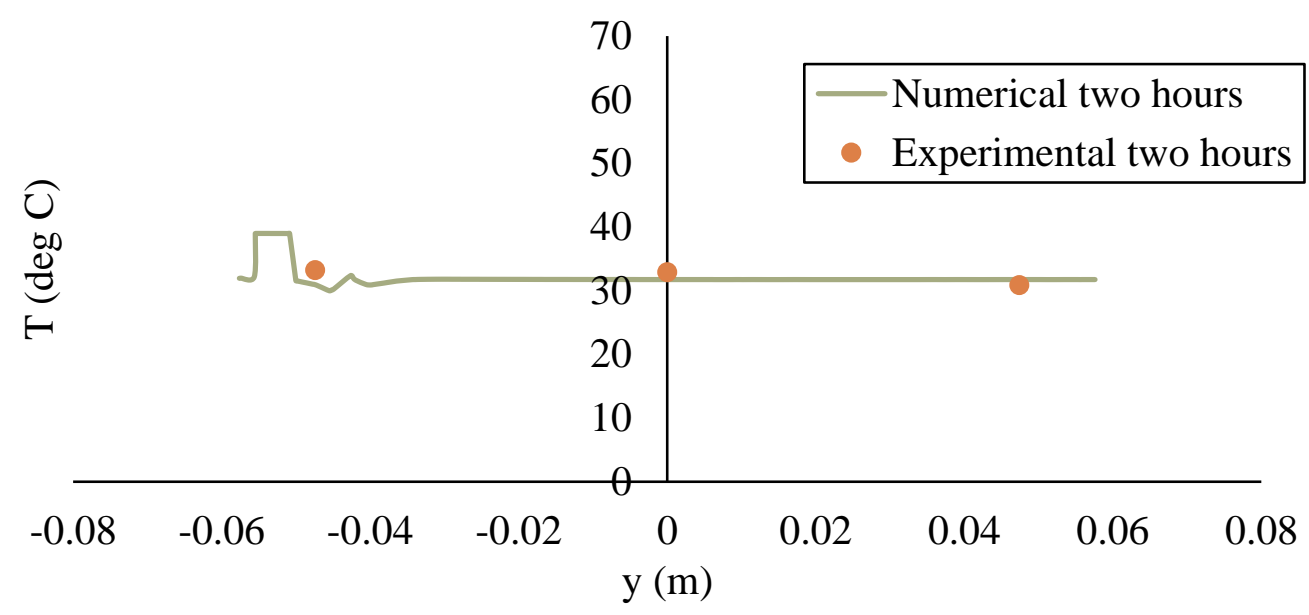

(a) $\mathbf{t}=\mathbf{2}$ hours

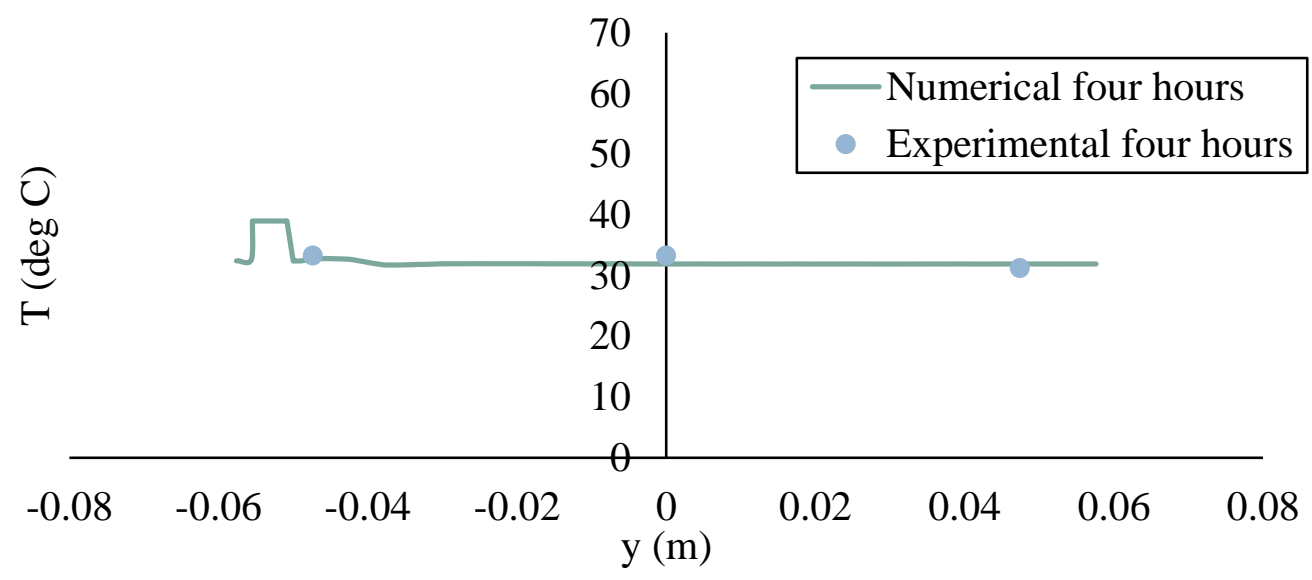

(b) $\mathrm{t}=\mathbf{4}$ hours

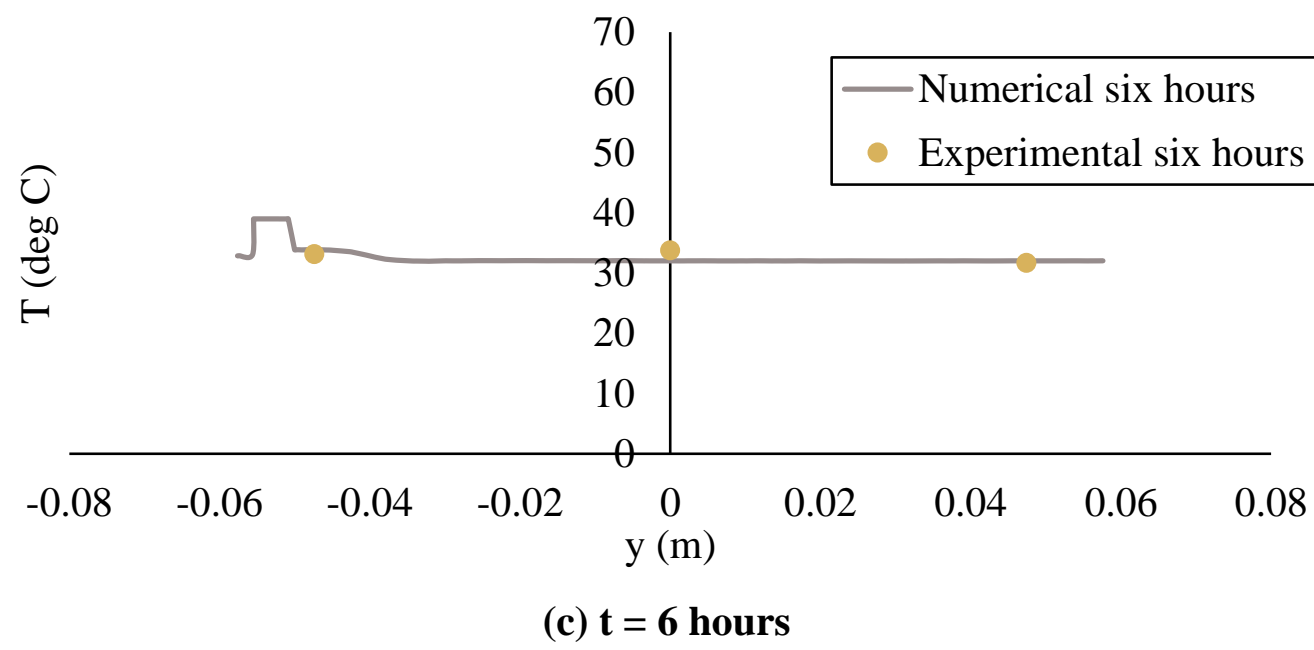

Figure 3.4: Temperature distributions at $x=0 \mathrm{~m}$ of the cavity along $y$-axis 


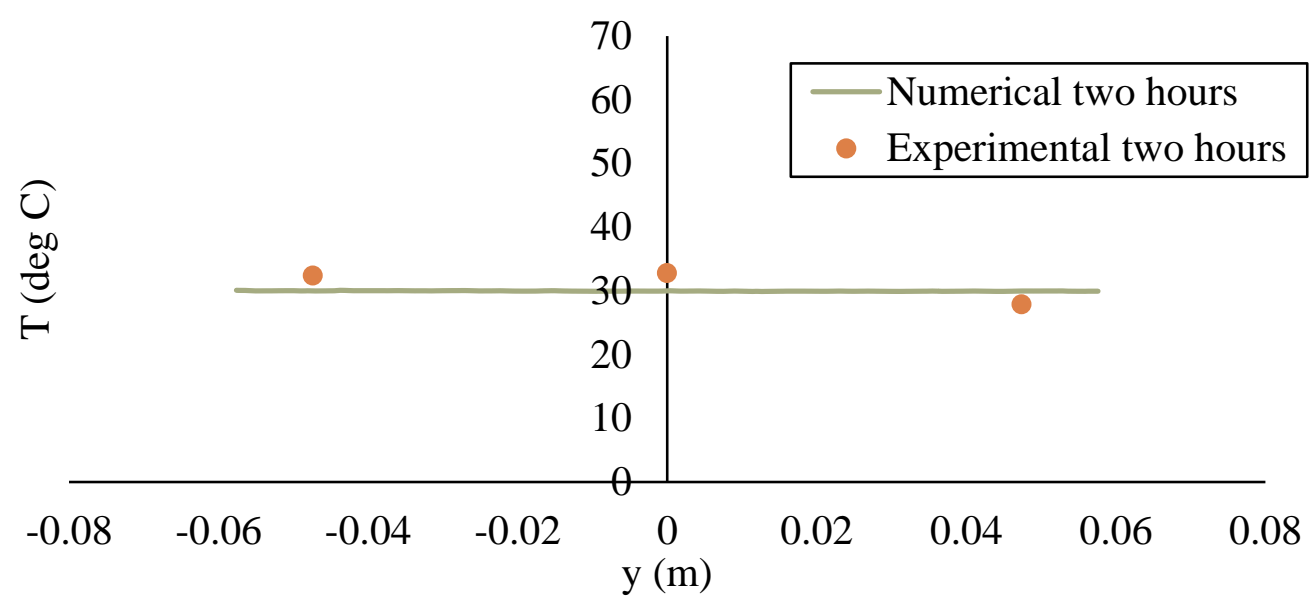

(a) $\mathbf{t}=\mathbf{2}$ hours

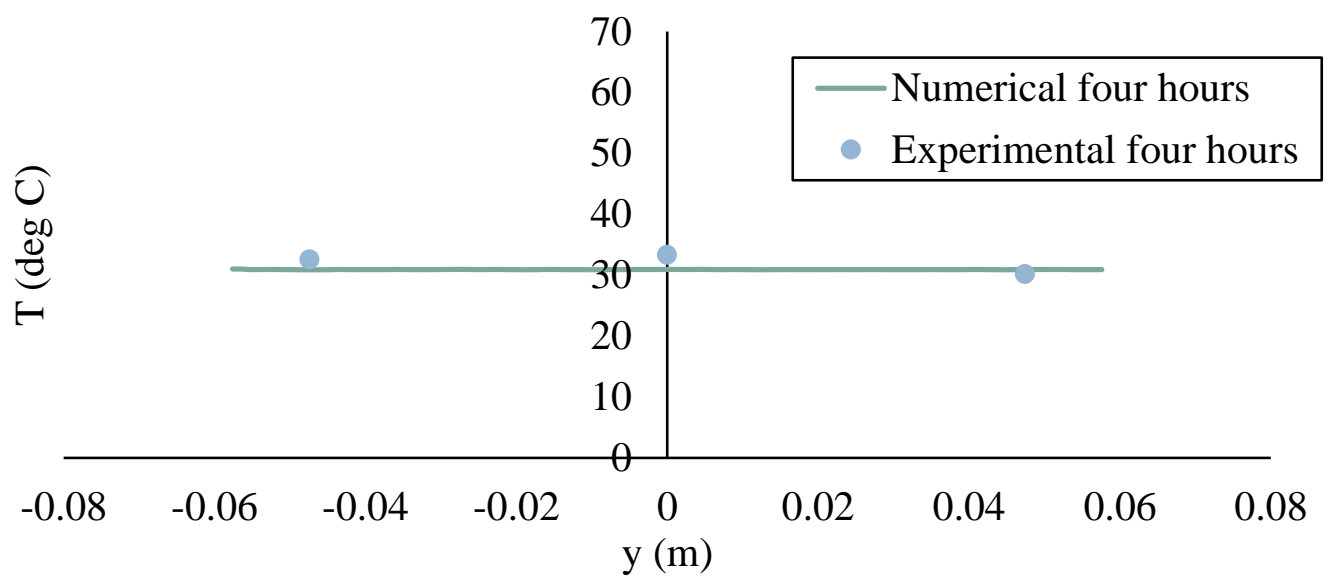

(b) $\mathrm{t}=\mathbf{4}$ hours

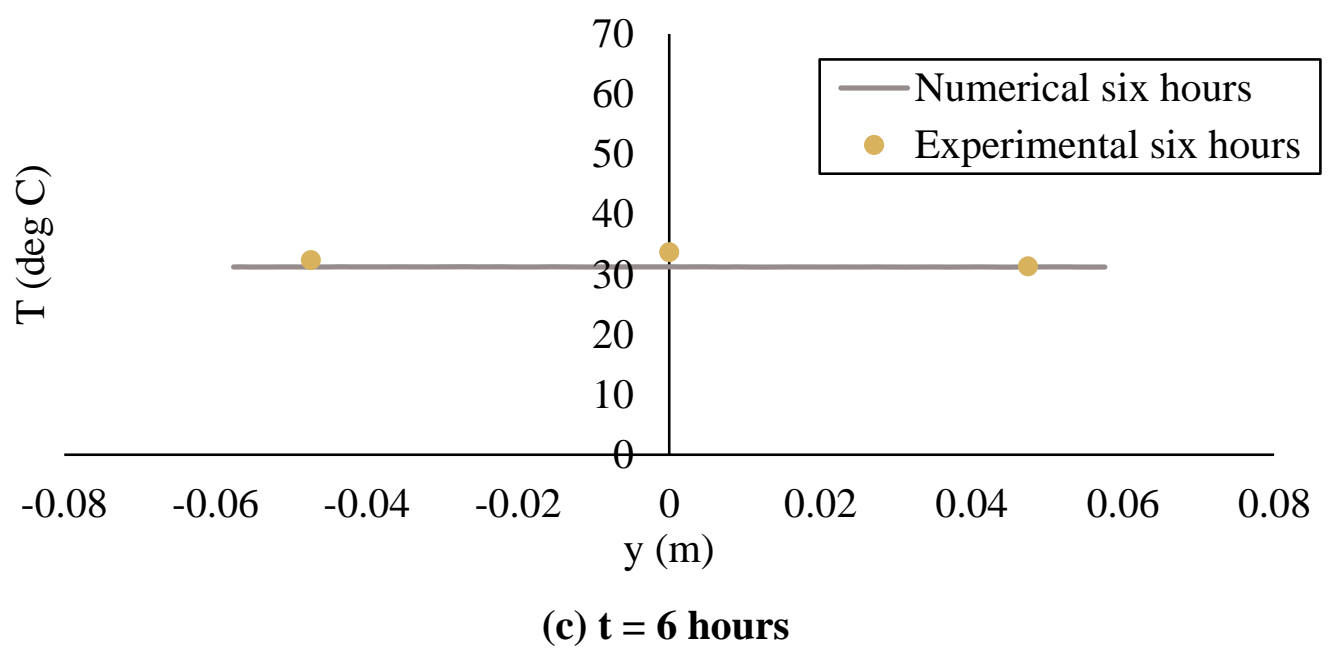

Figure 3.5: Temperature distributions at $x=0.02 \mathrm{~m}$ of the cavity along $y$-axis 40 
Figure 3.5(b) shows the surface temperature distributions at the position of $x=0.02 \mathrm{~m}$ of the cavity along y-axis at four hours. The temperature of the cavity is little bit increased at four hours rather than two hours in everywhere of the line. So, the PCM inside the cavity absorbs more heat from the tube with the increasing of time.

At the time of six hours, the experimental and numerical agreement was good as shown in figure $3.5(\mathrm{c})$. For both cases, temperature is above $32{ }^{\circ} \mathrm{C}$ in everywhere of the line. It means that the PCM is melted in everywhere. The temperature distribution is linear and in the middle of the cavity and it is little bit higher rather than the other part.

\subsubsection{Surface temperature distributions at $x=0.06 \mathrm{~m}$ of the cavity along $y$-axis}

At different timewise analysis shows the surface temperature distributions in figure 3.6(a), 3.6(b) and 3.6(c) in the direction of $y$-axis at $\mathrm{x}=0.06 \mathrm{~m}$ of the rectangular cavity.

The results revealed that, at the time of two hours experimental and numerical surface temperature distributions at $\mathrm{x}=0.06 \mathrm{~m}$ of the rectangular cavity is not as much higher as around the tube as shown in figure 3.6(a), because the inlet point of temperature is too far from there. The temperature of the top of the cavity was around $28{ }^{\circ} \mathrm{C}$, and in the middle and bottom portion it was around $26^{\circ} \mathrm{C}$. So, at the time two hours, PCM of left side of the cavity was not melted.

Figure 3.6(b) shows the surface temperature distributions at the position $\mathrm{x}=0.06 \mathrm{~m}$ of the rectangular cavity at four hours of flowing water inside the tube. The temperature was raised little bit more rather than the two hours, because that part of PCM gained heat by conduction process from the middle portion of the cavity.

The temperature distributions at $\mathrm{x}=0.06 \mathrm{~m}$ of the rectangular cavity at six hours is shown in the figure 3.6(c). This part of the cavity is close to the melting the PCM at six hours but was not melted. There was little bit variation between experimental and numerical results in the middle of the cavity. However, the agreement between top and bottom portion of the was good. So, the error is negligible.

\subsubsection{Surface temperature distributions at $x=-\mathbf{0 . 0 2} \mathrm{m}$ of the cavity along $y$-axis}

The surface temperature distributions along the direction of $y$-axis at $\mathrm{x}=-0.02 \mathrm{~m}$ of the rectangular cavity at different timewise analysis is shown in figure 3.7(a), 3.7(b) and 3.7(c). 


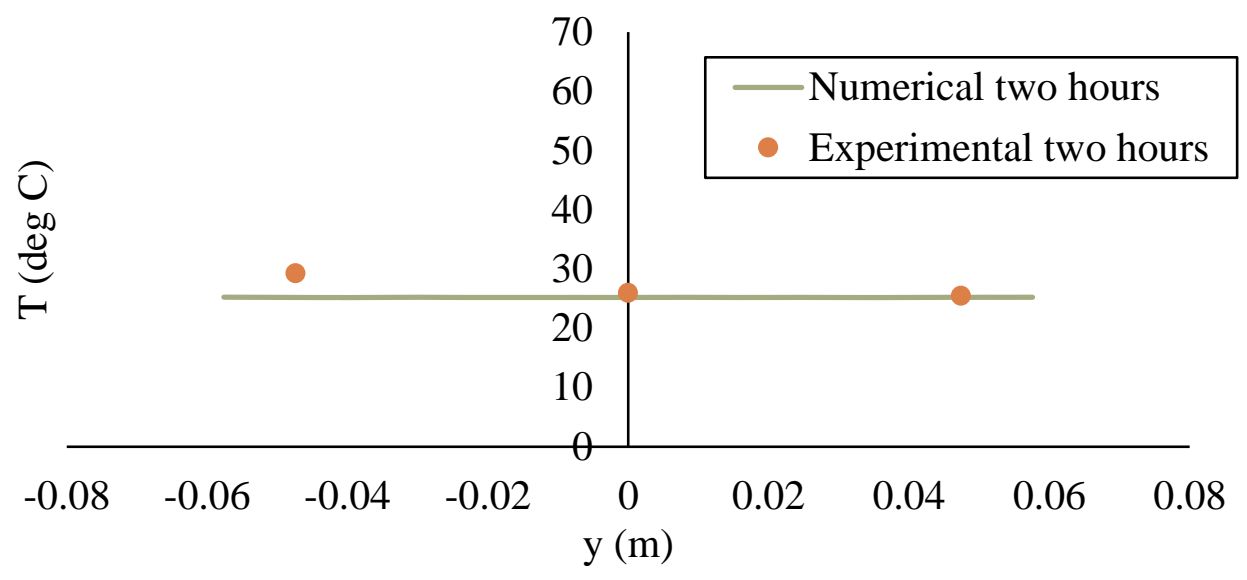

(a) $\mathbf{t}=\mathbf{2}$ hours

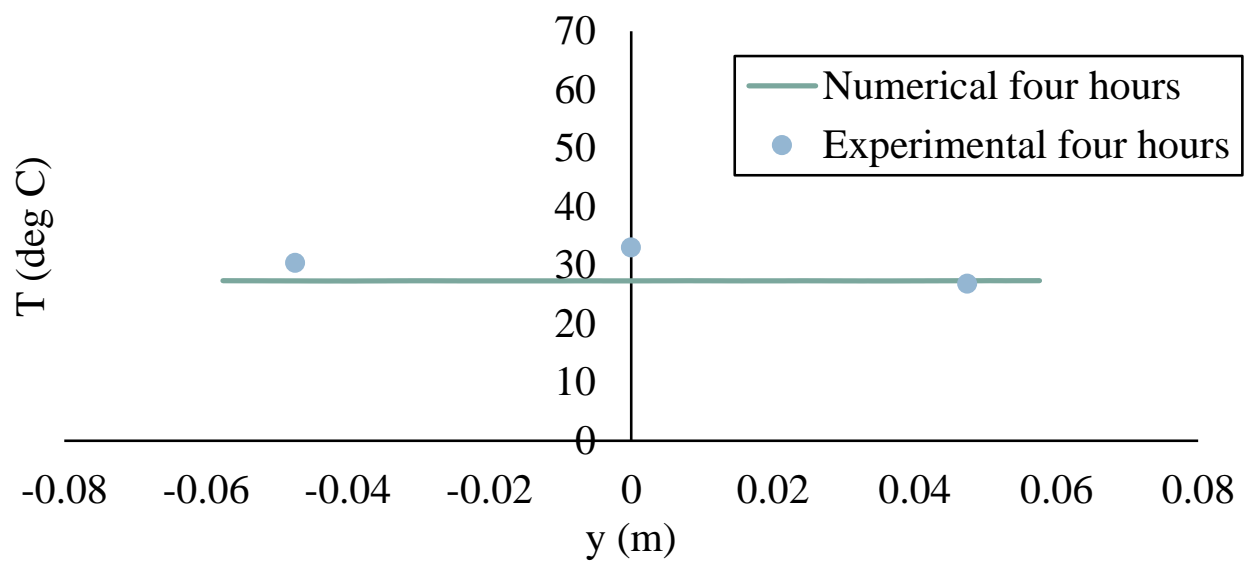

(b) $\mathrm{t}=\mathbf{4}$ hours

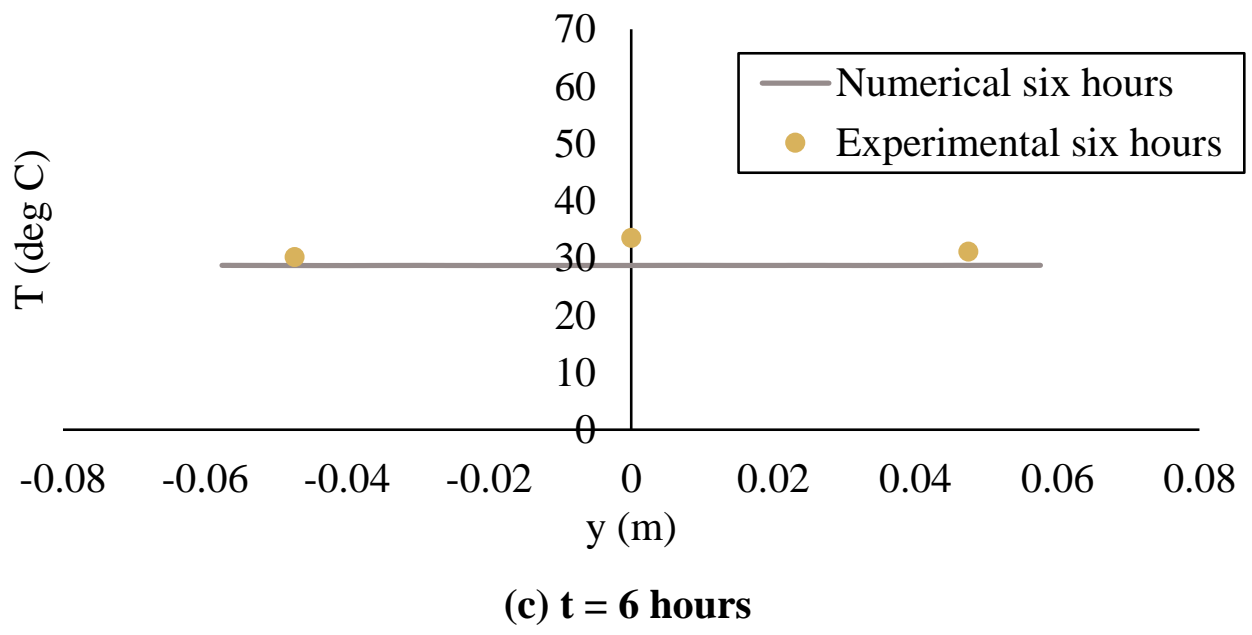

Figure 3.6: Temperature distributions at $x=0.06 \mathrm{~m}$ of the cavity along $y$-axis 
The results revealed that a good agreement at two hours between experimental and numerical surface temperature distributions at the position of $\mathrm{x}=-0.02 \mathrm{~m}$ of $\mathrm{y}$-axis of the cavity as shown in figure 3.7(a). The surface temperature of the top portion of the cavity is above $32{ }^{\circ} \mathrm{C}$, that means PCM of top part of the cavity in this position is melted at that time. However, the surface temperature of the bottom part of the cavity is below $28^{\circ} \mathrm{C}$ during this time, that means the PCM of that part is still solid at the time of two hours. The error of the results of experimental and numerical model is less than 5\%, so, it is negligible.

Figure 3.7(b) shows the surface temperature distributions at the point $\mathrm{x}=-0.02 \mathrm{~m}$ of the cavity along y-axis at four hours. The temperature of the cavity is little bit increased at four hours rather than two hours in everywhere of the line. So, the PCM inside the cavity absorbed more heat from the heat transfer fluid (HTF) tube with increasing of time.

At the time of six hours, the experimental and numerical agreement of results was good as shown in figure 3.7(c). For both cases, temperature was above $32{ }^{\circ} \mathrm{C}$ in everywhere of the line. It means that the PCM was melted in everywhere. The temperature distribution is linear, and in the middle of the cavity it is little bit more rather than the other part.

\subsubsection{Surface temperature distributions at $\mathrm{x}=\mathbf{- 0 . 0 6} \mathrm{m}$ of the cavity along $\mathrm{y}$-axis}

Different timewise data analysis shows the surface temperature distributions in figure 3.8(a), 3.8(b) and 3.8(c) in the direction of $y$-axis at $x=-0.06 \mathrm{~m}$ of the rectangular cavity.

The results revealed that at the time of two hours, experimental and numerical surface temperature distributions at $\mathrm{x}=-0.06 \mathrm{~m}$ of the rectangular cavity was not that much higher as much as around the tube as shown in figure 3.8(a), because the inlet point of temperature was too far from there. The temperature at the top and middle of the cavity was around $26{ }^{\circ} \mathrm{C}$, and at the bottom, it was around $29^{\circ} \mathrm{C}$. So, after two hours, PCM of right side of the cavity was not melted.

Figure 3.8(b) shows the surface temperature distributions at $\mathrm{x}=-0.06 \mathrm{~m}$ of the rectangular cavity after four hours of flowing HTF inside the tube. The temperature was raised little bit more rather than the two hours, because, that part of PCM gained heat by conduction process from the middle portion of the cavity.

The temperature distributions at $\mathrm{x}=-0.06 \mathrm{~m}$ of the rectangular cavity at six hours is shown in the figure 3.8(c). This part of the cavity is close to melting phase at six hours, but was not melted 


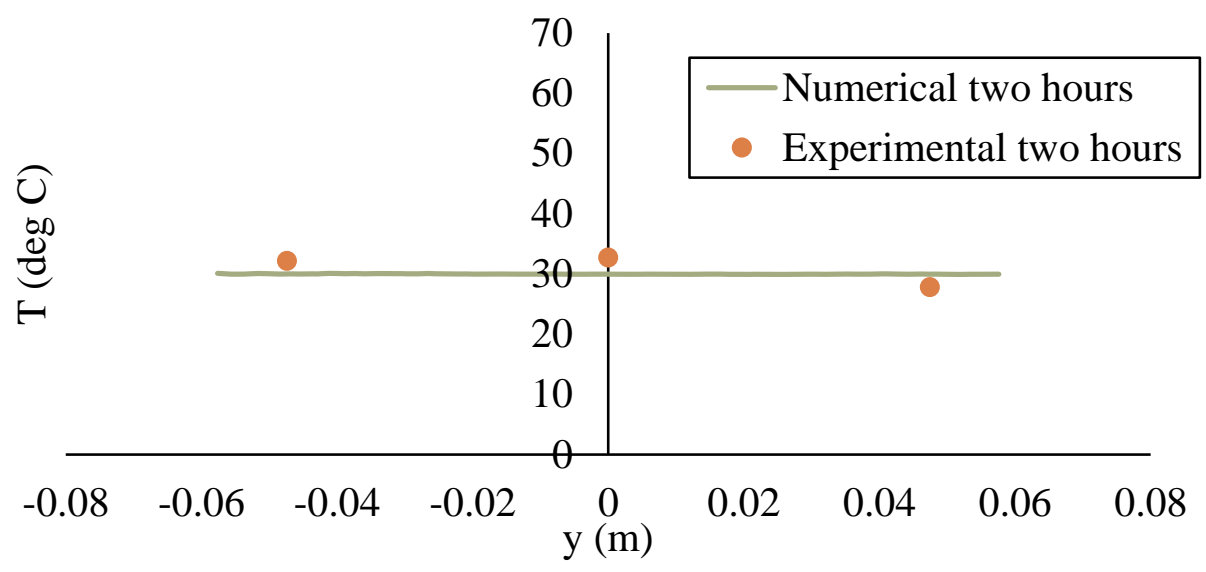

(a) $\mathbf{t}=\mathbf{2}$ hours

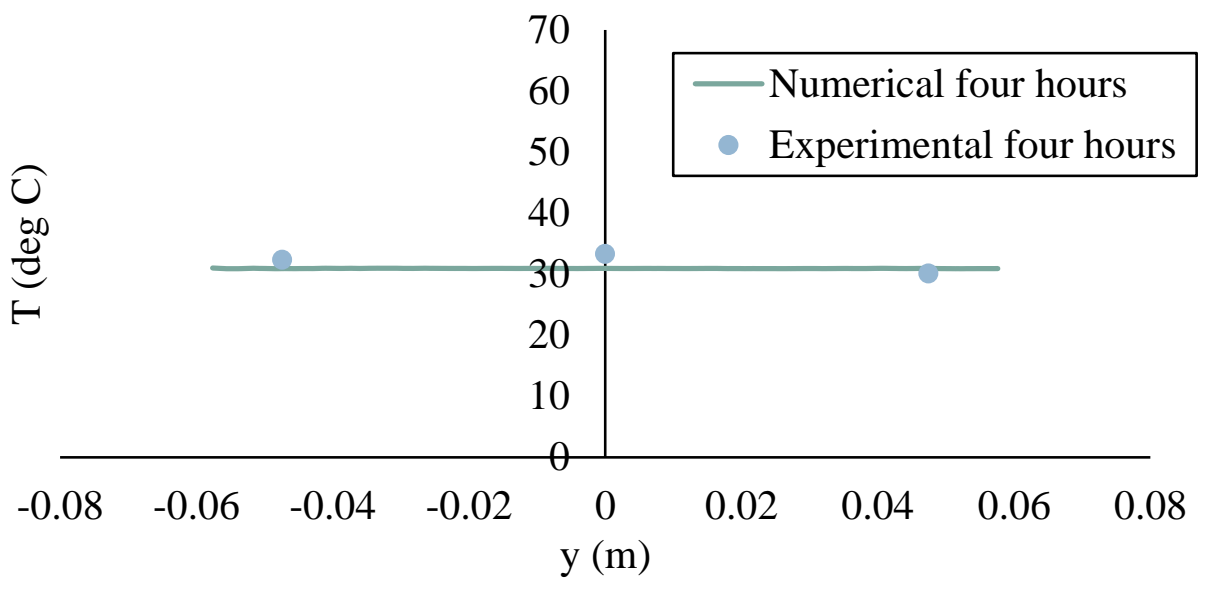

(b) $\mathrm{t}=\mathbf{4}$ hours

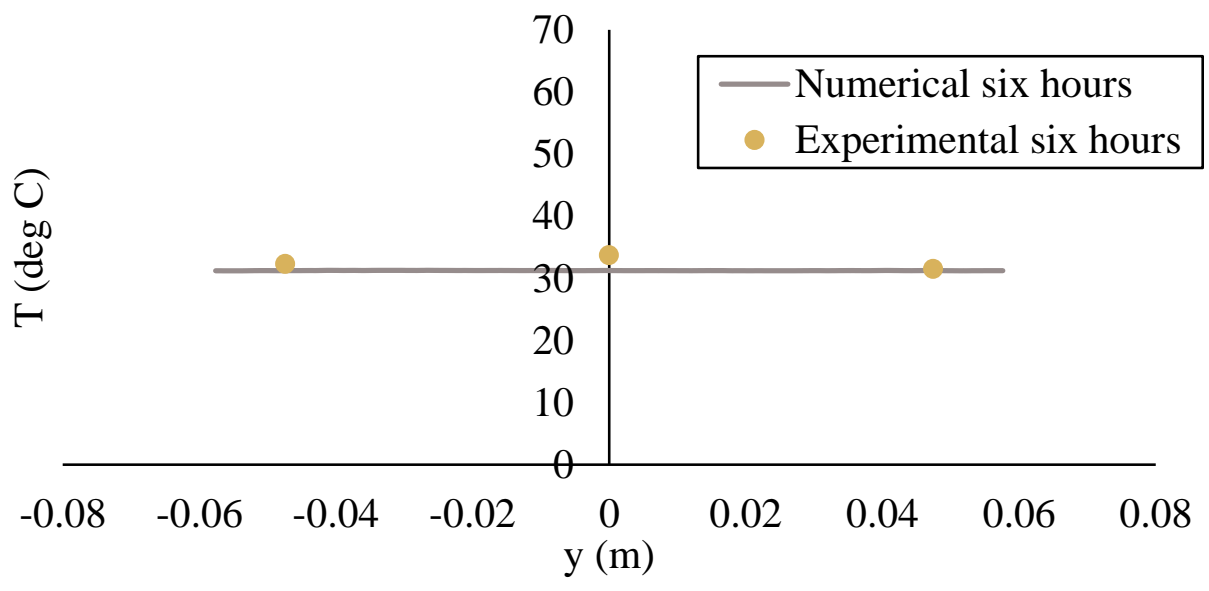

(c) $\mathrm{t}=6$ hours

Figure 3.7: Temperature distributions at $x=\mathbf{- 0 . 0 2} \mathbf{m}$ of the cavity along $y$-axis 


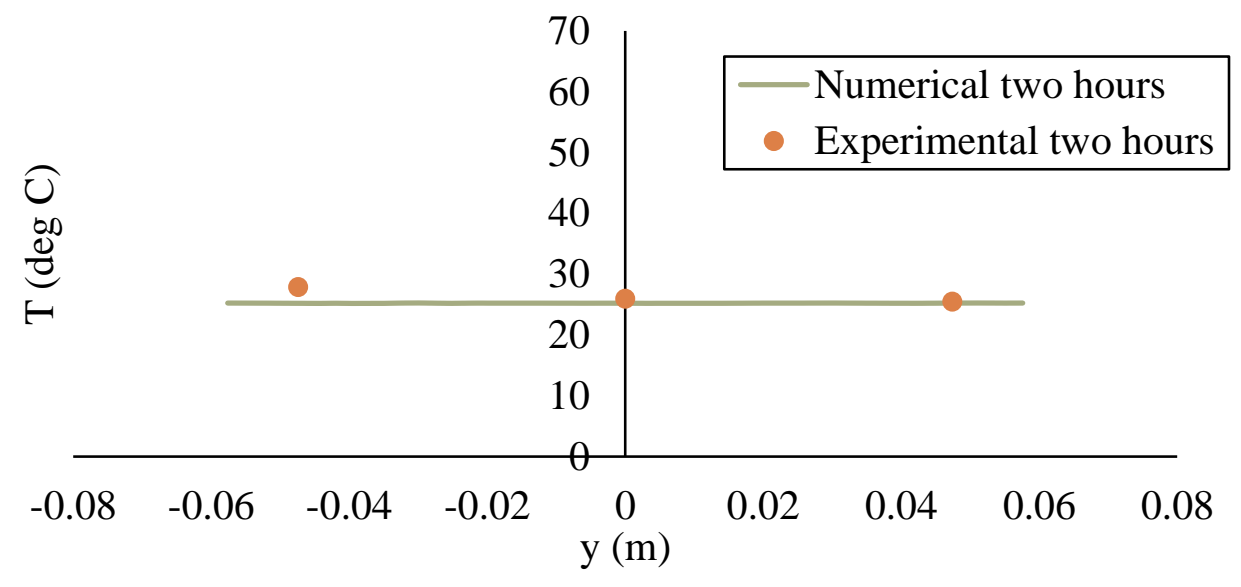

(a) $\mathrm{t}=\mathbf{2}$ hours

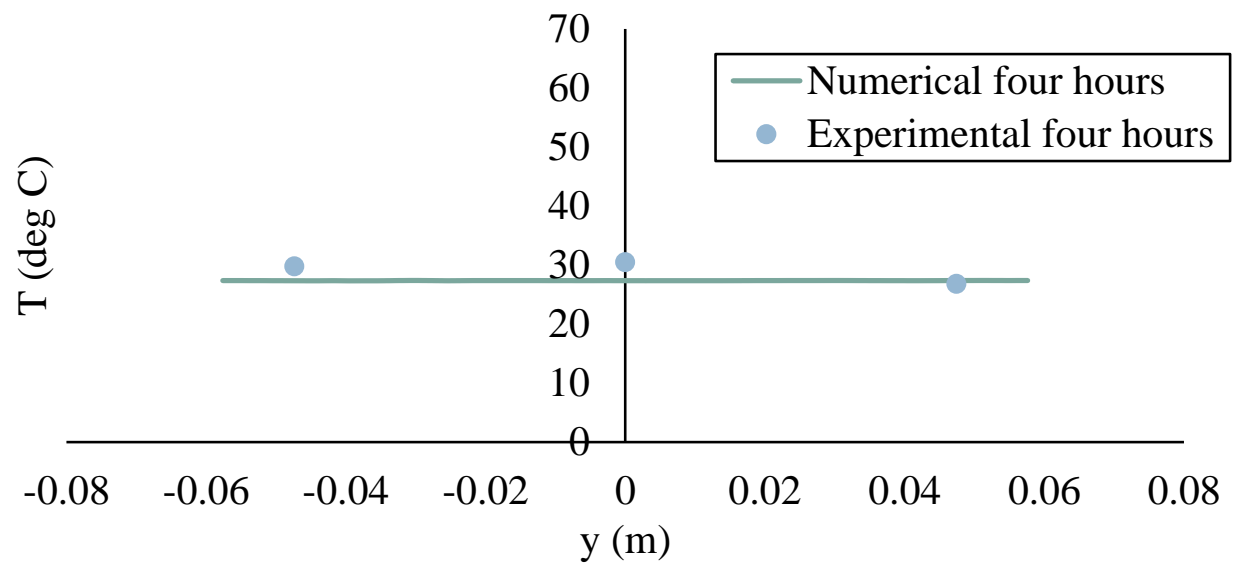

(b) $\mathrm{t}=\mathbf{4}$ hours

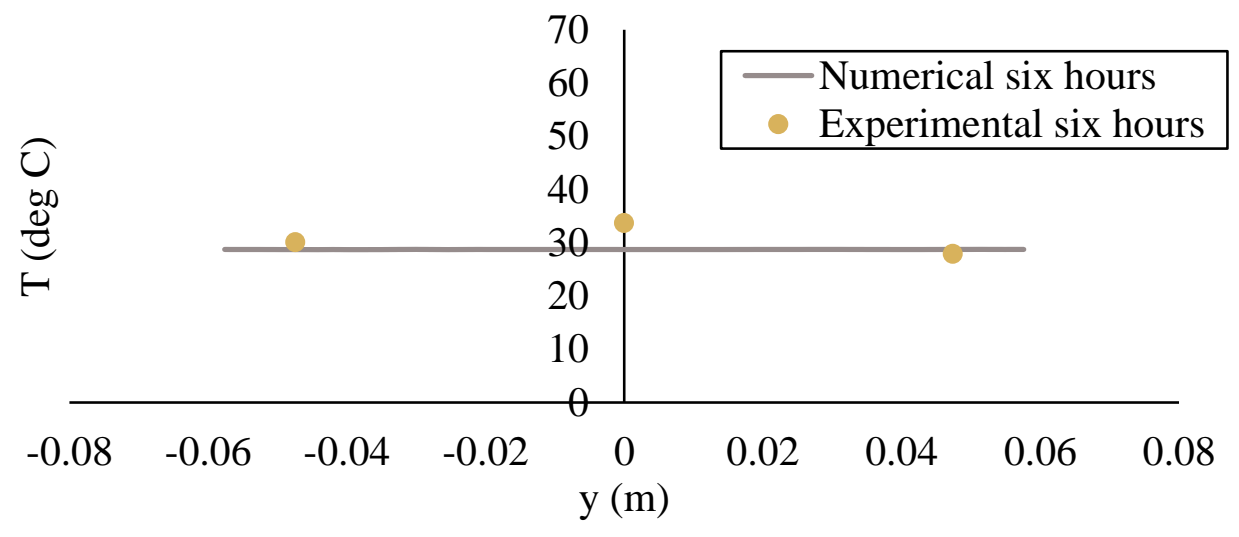

(c) $\mathrm{t}=6$ hours

Figure 3.8: Temperature distributions at $\mathrm{x}=\mathbf{- 0 . 0 6} \mathbf{m}$ of the cavity along $\mathbf{y}$-axis 
There was little bit variation between experimental and numerical results in the middle of the cavity but, the agreement in top and bottom portion is good. So, the error is negligible.

\subsection{Numerical Model Validation between PCM and Bentonite}

In this numerical study, the U-shaped copper tube has been inserted in the rectangular cavity filled with PCM and bentonite, which was described in model A, model B, model C and model D. The hot water $39^{\circ} \mathrm{C}$ was flowing through the tube for the first three hours and extracted heat to the solutions, then, the cold water at the temperature of $15^{\circ} \mathrm{C}$ was flowing through the tube for another three hours to absorb heat from the solutions for all models. For comparing the results between all models, some cutline in both horizontal axis and vertical axis in the cavity have chosen, and the data was analyzed at two different times.

\subsubsection{Surface temperature distributions of the cavity along $x$-axis}

For a good discussion, three cutline at the middle $(\mathrm{y}=0 \mathrm{~m})$, top $(\mathrm{y}=0.04741 \mathrm{~m})$ and bottom $(y=-0.04741 \mathrm{~m})$ of the cavity along $\mathrm{x}$-axis have been considered. After the time of hot-water supply and cold-water supply, data were collected and analyzed among all models.

\subsubsection{Surface temperature distributions at $y=0 \mathrm{~m}$ of the cavity along $x$-axis}

Figure 3.9(a) and 3.9(b) illustrates the surface temperature distributions of all four models along the direction of $\mathrm{x}$-axis in the middle of the rectangular cavity at two different time steps.

The figure 3.9(a) revealed that heat transfer rate during the heating was higher in bentonite rather than PCM. Temperature distributions was linear, that means same as $32{ }^{\circ} \mathrm{C}$ in everywhere of the cavity when only bentonite has been used for simulations as shown in model B. But, for PCM, temperature distributions were not same in everywhere of the cavity. Temperature around the U-shaped tube was approximately $31.5{ }^{\circ} \mathrm{C}$, however, it decreases dramatically near the two side walls just above $25^{\circ} \mathrm{C}$, as shown in model A. Surface temperature has been reached very high at $36{ }^{\circ} \mathrm{C}$ rather than PCM around the U-shaped tube when bentonite has been used in the middle, and PCM was used around the cavity. However, the reverse thing happened near the walls, the temperature reaches higher rather than bentonite as shown in model C and D. It is clear from the results that for higher thermal conductivity heat transfer rate is higher than the PCM. 


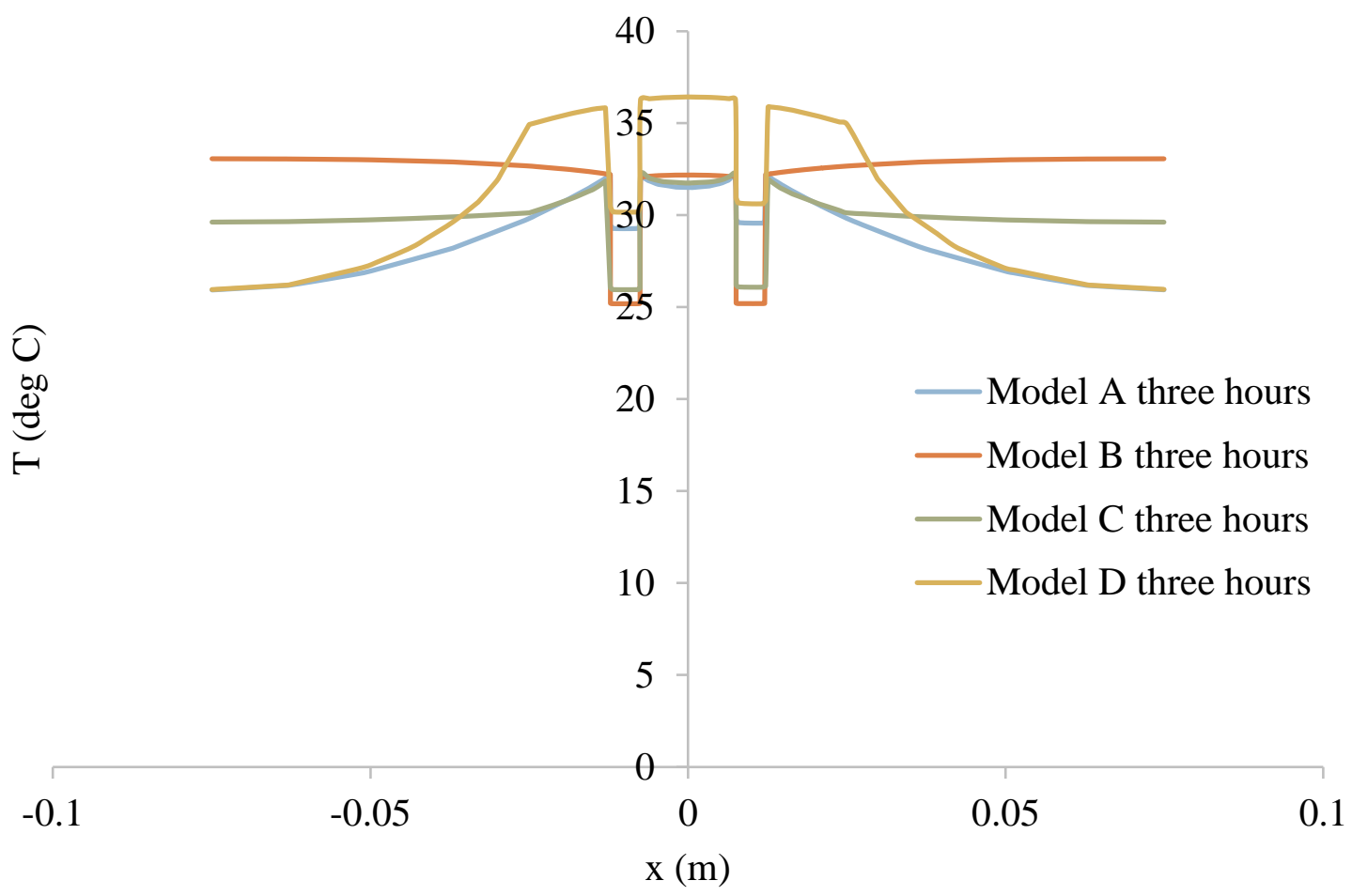

(a) $\mathbf{t}=\mathbf{3}$ hours

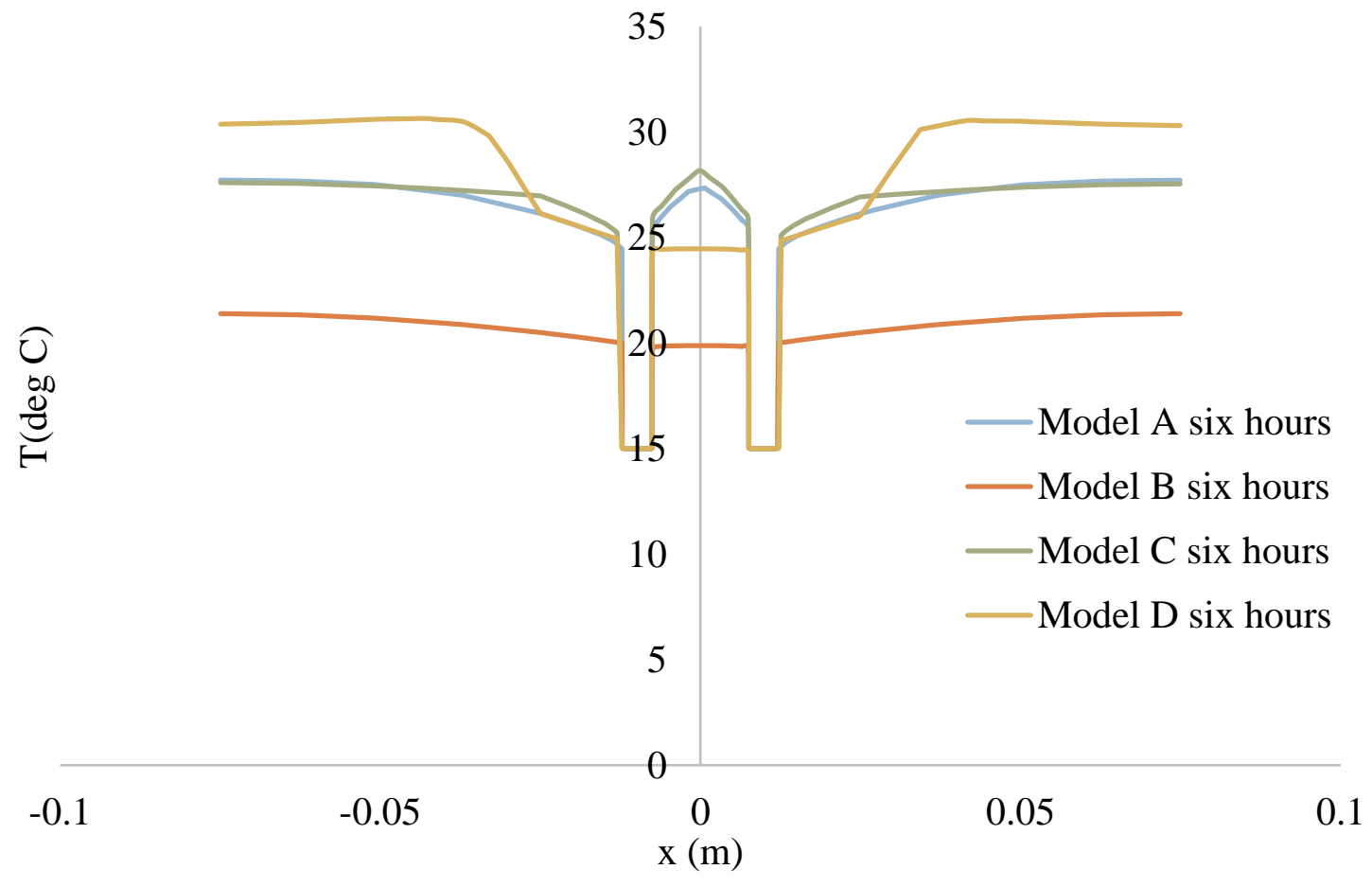

(b) $\mathrm{t}=6$ hours

Figure 3.9: Temperature distributions at $y=0 \mathrm{~m}$ of the cavity along $x$-axis 
The figure 3.9(b) shows that heat transfer rate during the cooling was higher in bentonite rather than PCM. The temperature of model A is decreased from $31.5^{\circ} \mathrm{C}$ to approximately $27^{\circ} \mathrm{C}$ after three hours of cold water supply around the U-shaped tube, but, near the wall it was remained same as during the heating. But, for the model $\mathrm{B}$, the temperature is decreased too fast from $32{ }^{\circ} \mathrm{C}$ to $20{ }^{\circ} \mathrm{C}$ after three hours of cooling in everywhere of the cavity. Temperature distributions between model $\mathrm{C}$ and model $\mathrm{A}$ was almost the same, little bit variation was observed around the U- shaped tube. However, in model D temperature around the U-shaped tube was decreased from $36{ }^{\circ} \mathrm{C}$ to $24^{\circ} \mathrm{C}$ which has been filled by bentonite, but, near the wall it was $30^{\circ} \mathrm{C}$, which has been filled by PCM for three hours cooling.

\subsubsection{Surface temperature distributions at $y=0.04741 \mathrm{~m}$ of the cavity along $x$-axis}

Figure 3.10(a) and 3.10(b) describe the surface temperature distributions in top of the rectangular cavity at two different time along the direction of $\mathrm{x}$-axis.

In this study, figure 3.10(a) revealed that heat transfer rate during the heating in top of the cavity was almost same as like that was in the middle of the cavity as shown in figure 3.9(a). After three hours, the temperature inside the tube is not the same for every model. For model D, it is higher approximately $30.5{ }^{\circ} \mathrm{C}$, for model $\mathrm{A}$ it is around $30^{\circ} \mathrm{C}$ at the inlet, but in outlet, it was little bit less approximately $0.5{ }^{\circ} \mathrm{C}$ than the inlet, because, some heat was regenerated to solutions inside the cavity. On the other hands, for model B and model $\mathrm{C}$ the inlet and outlet temperature $25.5^{\circ} \mathrm{C}$ were less than the model $\mathrm{A}$ and $\mathrm{D}$. The main reason for this, model $\mathrm{B}$ was fully bentonite and model $\mathrm{C}$ was mostly bentonite and, bentonite have higher thermal conductivity rather than PCM. So, after three hours when cold water was supplied, suddenly temperature of that portion was drastically decreased.

Figure 3.10(b) shows that heat transfer rate during the cooling in top of the cavity was almost same as like that was in the middle of the cavity as shown in figure 3.9(b). After six hours, the temperature inside the tube was approximately $26{ }^{\circ} \mathrm{C}$ for model A, but it was like $31{ }^{\circ} \mathrm{C}$ after first three hours. For model B, it was $20{ }^{\circ} \mathrm{C}$ after six hours, but it was around $36{ }^{\circ} \mathrm{C}$ after three hours. In model $\mathrm{C}$, the temperature was around $27{ }^{\circ} \mathrm{C}$ in everywhere of the cavity. The temperature was around $30^{\circ} \mathrm{C}$ near the two side walls and about $24{ }^{\circ} \mathrm{C}$ around the tube for model D. Finally, one thing we noticed that the temperature inside the tube was same for every model that was exactly $15^{\circ} \mathrm{C}$ after six hours. So, there was no heat loss after six hours inside the tube. 


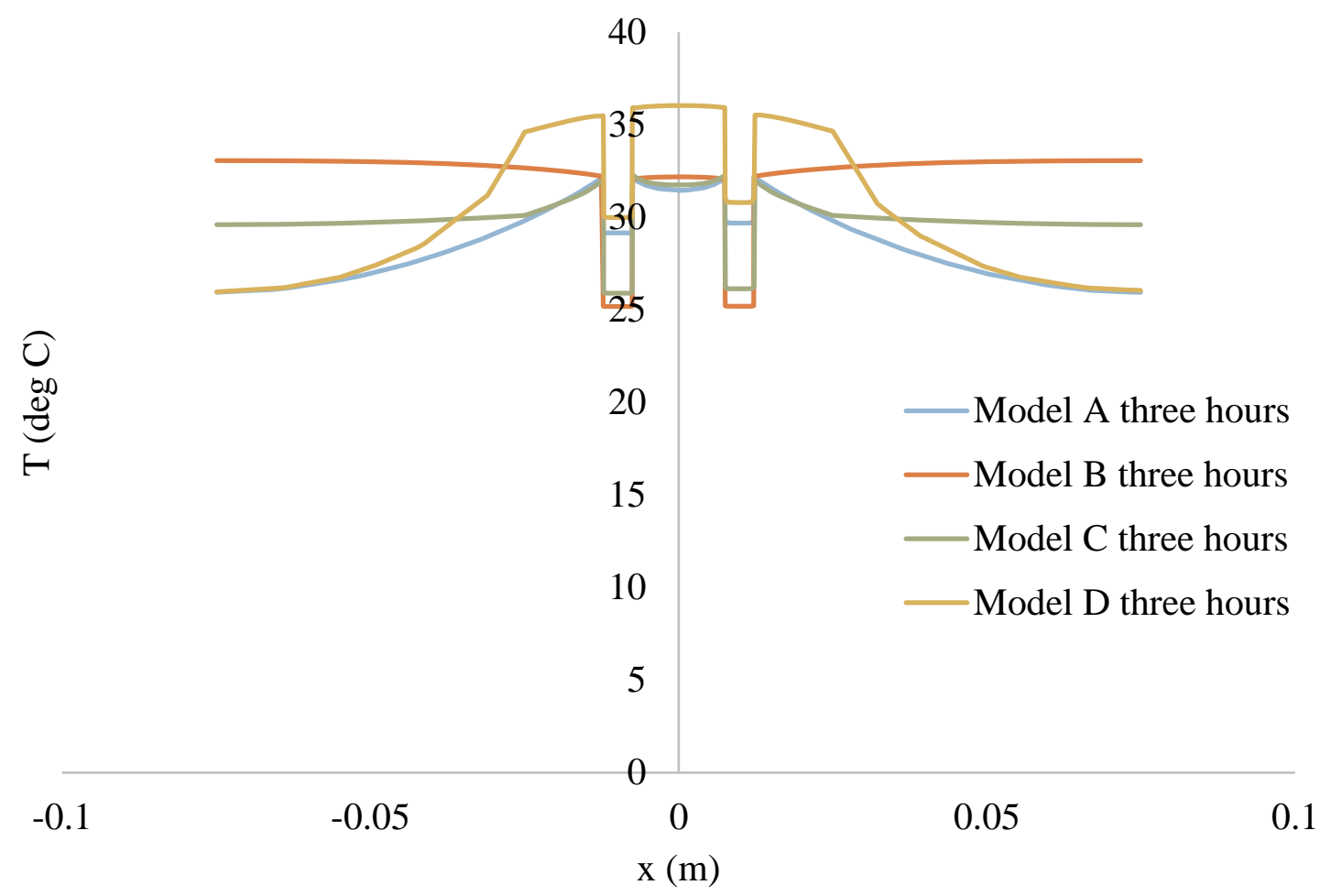

(a) $\mathrm{t}=\mathbf{3}$ hours

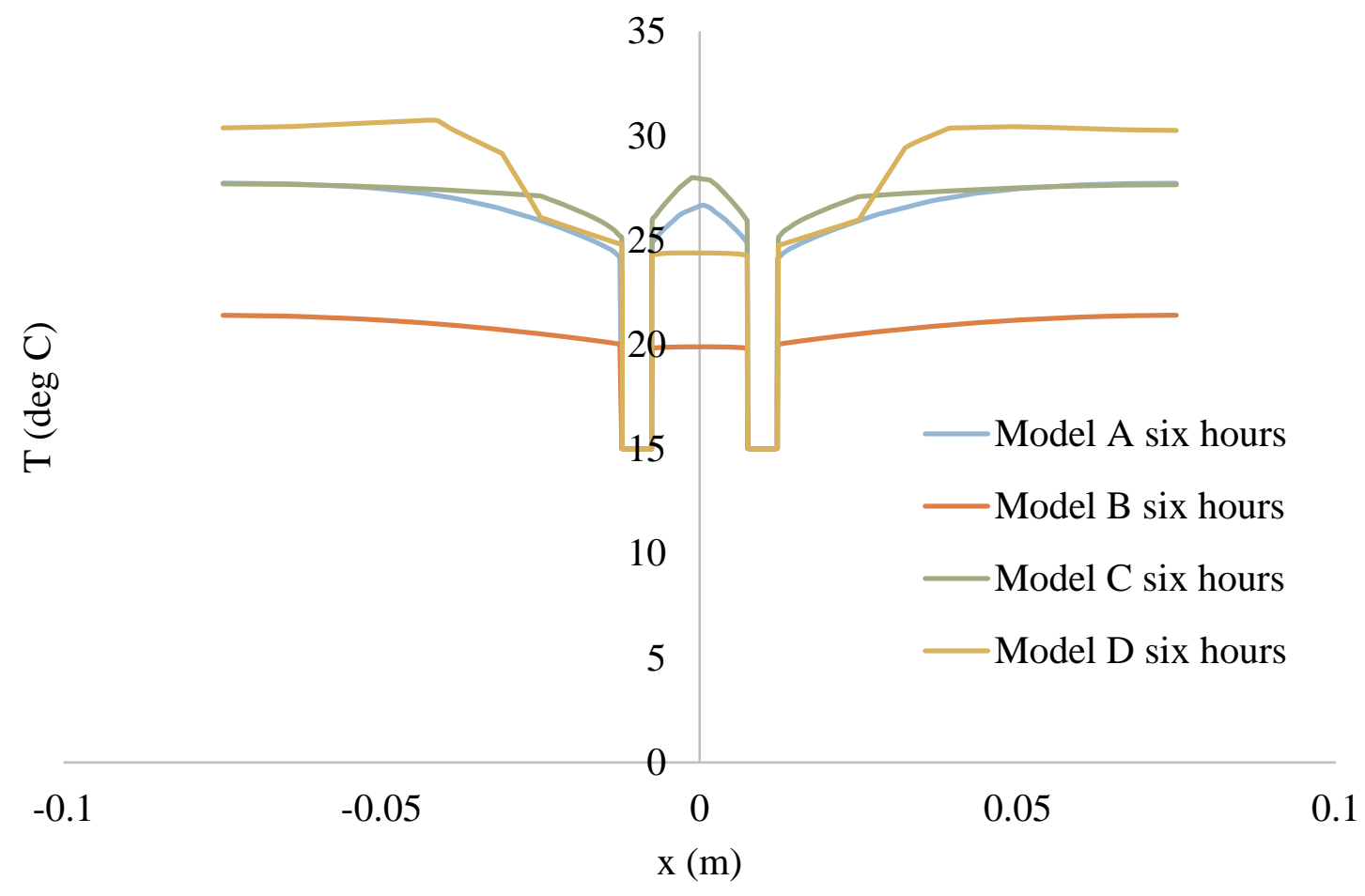

(b) $\mathrm{t}=6$ hours

Figure 3.10: Temperature distributions at $y=0.04741 \mathrm{~m}$ of the cavity along $\mathrm{x}$-axis 


\subsubsection{Surface temperature distributions at $y=\mathbf{- 0 . 0 4 7 4 1} \mathbf{m}$ of the cavity along $x$-axis}

Figure 3.11(a) and 3.11(b) describe the surface temperature distributions in bottom of the rectangular cavity at two different times along the direction of $\mathrm{x}$-axis.

The results revealed that heat transfer rate during the heating was higher in bentonite rather than PCM as shown in figure 3.11(a). For PCM, temperature distributions were not same in everywhere of the cavity. Temperature around the U-shaped tube was approximately $31.5{ }^{\circ} \mathrm{C}$, but, it was decreased drastically near the two side walls just above $25{ }^{\circ} \mathrm{C}$, as shown in model A. However, temperature distributions were linear that means same $32{ }^{\circ} \mathrm{C}$ in everywhere in the cavity when only bentonite has been used, as shown in model B. Surface temperature is reached very high at $37{ }^{\circ} \mathrm{C}$ rather than PCM around the U-shaped tube when bentonite has been used in the middle, and PCM is used around the cavity as shown in model D. However, temperature is reached at $32{ }^{\circ} \mathrm{C}$ around the tube for model $\mathrm{C}$, but near the side walls it is approximately $30^{\circ} \mathrm{C}$. It was clear from the results that for higher thermal conductivity of bentonite, heat transfer rate is higher than the PCM.

Figure 3.11(b) shows that heat transfer rate during the cooling was higher in bentonite rather than PCM. The temperature of model A is decreased from $31.5^{\circ} \mathrm{C}$ to approximately $23{ }^{\circ} \mathrm{C}$ after three hours of cold water supply around the U-shaped tube, but near the wall the temperature was $27{ }^{\circ} \mathrm{C}$. But, for model $\mathrm{B}$, the temperature is decreased significantly from $32{ }^{\circ} \mathrm{C}$ to $20{ }^{\circ} \mathrm{C}$ after three hours of cooling in everywhere of the cavity. Temperature distributions between model $\mathrm{C}$ and model $\mathrm{A}$ is almost the same, little bit variation was observed around the $\mathrm{U}$ - shaped tube. However, in model D temperature around the U-shaped tube decreased from $37{ }^{\circ} \mathrm{C}$ to $24{ }^{\circ} \mathrm{C}$ which was filled by bentonite, but, near the wall it was $30{ }^{\circ} \mathrm{C}$ which was filled with PCM after three hours of cooling.

\subsubsection{Surface temperature distributions of the cavity along $y$-axis}

For the fruitful discussion, five cut line of all four models have been considered along the middle $(x=0 \mathrm{~m})$, two in the left side $(\mathrm{x}=0.02 \mathrm{~m}$ and $\mathrm{x}=0.06 \mathrm{~m})$ and another two in the right side $(\mathrm{x}=-0.02 \mathrm{~m}$ and $\mathrm{x}=-0.06 \mathrm{~m})$ of the cavity in $\mathrm{x}$-axis. Two different timewise data collected and analyzed for all four models A, B, C and D. 


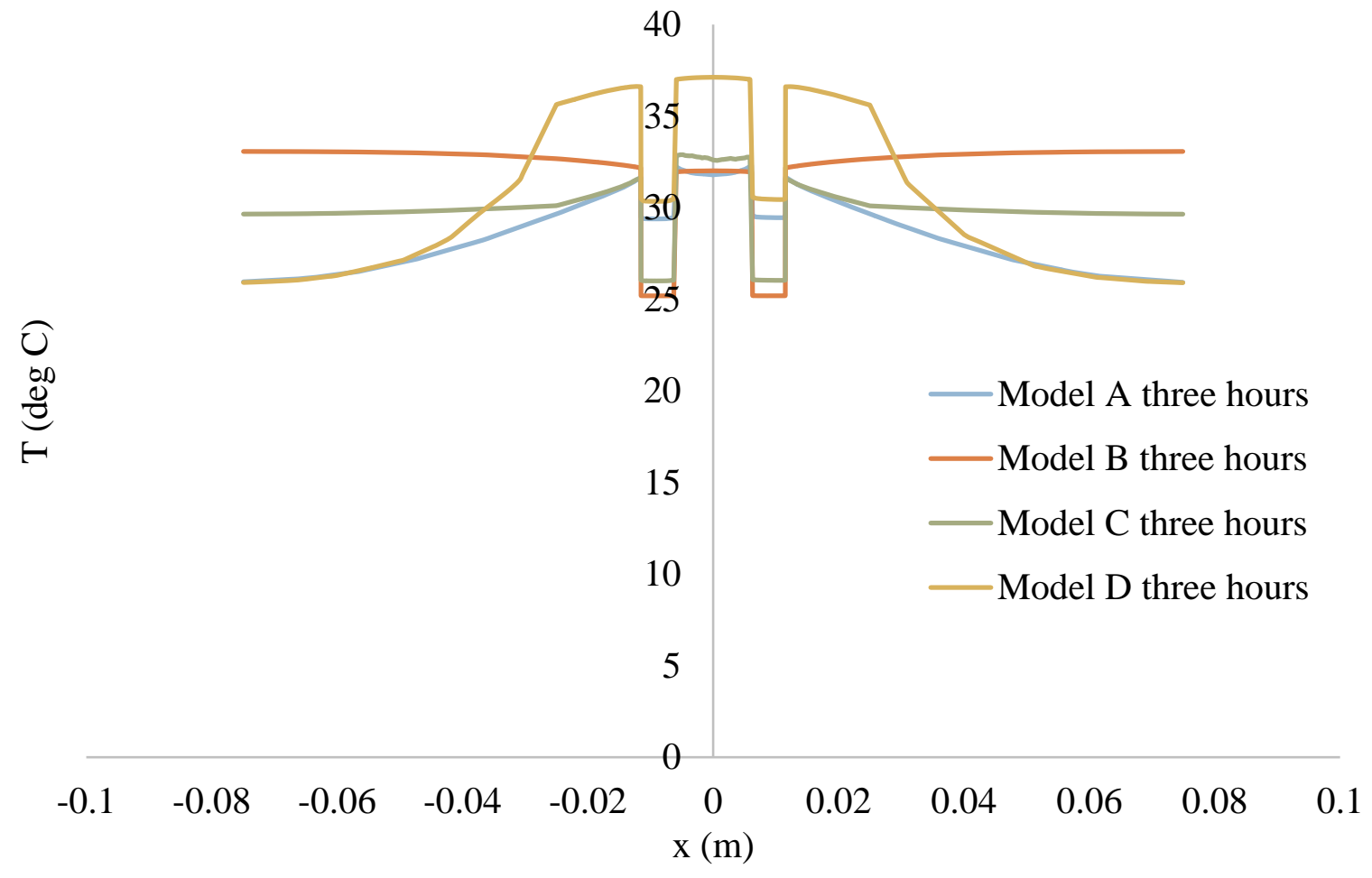

(a) $\mathrm{t}=\mathbf{3}$ hours

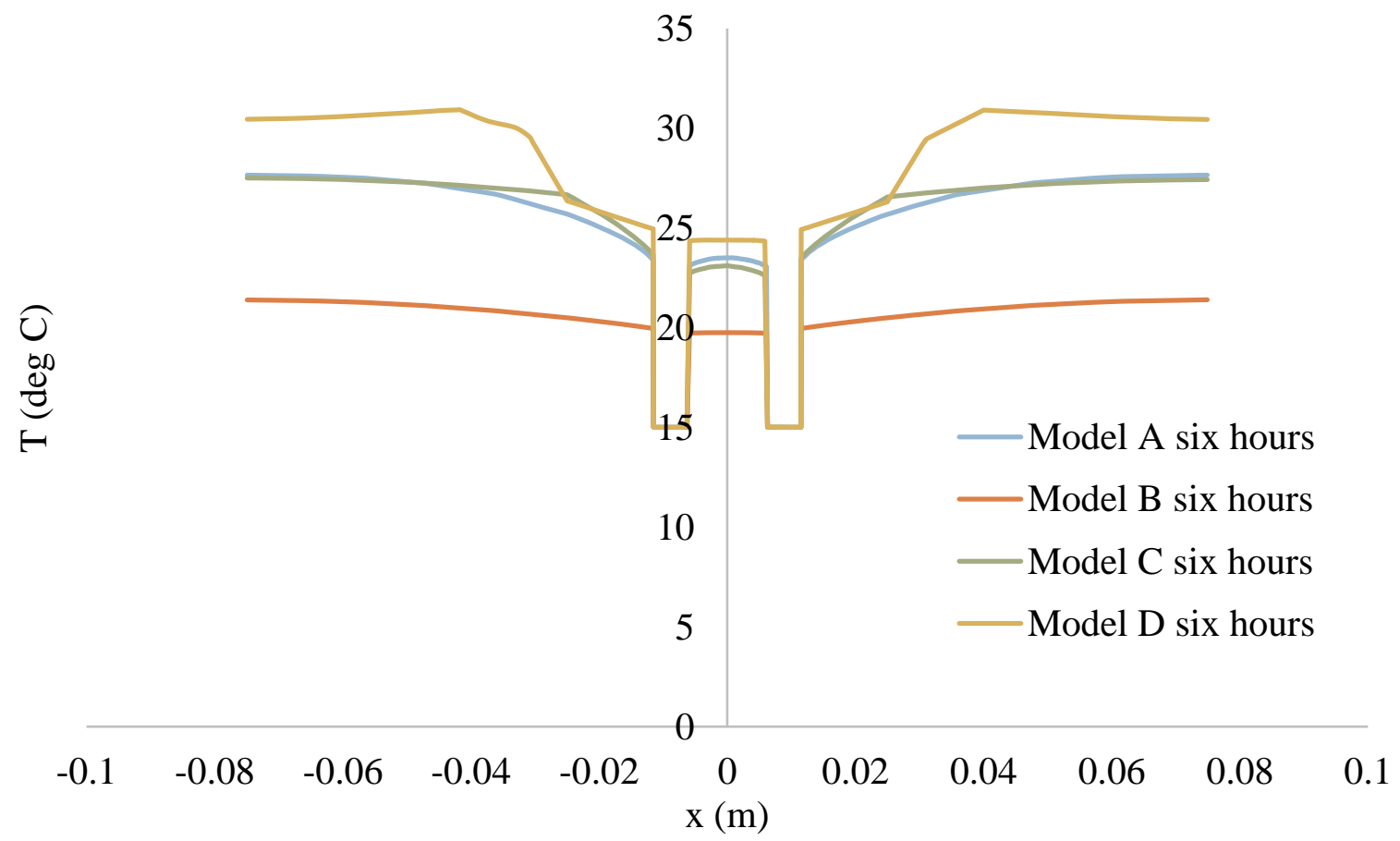

(b) $\mathrm{t}=6$ hours

Figure 3.11: Temperature distributions at $y=\mathbf{- 0 . 0 4 7 4 1} \mathbf{m}$ of the cavity along $\mathrm{x}$-axis 


\subsubsection{Surface temperature distributions at $\mathrm{x}=0 \mathrm{~m}$ of the cavity along $\mathrm{y}$-axis}

Figure 3.12(a) and 3.12(b) illustrates the surface temperature distributions along the direction of y-axis in the middle of the rectangular cavity at two different time.

Figure 3.12(a) shows that the temperature distributions of all four models in the middle of the cavity along y-axis after three hours or after hot water supply. Temperature in model A and model $\mathrm{C}$ were almost same as $31.5^{\circ} \mathrm{C}$ in everywhere except around the tube. This was happened because, for both models PCM were used around the U-shaped tube. Besides, the tube temperature was little bit high in model $\mathrm{C}$ rather than model $\mathrm{A}$, because, in model $\mathrm{C}$ bentonite was outside the U-shaped tube. So, heat transfer rate was little bit high. But, for the model B, temperature was also similar in model $\mathrm{A}$ and $\mathrm{C}$, and it was $32{ }^{\circ} \mathrm{C}$, because in this model only bentonite has been used. However, for model $\mathrm{D}$, temperature reached at $36{ }^{\circ} \mathrm{C}$ that is higher than other models. Because, bentonite has been used around the tube and PCM has been used near the side walls. So, the temperature gradient was much higher near the tube.

Figure 3.12(b) shows that at six hours, that means after cooling, model B and model D cooled down sharply and the temperature was linear in the middle of the cavity. That was happened because of using bentonite. The temperature of model B was $20{ }^{\circ} \mathrm{C}$ and for model $\mathrm{D}$ temperature was $24{ }^{\circ} \mathrm{C}$. However, the temperature for model A and model $\mathrm{C}$ was not linear and they did not fall like model B and D. The main cause of it was that, PCM have low heat capacity. So, it was consuming more time to cooling down and, the line graph was like curve shaped.

\subsubsection{Surface temperature distributions at $x=0.02 \mathrm{~m}$ of the cavity along $y$-axis}

Figure 3.13(a) and 3.13(b) illustrates the surface temperature distributions along the direction of $y$-axis at the position of $x=0.02 \mathrm{~m}$ of the rectangular cavity at two different time steps.

In this study, figure 3.13(a) shows that the surface temperature distributions of all four models at $\mathrm{x}=0.02 \mathrm{~m}$ of cavity along $\mathrm{y}$-axis at three hours or after hot water supply. Temperature in model $\mathrm{A}$ and model $\mathrm{C}$, were almost the same as below $31^{\circ} \mathrm{C}$ in everywhere, except lower portion of the tube. This was happened because, for both models, PCM were used around the Ushaped tube. Besides, the tube temperature was little bit high in model $\mathrm{C}$ rather than model $\mathrm{A}$, because in model $\mathrm{C}$ bentonite was outside the $\mathrm{U}$-shaped tube, so heat transfer rate was little bit high. For model B, temperature was linear everywhere and it was $32.5^{\circ} \mathrm{C}$. However, in model D, 


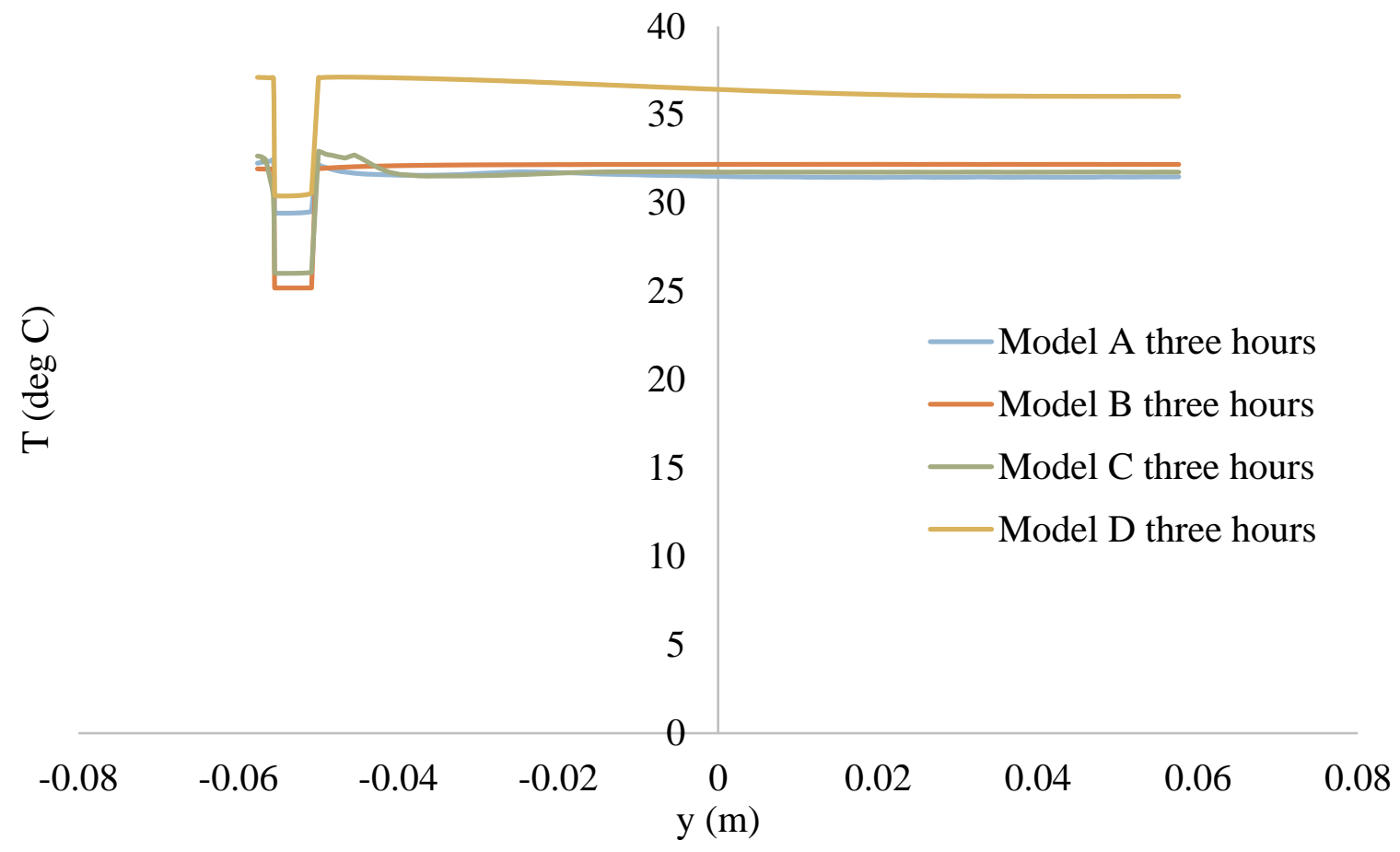

(a) $\mathrm{t}=\mathbf{3}$ hours

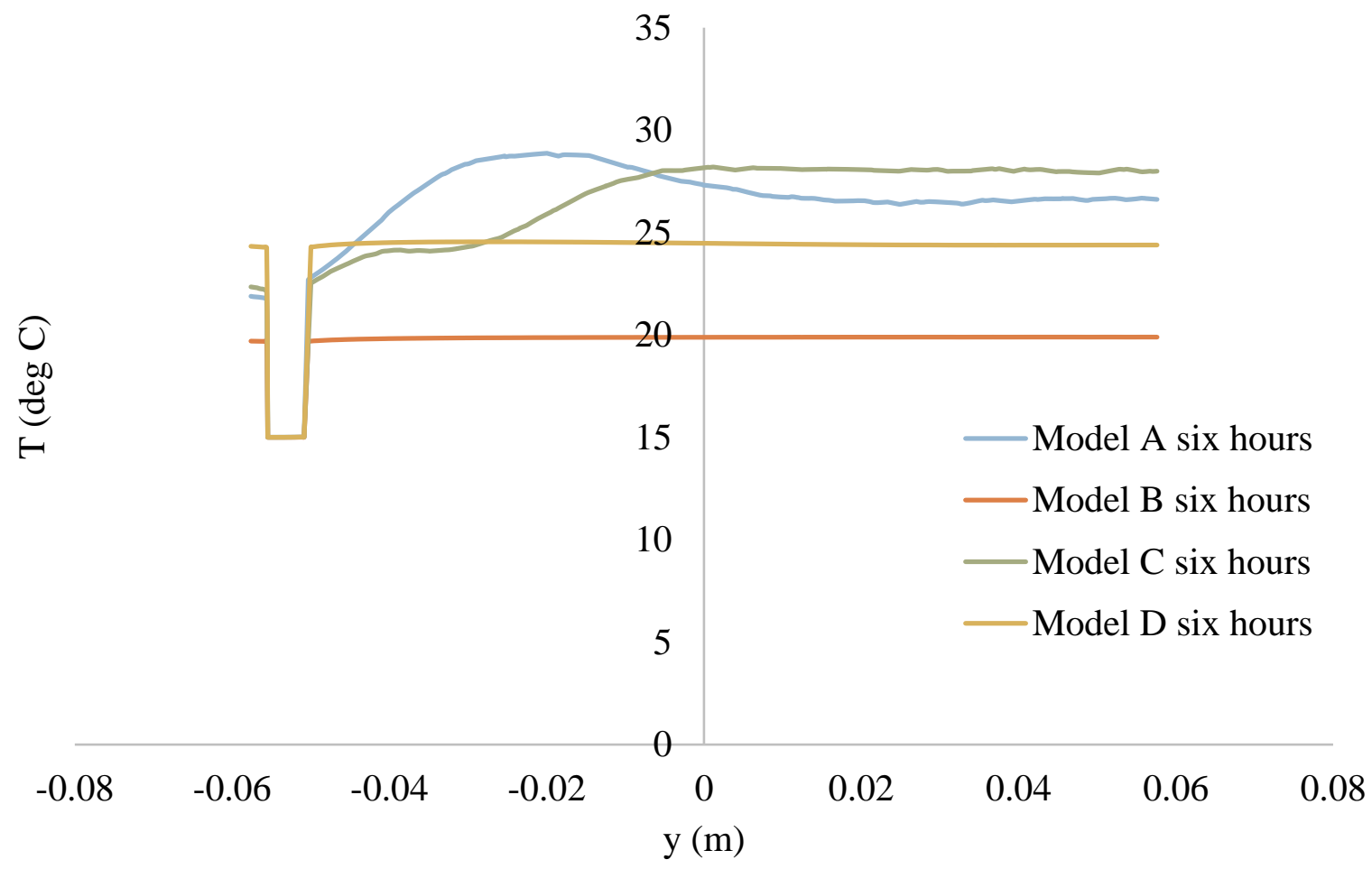

(b) $\mathrm{t}=6$ hours

Figure 3.12: Temperature distributions at $x=0 \mathrm{~m}$ of the cavity along $y$-axis 


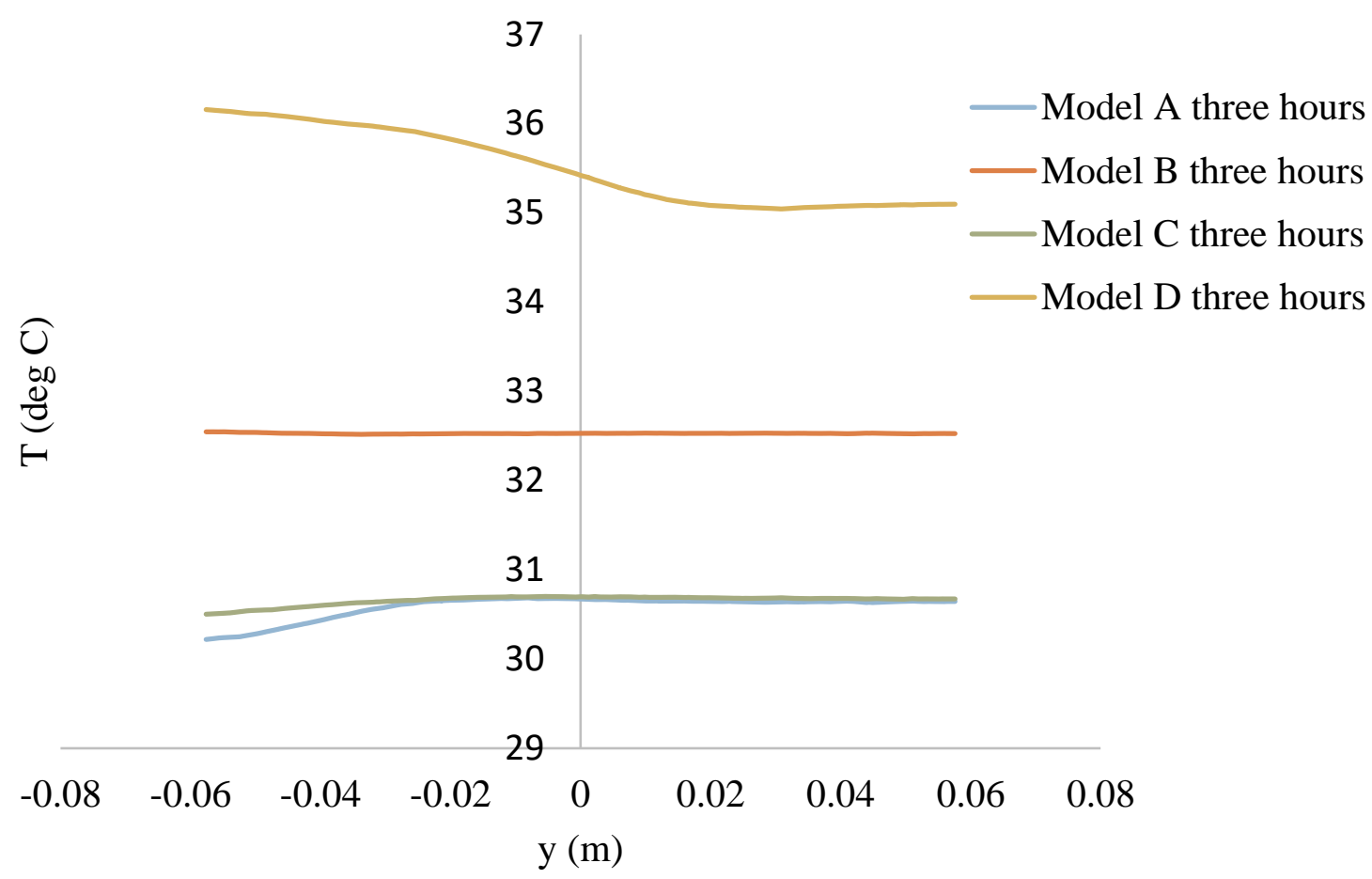

(a) $\mathbf{t}=\mathbf{3}$ hours

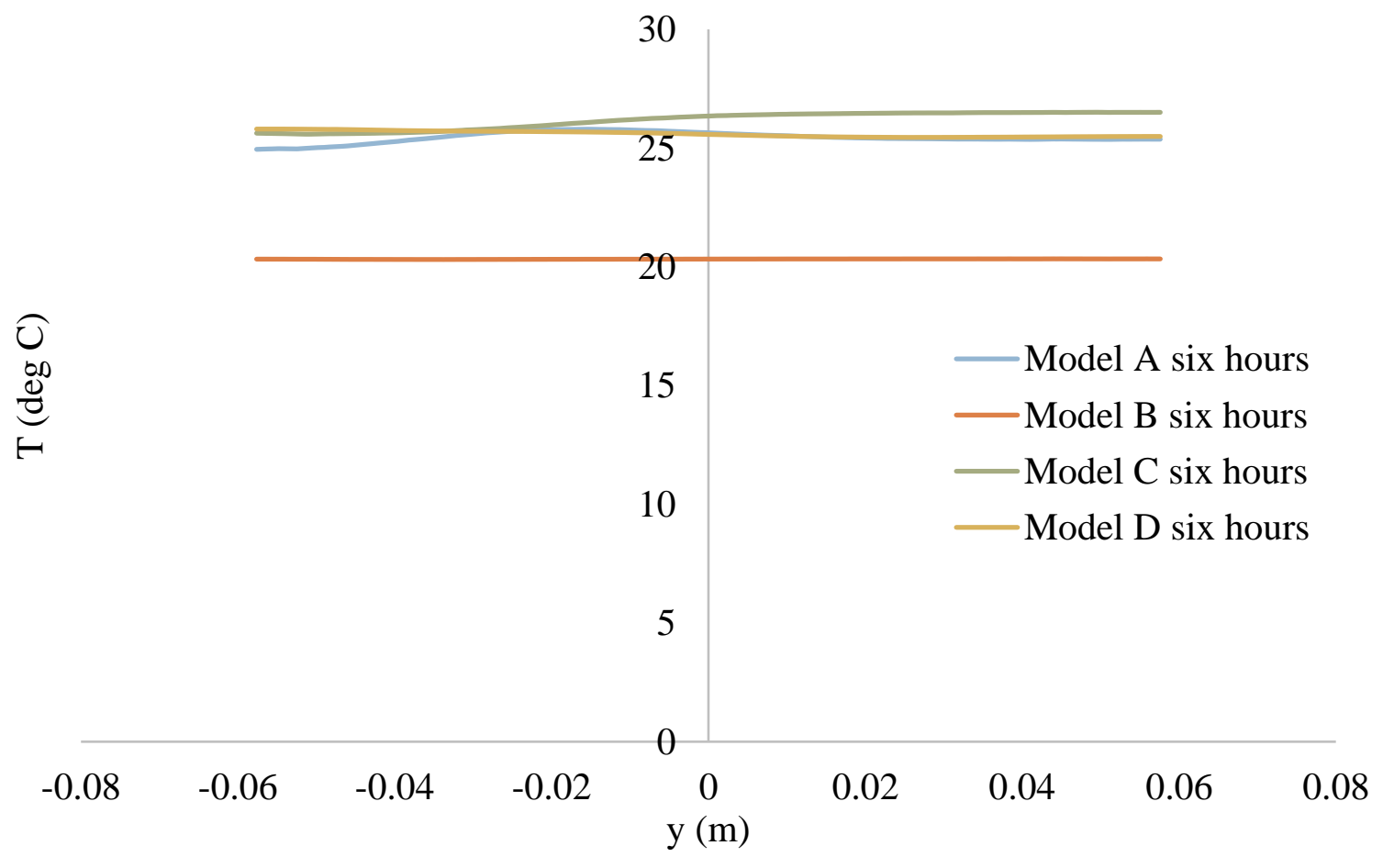

(b) $\mathrm{t}=6$ hours

Figure 3.13: Temperature distributions at $x=0.02 \mathrm{~m}$ of the cavity along $y$-axis 
temperature was approximately $35^{\circ} \mathrm{C}$ on top of the cavity, but, at the bottom of the cavity it was around $36{ }^{\circ} \mathrm{C}$.

The results revealed that heat transfer rate during cooling was higher in bentonite rather than PCM as shown in figure 3.13(b). The surface temperature in model A, C and D are almost same approximately $26^{\circ} \mathrm{C}$ after six hours or after cooling, except model B which is $20{ }^{\circ} \mathrm{C}$. The reason of low temperature of model B is that only bentonite was used, and rest of the model was fully PCM or mixed of PCM. Though, the temperature gradient of bentonite is higher than the PCM, model B cooled sharply rather than other three models.

\subsubsection{Surface temperature distributions at $\mathrm{x}=0.06 \mathrm{~m}$ of the cavity along $\mathrm{y}$-axis}

Figure 3.14(a) and 3.14(b) illustrates the surface temperature distributions along the direction of $\mathrm{y}$-axis at $\mathrm{x}=0.06 \mathrm{~m}$ of the rectangular cavity at two different time steps.

Figure 3.14(a) shows that the surface temperature distributions of all four models at the time of three hours at the position of $\mathrm{x}=0.06 \mathrm{~m}$ of the cavity along $\mathrm{y}$-axis. At $\mathrm{x}=0.06 \mathrm{~m}$ of the cavity means, it was too far from the heating source. So, generally temperature of this position was less than near the heating source. For model A and model D, where most part of the cavity has been used PCM, temperature shows here at $26^{\circ} \mathrm{C}$, but in model $\mathrm{C}$ it is little bit high around $30{ }^{\circ} \mathrm{C}$ than model A and D. Because, in model C most part of the cavity was filled with bentonite and little bit of PCM. However, in model B where the cavity was filled with bentonite only, temperature was too high at $33{ }^{\circ} \mathrm{C}$. It was the effect of clear reflection of higher thermal conductivity of bentonite.

The results revealed that heat transfer during the cooling of all four models at six hours in $\mathrm{x}=$ $0.06 \mathrm{~m}$ of the cavity along $\mathrm{y}$-axis as shown in figure 3.14(b). The temperature approximately 21 ${ }^{\circ} \mathrm{C}$ of the model $\mathrm{B}$, that was decreased dramatically because only bentonite has been used in Model A, and model $\mathrm{C}$ shows their temperature around $27.5^{\circ} \mathrm{C}$, because model A was filled with PCM only, and model C was almost filled with PCM. So, it was taking more time to cooling rather than model B. Finally, model D showed higher temperature just above $30{ }^{\circ} \mathrm{C}$. Because, in model D, PCM has been used around the tube and bentonite has been used near the two side walls. Though, the thermal conductivity of PCM is low, it was impossible to cool down the bentonite near the walls within short time period. 


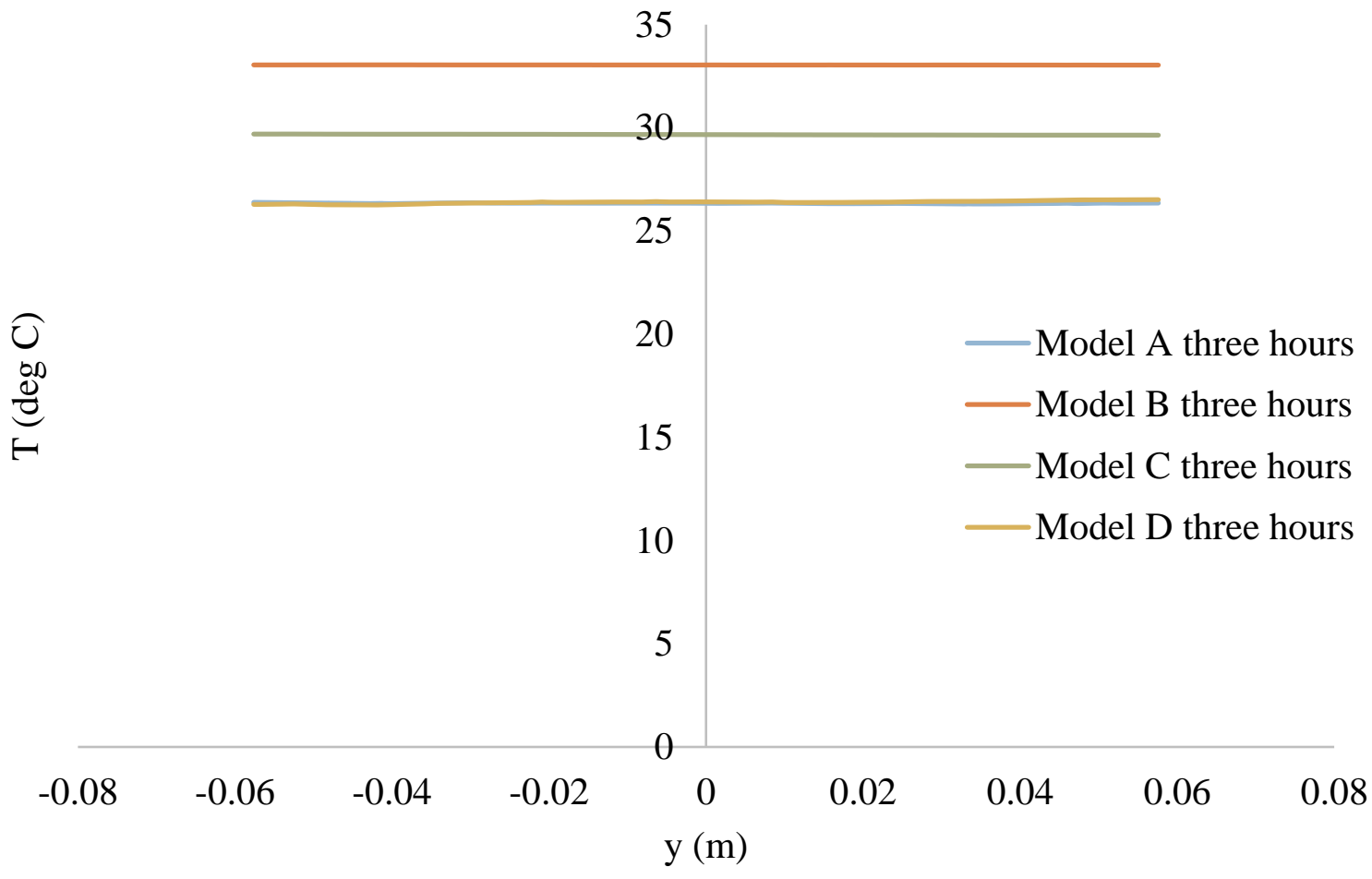

(a) $\mathrm{t}=\mathbf{3}$ hours

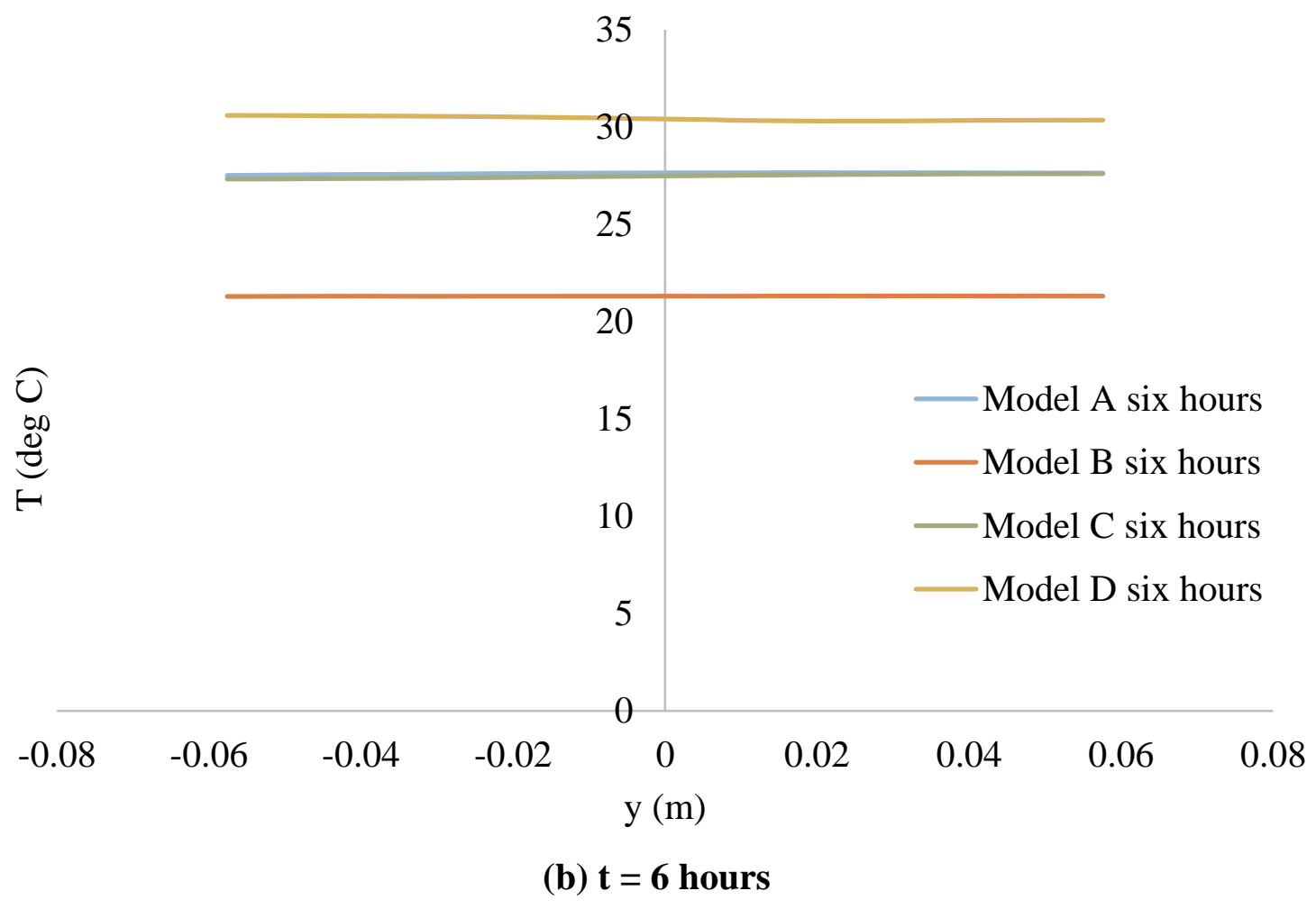

Figure 3.14: Temperature distributions at $x=0.06 \mathrm{~m}$ of the cavity along $\mathrm{y}$-axis 


\subsubsection{Surface temperature distributions at $x=\mathbf{- 0 . 0 2} \mathbf{m}$ of the cavity along $y$-axis}

Figure 3.15(a) and 3.15(b) illustrates the surface temperature distributions along the direction of $\mathrm{y}$-axis at $\mathrm{x}=-0.02 \mathrm{~m}$ of the rectangular cavity at two different time steps.

Figure 3.15(a) shows that the surface temperature distributions of all four models at $x=-0.02$ $\mathrm{m}$ of cavity along $\mathrm{y}$-axis at three hours or after hot water supply. Temperature in model $\mathrm{A}$ and model $\mathrm{C}$, were almost same as below $31{ }^{\circ} \mathrm{C}$ in everywhere, except lower part of the tube. This was happened because, for both models PCM were used around the U-shaped tube. Besides, the tube temperature was little bit high in model $\mathrm{C}$ rather than model $\mathrm{A}$, because in model $\mathrm{C}$ bentonite was around the $\mathrm{U}$-shaped tube, so, heat transfer rate was little bit high. For model B, temperature was linear everywhere and, it was at $32.5{ }^{\circ} \mathrm{C}$. But, in model $\mathrm{D}$, temperature was approximately $35^{\circ} \mathrm{C}$ on top of the cavity, but at the bottom it was around $36{ }^{\circ} \mathrm{C}$.

In this study, heat transfer rate during cooling is higher in bentonite rather than PCM as shown in figure 3.15(b). The surface temperatures in model A, C and D are almost same between $25{ }^{\circ} \mathrm{C}$ to $26{ }^{\circ} \mathrm{C}$ after six hours or after cooling, except model B which is $20{ }^{\circ} \mathrm{C}$. The reason for low temperature in model B is that only bentonite has been used and, in the rest of the model was fully PCM or partial PCM. Though, the temperature gradient of bentonite is higher than the PCM, so model B cooled sharply than the other three models.

\subsubsection{Surface temperature distributions at $\mathbf{x}=\mathbf{- 0 . 0 6} \mathbf{m}$ of the cavity along $\mathbf{y}$-axis}

Figure 3.16(a) and 3.16(b) illustrates the surface temperature distributions along the direction of $\mathrm{y}$-axis at $\mathrm{x}=-0.06 \mathrm{~m}$ of the rectangular cavity at two different time steps.

Figure 3.16(a) revealed the surface temperature distributions of all four models at three hours at the position of $x=-0.06 \mathrm{~m}$ of the cavity along $\mathrm{y}$-axis. At $\mathrm{x}=-0.06 \mathrm{~m}$ of the cavity that means it was too far from the heating source and near the side wall. So, generally temperature of this point was less than near the heating source. For model A and model D, where most part of the cavity was filled up by PCM, temperature shows here $26^{\circ} \mathrm{C}$, however, in model C, it was little bit more around $30{ }^{\circ} \mathrm{C}$ than model $\mathrm{A}$ and $\mathrm{D}$. Because, in model $\mathrm{C}$ most part of the cavity was filled with bentonite and little bit of PCM was used. However, in model B where the cavity was filled with bentonite, temperature was too high (above $33{ }^{\circ} \mathrm{C}$ ). It is the clear reflection of higher thermal conductivity of bentonite. 


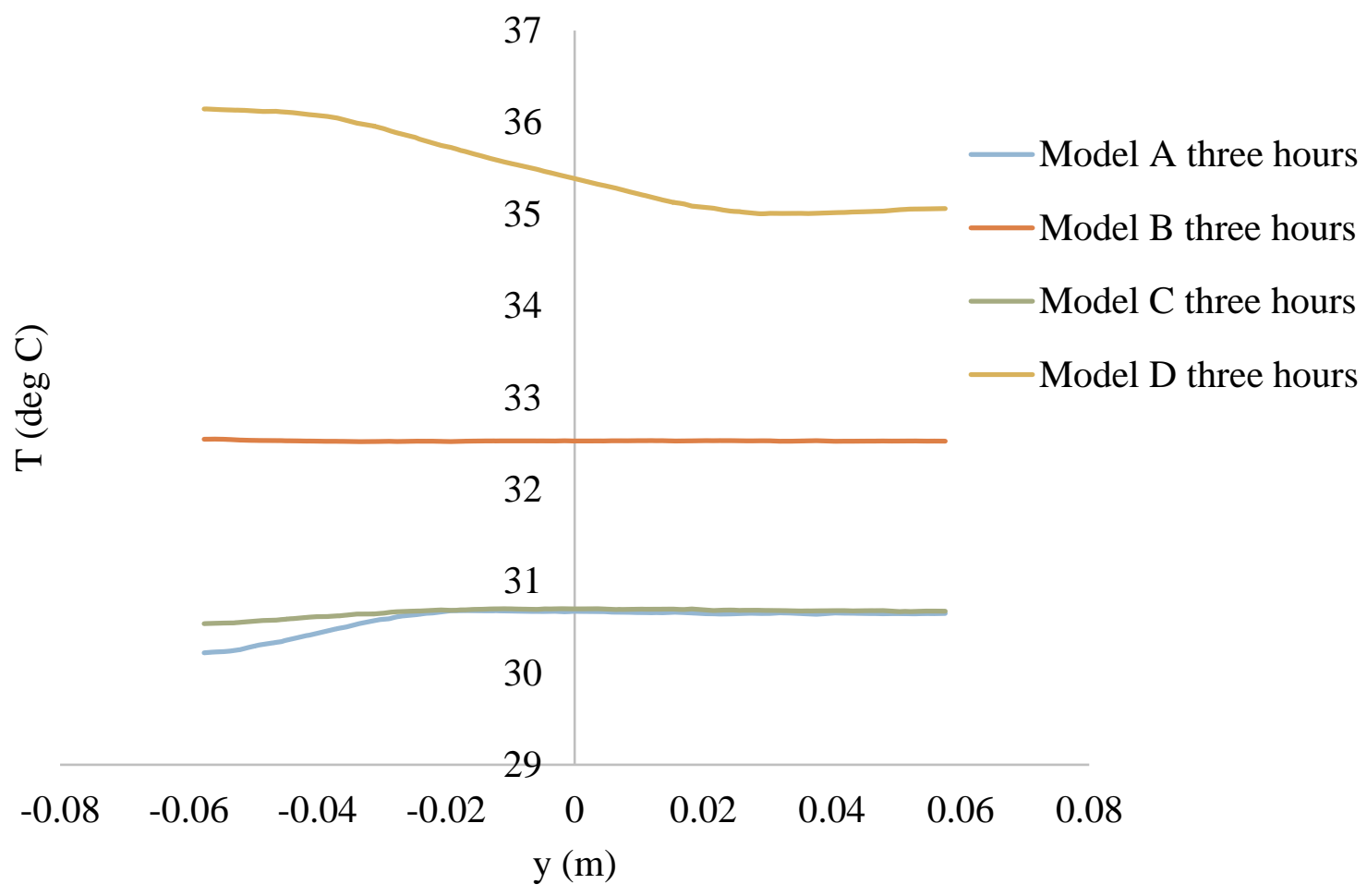

(a) $\mathbf{t}=\mathbf{3}$ hours

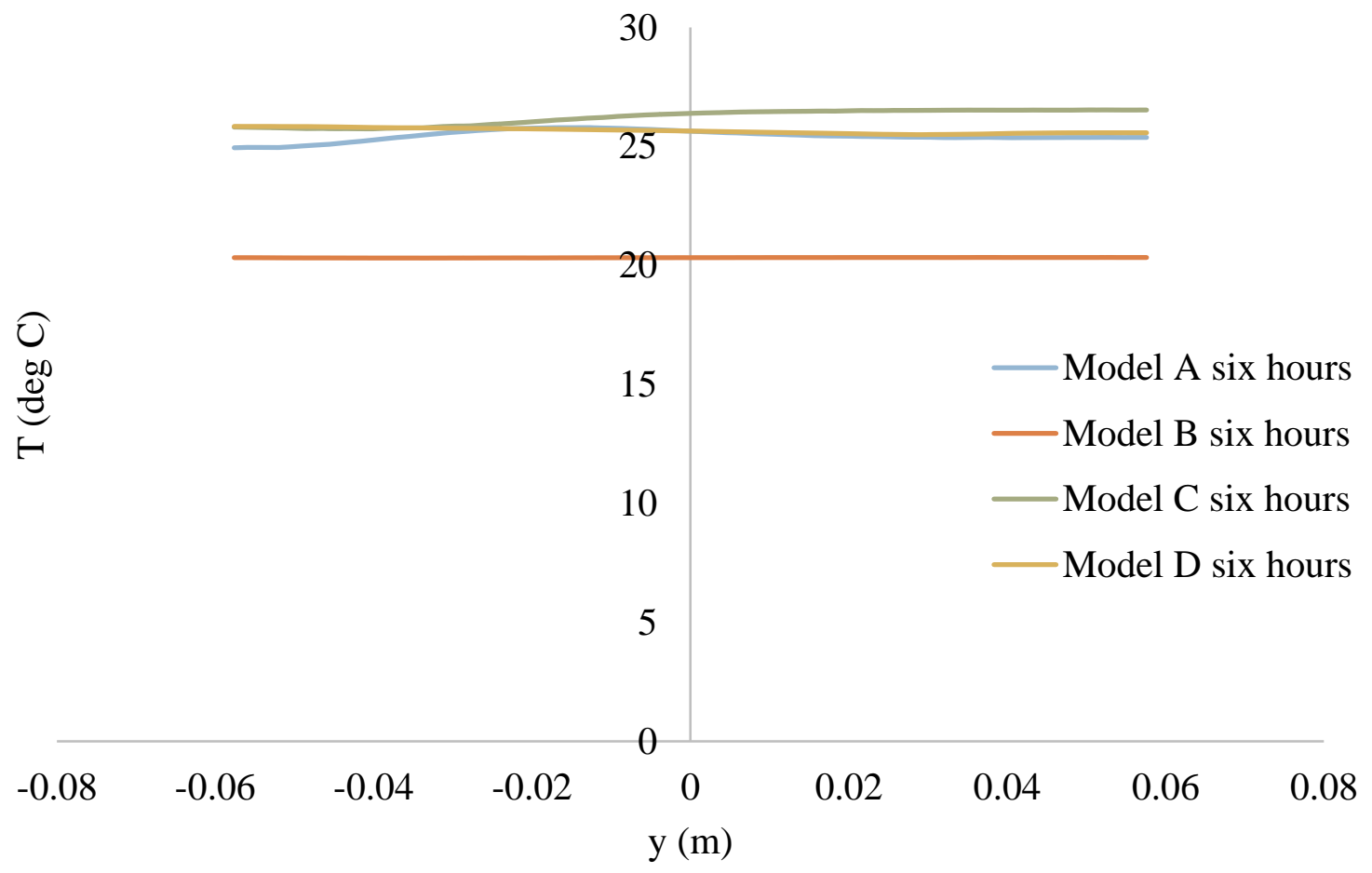

(b) $\mathbf{t}=\mathbf{6}$ hours

Figure 3.15: Temperature distributions at $x=\mathbf{- 0 . 0 2} \mathrm{m}$ of the cavity along $\mathrm{y}$-axis 


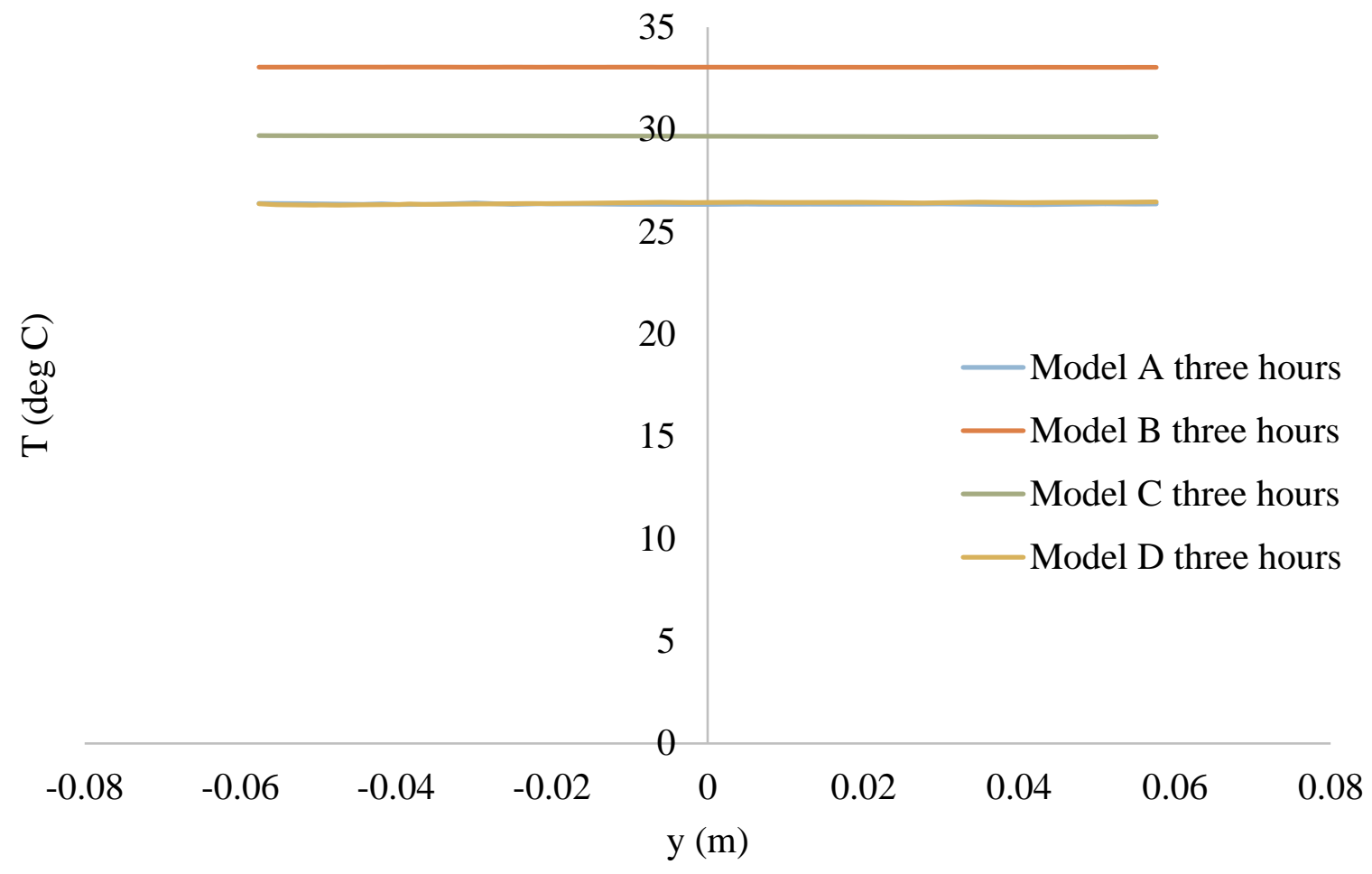

(a) $\mathbf{t}=\mathbf{3}$ hours

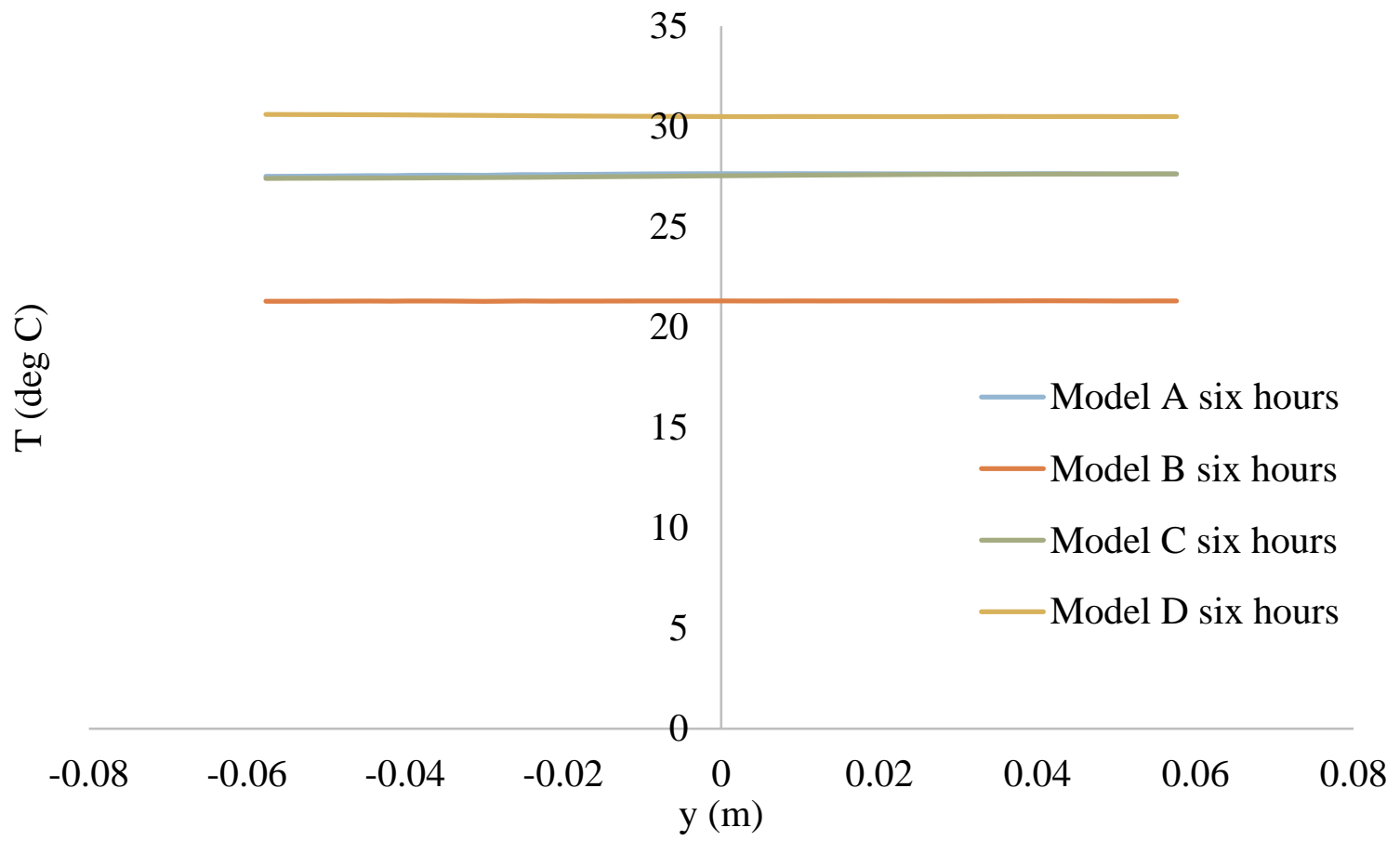

(b) $\mathrm{t}=6$ hours

Figure 3.16: Temperature distributions at $x=-\mathbf{- 0 . 0 6} \mathbf{m}$ of the cavity along $y$-axis 
In this study, heat transfer during the cooling of all four models at six hours at $\mathrm{x}=-0.06 \mathrm{~m}$ of the cavity along $\mathrm{y}$-axis is shown in figure 3.16(b). The temperature approximately $21{ }^{\circ} \mathrm{C}$ in model B which has decreased drastically because, only bentonite has been used. Model A and model $\mathrm{C}$ shows the temperatures around $27.5^{\circ} \mathrm{C}$ because model A was filled up by PCM only, and model $\mathrm{C}$ was almost filled up by PCM. So, it was taking more time to cooling down rather than model B. Finally, model D shows higher temperature just above $30{ }^{\circ} \mathrm{C}$. Because, in model D, PCM has been used around the tube and bentonite has been used near the two side walls. Though, the thermal conductivity of PCM was low, so it was impossible to cool down the bentonite near the walls within short time period.

\subsection{Heat Transfer Rate Analysis}

Heat transfer is the process of heat from one place to another by the movement of fluids. Bulk motion of fluid enhances heat transfer in many physical situations, between a solid surface and the fluid. Convection is usually the dominant form of heat transfer in fluids.

The heat transfer rate $(\mathrm{Q})$ of a cavity is related to mass flow rate $\left(\mathrm{m}^{\circ}\right)$, heat capacity $\left(\mathrm{c}_{\mathrm{p}}\right)$ and temperature different $(\Delta \mathrm{T})$. The heat transfer rate was calculated from the following equation:

$$
\mathrm{Q}=\mathrm{m}^{\mathrm{o} *} \mathrm{c}_{\mathrm{p}} * \Delta \mathrm{T}
$$

The mass flow rate assumed, $\mathrm{m}^{\circ}=\rho \mathrm{VA}$, where, $\rho=$ density of water, $\mathrm{V}=$ velocity of water and $\mathrm{A}=$ area of the tube.

In this study, it has been examined that how much energy supplied $\left(Q_{S}\right)$, and how much energy absorbed $\left(Q_{A}\right)$ from the cavity after six hours in all four models are shows in table 3 . First three hours, hot water flowing through the U-shaped tube that means the total amount of heat supplied is $Q_{S}$ which is the inlet temperature. Last three hours, cold water flowing through the U-shaped tube that means the total amount of heat extracted from the PCM is $Q_{A}$ which is surface average temperature inside the cavity given by COMSOL Multiphysics. The amount of heat supplied is greater than the amount of heat extracted from the cavity because, still there were some heat in the PCM and Bentonite. The efficiency is calculated for each model and shows in table 3.

Table 3.1 shows that the slope of efficiency is higher in model $\mathrm{C}$ which is $83 \%$, than in model A which is $68 \%$, in model B which is $55 \%$, and finally in model D which is $33 \%$ 
respectively. The reason of it is that the heat capacity is higher and thermal conductivity is lower in PCM. However, in Bentonite heat capacity is low and thermal conductivity is higher. In model A, entire cavity is filled with PCM, so it stores huge amounts of heat and releases large amount of heat when heat was extracted. In model C, heat source was surrounded by PCM and Bentonite was in the outside. So, during the time of heat absorption, it releases all the heat from PCM because heat source and PCM were too close to each other. That is why the efficiency of model $\mathrm{C}$ is higher than any models. In model B and model D efficiencies are too low. Because model B filled with Bentonite only, and heat source was surrounded by Bentonite and outside of the cavity filled with PCM in model D.

Table 3.1: Total heat transfer analysis

\begin{tabular}{|c|c|c|c|}
\hline Model & $\begin{array}{c}\text { Heat supplied } \\
\mathbf{Q}_{\mathbf{S}}\left(\mathbf{W} / \mathbf{m}^{2}\right) .\end{array}$ & $\begin{array}{c}\text { Heat Extracted } \mathbf{Q}_{\mathbf{A}} \\
\left(\mathbf{W} / \mathbf{m}^{\mathbf{2}}\right) .\end{array}$ & $\begin{array}{c}\text { Efficiency } \\
\frac{\mathbf{Q}_{\mathbf{A}}}{\mathbf{Q}_{\mathbf{S}}} * \mathbf{1 0 0 \%}\end{array}$ \\
\hline Model A & 10472.48 & 7130.73 & 68 \\
\hline Model B & 127845.9 & 70916.4 & 55 \\
\hline Model C & 6246.63 & 5159.19 & 83 \\
\hline Model D & 4991.65 & 1665.72 & 33 \\
\hline
\end{tabular}

\subsection{Summary}

From the results and discussion of this chapter summaries are:

(a) temperature of PCM is higher near the heating source rather than two side walls, because PCM does not have the ability to pass the heat quickly in the cavity for its low thermal conductivity.

(b) PCM can absorbed and supply significant amount of heat because of its higher heat capacity.

(c) PCM can provide significant amount of heat from its total absorbing heat.

(d) Bentonite is more delicate in both cases rather than PCM in a rectangular cavity for its higher thermal conductivity and low heat capacity, during heating and cooling conditions.

(e) Bentonite is good as an insulator in thermal storage media. 


\section{CHAPTER 4 - CONCLUSIONS AND FUTURE WORK}

\subsection{Conclusion}

This experimental and numerical study was conducted to investigate a time-depended heat transfer process during the process of solid-liquid interface of the PCM inside the rectangular cavity, a U-shaped heat source embedded in it. The temperature fields, and the thermal behavior of PCM were recorded via thermocouples, and data acquisition system. The presented results showed that the geometry of the heating source has a great effect on the melting behavior of PCM as well as the melting period. In the case one, temperature around the U-shaped tube was reached above $36{ }^{\circ} \mathrm{C}$, which is close to the inlet temperature $39^{\circ} \mathrm{C}$. However, with the increasing of distance from the heat source which is near the cavity side walls, the highest temperature was observed to $28{ }^{\circ} \mathrm{C}$. So, it is clear from the results that heating source position has a significant role on heat transfer rate in a thermally insulated cavity. In the case two, when hot water was flowing through U-shaped tube, temperature was $32{ }^{\circ} \mathrm{C}$ in everywhere of the cavity in model B. But, in model A, temperature around the U-shaped tube was approximately $31.5^{\circ} \mathrm{C}$. However, it decreased dramatically near the two side walls just above $25^{\circ} \mathrm{C}$. In model $\mathrm{C}$, temperature around the heat source was $32{ }^{\circ} \mathrm{C}$, however, near the two side walls it was $30{ }^{\circ} \mathrm{C}$. Surface temperature reached very high at $36{ }^{\circ} \mathrm{C}$ around the U-shaped heat source in model $\mathrm{D}$, and near the two side walls it was the same as model A. However, when cold water flowing through the tube, the temperature of model $\mathrm{A}$ is decreased from $31.5{ }^{\circ} \mathrm{C}$ to approximately $27{ }^{\circ} \mathrm{C}$. In model $\mathrm{B}$, the temperature decreased significantly from $32{ }^{\circ} \mathrm{C}$ to $20^{\circ} \mathrm{C}$. Model $\mathrm{C}$ and model A was almost the same in everywhere of the cavity. In model D, temperature around the U-shaped tube was decreased from $36{ }^{\circ} \mathrm{C}$ to $24{ }^{\circ} \mathrm{C}$, however, near the two side walls it was $30{ }^{\circ} \mathrm{C}$. So, it is clear from the results that bentonite is more sensitive to temperature variation in a cavity rather than PCM because of higher thermal conductivity, and higher temperature gradient of bentonite. 


\subsection{Contributions}

Based on the results and conclusions presented above, the contributions of the current study are as follows:

(a) A comprehensive study of the thermal behavior and heat transfer characteristics of the rectangular cavity filled with PCM subjected to a laminar flow has been done.

(b) A comprehensive study of the thermal behavior and heat transfer characteristics of the rectangular cavity filled with PCM, Bentonite and the combination of both subjected to a laminar flow has been done.

(c) A study of the effect of a flowing of HTF through the U-Shaped tube in the cavity surface temperature uniformity and heat transfer rate has been presented.

(d) A comparison of the thermal performance of difference conditions and materials has been presented.

(e) A study of the heat transfer characteristics of PCM and Bentonite under heating and cooling conditions has been conducted. 


\subsection{Future works}

The following are the areas which were not addressed by this study and are suggested for future research:

(a) Nanofluid would be a good option for effective as a flowing HTF through the U-shaped tube for significant heat transfer in the rectangular cavity for its higher thermal conductivity.

(b) Air can be tested as a flowing HTF through the U-shaped tube of the rectangular cavity.

(c) Also, it would be interesting that rectangular cavity filled with fully or mixture of bentonite, sand and concrete. That could be simulated and validated between experimental and numerical models.

(d) Rectangular cavity filled with MEPCM and heated it up would be a best option to verify with experimental and numerical works. 


\section{Bibliography}

[1] C.J. Ho, C.Chen and W. Yan, "Experimental and numerical study on transient thermal energy storage of micoencapsulated phase change material particles in an enclosure," International Journal of Heat and Mass Transfer, vol. 94, pp. 191-198, 2016.

[2] C.J. Ho, J.B. Huang, P.S. Tsai and Y.M. Yang, "Water-based suspensions of Al2O3 nanoparticles and MEPCM particles on convection effectivness in a circular tube," International Journal of Thermal Science, vol. 50, pp. 736-748, 2011.

[3] C.J. Ho, J.B. Huang, P.S. Tsai and Y.M. Yang, "Preparetion and properties of hybrid waterbased suspension of $\mathrm{Al} 2 \mathrm{O} 3$ nanoparticles and MEPCM particles as functional forced convection fluid," International Communications in Heat and Mass Transfer, vol. 37, pp. 490-494, 2010.

[4] M. Goel, S.K. Roy and S. Sengupta, "Laminar forced convection heat transfer in microcapsulated phase change material suspensions," International Journal of Heat and Mass Transfer, vol. 37, pp. 593-604, 1994.

[5] C.J. Ho, J.F. Lin and S.Y. Chiu, "Heat transfer of solid-liquid phase-change material suspensions in circular pipes: Effects of wall condition," Numerical Heat Transfer, vol. 45, pp. 171-190, 2004.

[6] B. Chen, X. Wang, R. Zeng, Y. Zhang, X. Wang, J. Niu, Y. Li and H Di, "An experimental study of convective heat transfer with microencapsulated phase change material suspension: Laminar flow in a circular tube under constant heat flux," Experimental Thermal and Fluid Science, vol. 32, pp. 1638-1646, 2008.

[7] M. Sabour, M. Ghalambaz and A. Chamkha., "Natural convection of nanofluids in a cavity: criteria for enhancement of nanofluids.," International Journal of Numerical Methods for Heat \& Fluid Flow, vol. 27, pp. 1504-1534, 2017.

[8] A. Rahman, A. D. Smith and N. Fumo., "Performance modeling and parametric study of a stratified water thermal storage tank.," Applied Thermal Engineering, vol. 100, pp. 668-679, 2016.

[9] W. Yaici, M. Ghorab, E. Entchev and S. Hayden., "Three-dimensional unsteady CFD 
simulation of a thermal storage tank performance for optimum design.," Appplied thermal Engineering, vol. 60, pp. 152-163, 2013.

[10] K. H. Kim and C. H. Han, "Thermal Analysis of a Solar energy System with Storage Tank in Different Weather Conditions.," International Journal of Mining, Metallurgy and Mechanical Engineering., vol. 2, pp. 111-115, 2014.

[11] C. J. Ho, J. F. Lin and S. Y. Chiu., "Heat Transfer of solid-liquid phase-change material suspensions in circular pipes: Effects of wall condition.," Numerical Heat Transfer, vol. 45, pp. 171-190, 2004.

[12] K. Kant, A. Shukla, A. Sharma and P. H. Biwole., "Heat transfer study of phase change materials with graphene nano particles for thermal energy storage.," Solar Energy, vol. 146, pp. 453-463, 2017.

[13] A. Gil, E. Oro, A. Castell and L. F. Cabeza., "Experimental analysis of the effectiveness of a high temperature thermal storage tank for solar cooling applications.," Applied Thernal Engineering, vol. 54, pp. 521-527, 2013.

[14] B. Touatia, N. Kerroumia and J. Virgoneb., "Solar Thermal Energy Discharging from a Multiple Phase Change Materials Storage Tank.," Applied Solar Energy., vol. 53, pp. 185189, 2017.

[15] K. Janagi, S. Sivasankaran, M. Bhuvaneswari and M. Eswaramurthi., "Numerical study on free convection of cold water in a square porous cavity heated with sinusoidal wall temperature.," International Journal of Numerical Methods for Heat and Fluid Flow. , vol. 27, pp. 1000-1014, 2017.

[16] M. delgado, A. Lazaro, J. Mazo, C. Penalosa, J. M. Marin and B. Zalba., "Experimental analysis of a coiled stirred tank containing a low cost PCM emulsion as a thermal energy storage system.," Energy., vol. 138, pp. 590-601, 2017.

[17] B. Zalba, J. M. Marin, L. F. Cabeza and H. Mehling., "Review on thermal energy storage with phase change: materials, heat transfer analysis and applications.," Applied Thermal Engineering, vol. 23, pp. 251-283, 2003.

[18] M. Bashar and K. Siddiqui, "Investigation of heat transfer during melting of a PCM by a Ushaped heat source.," Energy Research, vol. 41, pp. 2091-2107, 2017. 
[19] M. K. Koukou, M. G. Vrachopoulos, N. S. Tachos, G. Dogkas, K. Lymperis and V. Stathopoulos., "Experimental and computational investigation of a latent heat energy storage system with a staggered heat exchanger for varous phase change materials.," Thernal Science and Engineering Process..

[20] M. Plotze, U. Scharli, A. Koch and H. Weber., "Thermophysical properties of Bentonite.," International Meeting, Little, France Clays in Natural \& Engineering Barriers for Radioactive Waste Confinement. , vol. P/THME/19, pp. 579-580, 2007.

[21] M. Z. Saghir, A. Ahadi, A. Mohamad and S. Srinivasan, "Water aluminum oxide nanofluid benchmark model," International Journal of Thermal Sciences, vol. 109, pp. 148-158, 2016.

[22] M. Z. Saghir, A. Ahadi, T. Yousafi and B. Farahbakhsh, "Two-phase and single phase models of flow of nanofluid in a squire cavity: Comparison with experimental resuls," International Journel of Thermal Science, vol. 100, pp. 372-380, 2016.

[23] M. Eslamian and M. Z. Saghir, "On thermophoresis modeling in inert nanofluids," International Journal of Thermal Science, vol. 80, pp. 58-64, 2014.

[24] M. Eslamian, M. Ahmed, M. F. El-Dosoky and M. Z. Saghir, "Effect of thermophoresis on natural convection in a Rayleigh-Benard cell filled with a nanofluid," International Journal of Heat and Mass Transfer, vol. 81, pp. 142-156, 2015.

[25] C.J. Ho and W.C. Chen, "An experimental study on thermal performance of Al2O3/water nanofluid in a minichannel heat sink," Applied Thermal Engineering, vol. 50, pp. 516-522, 2013.

[26] C.J. Ho, L.C. Wei and Z.W. Li, "An experimental investigation of forced convective cooling performance of a microchannel heat sink with Al2O3/water nanofluid," Applied Thermal Engineering, vol. 30, pp. 96-103, 2010.

[27] S.Z. Heris,M.N. Esfahany and S.G. Etemad, "Experimental investigation of convective heat transfer of A12O3/water nanofluid in circular tube," International Journal of Heat and Fluid Flow, vol. 28, pp. 203-210, 2007.

[28] A. Kasaeipoor, E. H. Malekshah and L. Kolsi, "Free convection heat transfer and entropy generation analysis of MWCNT-MgO (15\%-85\%)/water nanofluid using Lattice Boltzmann method in cavity with refrigerant solid body-Experimental thermo-physical properties.," 
Powder Technology, vol. 322, pp. 9-23, 2017.

[29] M. Sheikholeslami and H. B. Rokni., "Free convection of $\mathrm{CuO}-\mathrm{H} 2 \mathrm{O}$ nanofluid in a curved porous enclosure using mesoscopic approach.," International Journal of Hydrogen Energy., vol. 42, pp. 14942-14949, 2017.

[30] N. Rahimpour and M. K. Moraveji, "Free convection of water-Fe3O4 nanofluid in an inclined cavity subjected to a magnetic field: CFD modeling, sensitivity analysis.," Advanced Power Technology., vol. 28, pp. 1573-1584, 2017.

[31] Y. Ueki, T. Aoki, K. Ueda and M. Shibahara., "Thermophysical properties of carbon-based material nanofluid.," Inernational Journal of Heat and Mass Transfer., vol. 113, pp. 1130$1134,2017$.

[32] S. A. M. Mehryan, F. M. Kashkooli, M. Ghalambaz and A. J. Chamkha., "Free convection of hybrid Al2O3-Cu water nanofluid in a differentially heated porous cavity.," Advanced Powder Technology., vol. 28, pp. 2295-2305, 2017.

[33] R. Sajedi, M. Jafari, S. Nasirivatan and B. Osanloo., "An experimental study on the proper criterion to judge the thermal performance of the nanofluids.," vol. 82, pp. 20-28, 2017.

[34] R. S. Dondapati, V. Saini, K. N. Verma and P. R. Usurumarti., "Computational prediction of pressure drop and heat transfer with cryogen based nanofluids to be used in micro-heat exchangers.," International Journal of Mechanical Science., vol. 130, pp. 133-142, 2017.

[35] N. Friedoonimehr and A. B. Rahimi., "Exact-solution of entropy generation for MHD nanofluid flow indeed by a stretching/shrinking sheet with transpiration: Dual solution.," Advanced Powder Technology., vol. 28, pp. 671-685, 2017.

[36] M. R. Shamsi, O. A. Akbari, A. Marzban, D. Toghraie and R. Mashayekhi., "Increasing heat transfer of non-Newtonian nanofluid in rectangular microchannel with triangular ribs.," Physica E, vol. 93, pp. 167-178, 2017.

[37] M. H. Hamzah, N. A. C. Sidik, T. L. Ken, R. Mamat and G. Najafi., "Factors affecting the performance of hybrid nanofluids: A comprehensive review.," International Journal of Heat and Mass Transfer., vol. 115, pp. 630-646, 2017.

[38] L. Yang and K. Du., "A comprehensive review on heat transfer characteristics of TiO2 nanofluids.," International Journal of Heat and Mass Transfer., vol. 108, pp. 11-31, 2017. 
[39] L. R. Oliveira, A. C. A. Silva, N. O. Dantas and E. P. B. Filho., "Thermophysical properties of TiO2-PVA/water nanofluids.," International Journal of Heat and Mass Transfer., vol. 115, pp. 795-808, 2017.

[40] J. R. Satti, D. K. das and D. Ray., "Investigation of the thermal conductivity of propylene glycol nanofluids and comparison with correlations.," International Journal of Heat and Mass Transfer., vol. 107, pp. 871-881, 2017.

[41] G. Zyla, J. fal and P. Estelle., "Thermophysical and dielectric profiles of ethylene glycol based titanium nitride (TiN-EG) nanofluids with various size of particles.," International Journal of Heat and Mass Transfer., vol. 113, pp. 1189-1199, 2017.

[42] F. Yazdanifard, M. Ameri and E. E. Bajestan., "Performance of nanofluid-based photovoltaic/thermal systems: A review.," Renewable and Sustainable Energy Reviews., vol. 76, pp. 323-352, 2017.

[43] D. Sui, V. H. Langaker and Z. Yu., "Investigation of thermophysical properties of nanofluids for application in geothermal energy.," ScienceDirect, vol. 105, pp. 5055-5060, 2017.

[44] D. Khurana, R. Choudhary and S. Subudhi., "A critical review of forced convection heat transfer and pressure drop of $\mathrm{Al} 2 \mathrm{O} 3, \mathrm{TiO} 2$ and $\mathrm{CuO}$ nanofluids.," Heat Mass transfer., vol. 53, pp. 343-361, 2017.

[45] A.V. Minakov, M.I. Pryazhnikov, D.V. Guzei, G.M. Zeer and V.Y. Rudyak., "The experimental study of nanofluids boiling crisis on cylinderical heaters.," International Journal of Thermal Sciencre, vol. 116, pp. 214-223, 2017.

[46] A. Shahsavar, Z. Rahimi and M. Bahiraei., "Optimization of irreversibility and thermal characteristics of a mini heat exchanger operated with a new hybrid nanofluid containing carbon nanotubes decorated with magnetic nanoparticles.," Energy Conversion and Management., vol. 16, pp. 7-17, 2017.

[47] A. A. Minea and M. G. Moldoveanu., "Studies on Al2O3, CuO, and TiO2 Water-Based Nanofluids: A Comparative Approach in Laminar and Turbulent Flow.," Journal of Engineering Thermophysics. , vol. 26, pp. 291-301, 2017.

[48] S. Dinarvand, R. Hosseini and I. Pop., "Axisymmetric mixed convective stagnation-point 
flow of a nanofluid over a verticle permeable cylinder by Tiwari-Das nanofluid model.," Powder Technology., vol. 311, pp. 147-156, 2017. 